FÁBIO BRESCIA MIRACCA

OTIMIZAÇÃO DE ESTRUTURAS COM FLUIDO CONTIDO SUJEITA A MÚLTIPLOS CARREGAMENTOS

São Paulo 
FÁBIO BRESCIA MIRACCA

\section{OTIMIZAÇÃO DE ESTRUTURAS COM FLUIDO CONTIDO SUJEITA A MÚLTIPLOS CARREGAMENTOS}

Dissertação apresentada à Escola Politécnica da Universidade de São Paulo para obtenção do Titulo de Mestre em Engenharia.

Área de Concentração:

Engenharia de Controle e Automação Mecânica.

Orientador: Prof. Titular Emílio Carlos Nelli Silva

São Paulo 
MIRACCA, Fábio Brescia. Otimização de estruturas com fluido contido sujeita a múltiplos carregamentos. 2007. (Mestrado) Escola Politécnica, Universidade de São Paulo, São Paulo. 2007.

\section{ERRATA}

\begin{tabular}{|c|c|c|c|}
\hline PÁGINA & LINHA & ONDE SE LÊ & LEIA-SE \\
\hline 19 & 10 & um reator nuclear & um reator nuclear naval \\
\hline 22 & Fig 1.2 & Vista do LabGeNe. & $\begin{array}{c}\text { Vista da contenção do } \\
\text { LabGeNe. }\end{array}$ \\
\hline 50 & 9 & ou seja, quando $a=b=1$ & ou seja, quando $a=b=0$ \\
\hline 50 & 10 & e quando $a=b=0$ & e quando $a=b=1$ \\
\hline 54 & Eq.3.19 & $0<\eta_{\min } \leq \eta \leq 1$ & $0<\eta_{\min } \leq \eta_{e} \leq 1$ \\
\hline 96 & 11 & $=G_{x z}=2,0685 \mathrm{~Pa}$. & $\left.=G_{x z}=2,0685 \mathrm{~Pa}\right)$. \\
\hline 104 & 14 & o pior caso de $\mathrm{k}$ & o pior caso de $k$ \\
\hline 105 & 11 & $\mathrm{p}=1$ & $p=1$ \\
\hline 107 & 10 & Figura $6.13 \mathrm{e}$ Figura 6.14 & Figura 6.13 e Figura 6.14 \\
\hline 112 & 7 & $, 20$ iterações, $)$ &, 20 iterações). \\
\hline
\end{tabular}




\section{FICHA CATALOGRÁFICA}

Miracca, Fábio Brescia

Otimização de estruturas com fluido contido sujeita a múltiplos carregamentos / F.B. Miracca. -- São Paulo, 2007.

$123 \mathrm{p}$.

Dissertação (Mestrado) - Escola Politécnica da Universidade de São Paulo. Departamento de Engenharia Mecatrônica e de Sistemas Mecânicos.

1.Otimização topológica 2.Otimização estrutural paramétrica I.Universidade de São Paulo. Escola Politécnica. Departamento de Engenharia Mecatrônica e de Sistemas Mecânicos II.t. 
À minha esposa Débora. 


\section{AGRADECIMENTOS}

À Marinha do Brasil pela oportunidade oferecida para obtenção deste titulo, a todos os professores da Escola Politécnica que de alguma forma colaboraram com este trabalho, através das aulas ministradas, ou de participação nas bancas.

Ao professor Emilio pela clareza de suas orientações.

Ao comandante Sbragio e ao Engenheiro Orion do CTMSP, pelas valiosas informações fornecidas.

Aos amigos do grupo de otimização topológica.

À meus pais Marilena e Renato, que me deram base, educação e oportunidade de formação que me possibilitou atingir tais objetivos.

À minha esposa Débora, pela paciência, dedicação e apoio dado durante todo o período de execução deste trabalho.

$\mathrm{E}$ a todos que colaboraram direta ou indiretamente na execução deste trabalho. 


\section{RESUMO}

Muitas vezes encontram-se na Engenharia, estruturas que contenham fluido em seu interior, (estruturas com fluido contido). Uma vez que para determinados casos de carregamento, como por exemplo, carregamento hidrostático, o fluido colabora com a rigidez, pode ser conveniente para o engenheiro considerar a presença deste fluido com o objetivo de se obter uma estrutura mais leve, principalmente nos casos onde a presença do fluido é obrigatória à operação da estrutura.

Nesta dissertação, uma metodologia para otimização de estruturas com fluido contido é apresentada. Tal metodologia engloba a otimização de uma estrutura real, utilizando otimização paramétrica (OP) e topológica (OT). A rotina de OT implementada permite projetar estruturas compostas de aço e fluido contido (FC), e considera múltiplos casos de carregamento, peso próprio e a possibilidade de escolha de regiões a serem otimizadas ou não. Para validação da rotina de OT, exemplos clássicos da literatura considerando a presença de um ou dois materiais são apresentados.

Para implementar o algoritmo para resolução da OT utiliza-se um programa comercial para a análise de elementos finitos, complementado com uma rotina externa elaborada em linguagem do próprio programa. Isto possibilita agregar a vantagem da utilização de um programa comercial, multidisciplinar, e com um grande número de elementos finitos implementados, com a versatilidade de uma linguagem de programação, permitindo implementar uma solução específica para o problema estudado.

Como exemplo, apresenta-se um estudo de caso real, voltado a estruturas navais, apresentando, além da análise da estrutura inicial estudada, uma otimização paramétrica, e uma otimização topológica tridimensional da estrutura.

Os resultados alcançados, mostram-se satisfatórios, uma vez que a estrutura obtida no estudo de caso específico apresenta uma redução significativa em seu peso atendendo aos requisitos de projeto. 


\begin{abstract}
Several times, it is found in Engineering, structures with fluid inside (contained fluid structures). Since for some load cases, for instance, hydrostatic load, the fluid collaborates with stiffness, it may be convenient for the engineer to take into account this fluid to make the structure lighter, mainly if the presence of fluid is mandatory for operation.

In this work, a methodology for contained fluid structures optimization is presented. This methodology includes parametric and topology optimizations of a real structure. Topology optimization routine implemented allows us to design structures made by steel and contained fluid, and includes several load cases, selfweight, and the possibility of choosing areas to optimize or not. To validate the topology optimization routine, classical examples with one or two material are showed.

To perform topology optimization procedure, Finite Element Analysis commercial software is applied together with an external routine implemented using the software programming language, this allows us to take advantage of a multidisciplinary commercial software, which has a large number of finite elements implemented, and the versatility of a customized program for the studied problem.

As an example, it is showed a real case, within naval structures describing the initial structure analysis and its parametric optimization, and a tridimensional topology optimization.

The results obtained are satisfactory, since the final structure obtained has a significant reduction in its weight.
\end{abstract}




\title{
SUMÁRIO
}

\author{
LISTA DE FIGURAS \\ LISTA DE TABELAS \\ LISTA DE ABREVIATURAS E SIGLAS \\ LISTA DE SÍMBOLOS
}

1 INTRODUÇÃO.................................................................19

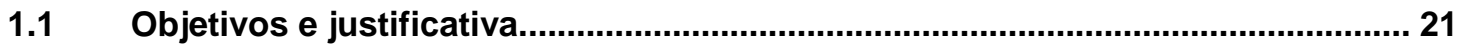

2 MÉTODO DOS ELEMENTOS FINITOS (MEF). ....................23

2.1 Elementos de Estado Plano de tensão (EPT) ................................................. 23

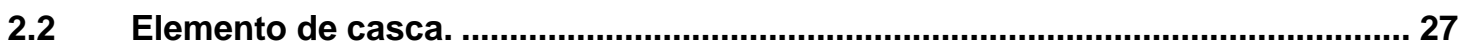

2.3 Elemento sólido tridimensional e elemento de fluido contido tridimensional. .. 33

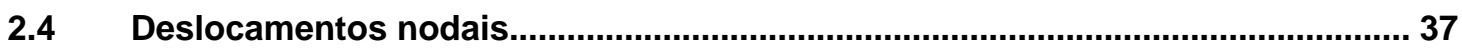

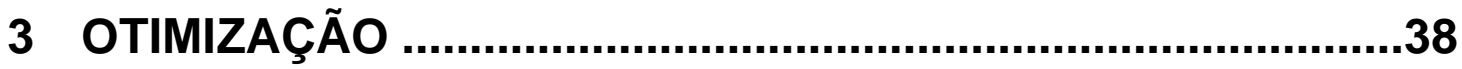

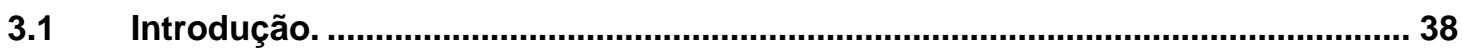

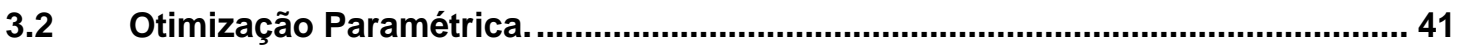

3.2.1 Método de penalização da função objetivo. .......................................................... 43

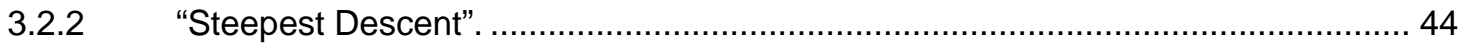

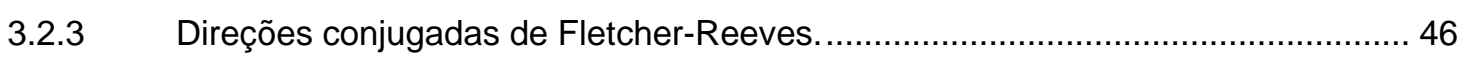

3.3 Método de Otimização Topológica (MOT).............................................................. 47

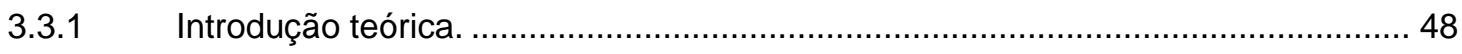

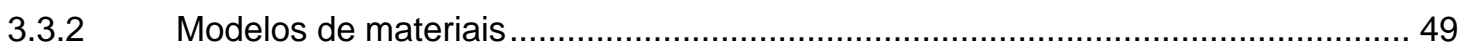

3.3.3 Formulação do problema de otimização topológica ............................................. 52

3.3.4 Método de solução - Critério de Optimalidade..................................................... 55

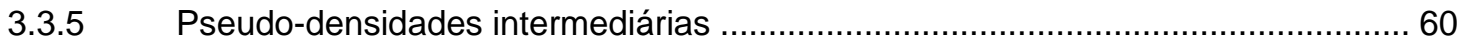

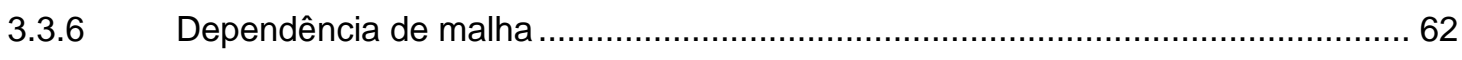

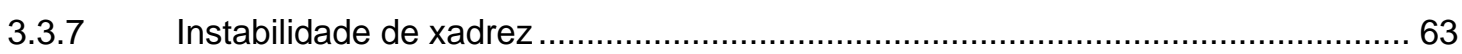

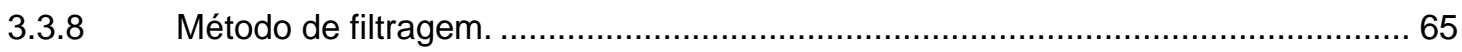




\section{FORMULAÇÃO DO PROBLEMA E IMPLEMENTAÇÃO} NUMÉRICA

4.1 Formulação do problema e implementação numérica da otimização paramétrica.

70

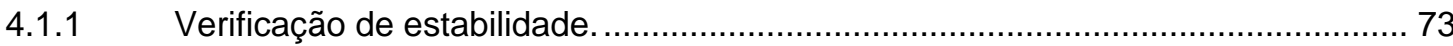

4.2 Formulação do problema e implementação numérica da otimização topológica... 75

\section{CÓPIA CEGA}

6 RESULTADOS.

\section{CÓPIA CEGA}


APÊNDICE A Resultados detalhados da Otimização paramétrica. APÊNDICE B Rotinas em "APDL" elaboradas (cd). 


\section{LISTA DE FIGURAS}

Figura 1.1 - Exemplo de estrutura com fluido contido, corte em seções. ..................19

Figura 1.2 - Vista do LabGeNE. (CTMSP-2002) ..................................................22

Figura 2.1 - Elemento isoparamétrico quadrilátero de quatro nós............................24

Figura 2.2- Elemento isoparamétrico de casca de quatro nós. ................................27

Figura 2.3 - Elemento isoparamétrico tridimensional de 8 nós..................................33

Figura 3.1 - (a e b) Exemplo de estruturas de Michell (1904), (c e d) estruturas

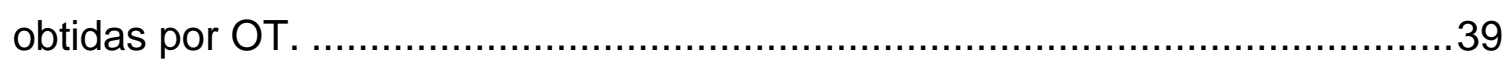

Figura 3.2 - Exemplo de abordagens de otimização estrutural. ...............................40

Figura 3.3- Exemplo de oscilação conhecida como fenômeno de "hemstitching" ou

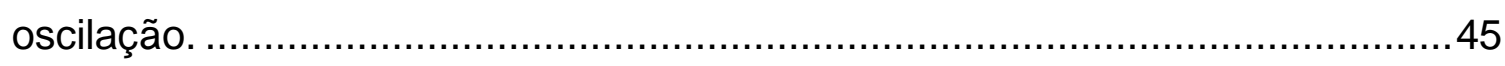

Figura 3.4 - Exemplo de um problema inicial e resultado da otimização topológica. 48

Figura 3.5 - Microestruturas utilizadas no método da homogeneização. ..................50

Figura 3.6 - Comparação entre o "SIMP" e os limites de Hashin-Shtrikman. .............52

Figura 3.7- Modelo generalizado de domínio para OT..........................................53

Figura 3.8 - Representação esquemática da influencia da penalização $p$ na solução do problema de OT.

Figura 3.9 - Exemplo de dependência de malha, (a) viga bi-apoiada com uma carga no centro, solução com: 5.120 EF em (b); 22.378 EF em (c); e 65.780 EF em (d).

Figura 3.10 - (a) Distribuição do material em xadrez. (b) Distribuição do material uniforme.

Figura 3.11 - Exemplo de estrutura apresentando padrão de instabilidade de xadrez 64

Figura 3.12- Exemplo de utilização de filtro para correção de dependência de malha $(65.780 \mathrm{EF})$ 66

Figura 3.13 - Exemplo de utilização do filtro para correção da instabilidade de xadrez (EF de 4 nós). 66

Figura 3.14 - Exemplo do efeito do múltiplo carregamento em uma viga biapoiada (a), onde as forças são aplicadas simultaneamente (b), e de maneira alternada (c). 
Figura 3.15 - Exemplo de carregamentos alternados que geram estruturas superdimensionadas (a), ou sub-dimensionadas (b), quando considerados

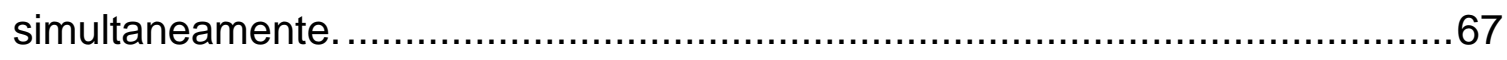

Figura 3.16 - Exemplo de influência do peso próprio (P). ................................68

Figura 3.17 - Resultados de OT utilizando dois materiais. (material "0" em vermelho,

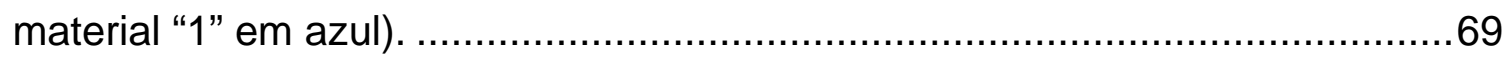

Figura 4.1 - Exemplo de OP onde se verifica a formulação MinMax........................72

Figura 4.2- Tensões máximas em função da área da seção transversal $\left(\left(\sigma_{1}, \sigma_{2}\right) \times A_{1}\right)$

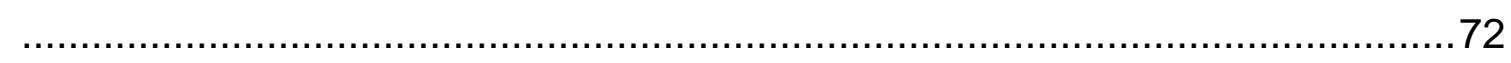

Figura 4.3 - Tensão crítica de flambagem de chapas. .................................. 74

Figura 4.4- Viga bidimensional com fluído contido. .......................................78

Figura 4.5 - Comparação entre deslocamentos entre modelo 1 e $5 \ldots \ldots \ldots \ldots \ldots \ldots \ldots \ldots . . . . . . . . . . .79$ Figura 4.6- Comparação entre deslocamentos quando ocorrem fluxos (modelos 1 e

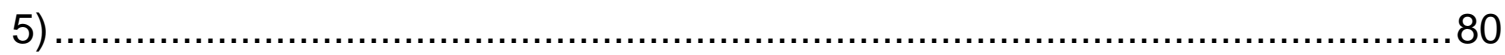

\section{CÓPIA CEGA}

Figura 6.19 - Exemplo da influência da malha no resultado da OT 


\section{LISTA DE TABELAS}

Tabela 4.1 - Flexibilidade do aço para cada modelo de viga. (FC - fluido contido) ..79

\section{CÓPIA CEGA}




\section{LISTA DE ABREVIATURAS E SIGLAS}

\begin{tabular}{|c|c|}
\hline ASME & "The American Society of Mechanical Engineers" \\
\hline APDL & "ANSYS Parametric Design Language" \\
\hline AV & Antepara de Vante \\
\hline $\mathrm{CCP}$ & Corredor do Compartimento do Primário \\
\hline CG & Centro de Gravidade \\
\hline $\mathrm{CP}$ & Compartimento do Primário \\
\hline CR & Compartimento de Ré \\
\hline CV & Compartimento de Vante \\
\hline CTMSP & Centro Tecnológico da Marinha em São Paulo \\
\hline EF & Elementos Finitos \\
\hline EFC & Estrutura com Fluido Contido \\
\hline EPT & Estado Plano de Tensão \\
\hline FC & Fluido Contido \\
\hline FSD & "Fully Stressed Design" \\
\hline INAP & $\begin{array}{l}\text { Instalação Nuclear de Água Pressurizada (antigo nome dado ao } \\
\text { LabGeNE) }\end{array}$ \\
\hline KKT & "Karush-Kuhn-Tucker" \\
\hline LabGeNE & Laboratório de Geração Núcleo-Elétrica (antiga INAP) \\
\hline LB & Linha de Base \\
\hline LC & Linha de Centro \\
\hline MEF & Método dos Elementos Finitos \\
\hline MOT & Método de Otimização Topológica \\
\hline OEE & Otimização Estrutural Evolucionária \\
\hline OP & Otimização Paramétrica \\
\hline OT & Otimização Topológica \\
\hline RV & Face de Ré da Antepara de Vante \\
\hline SIMP & "Solid Isotropic Material with Penalization" \\
\hline
\end{tabular}




\section{LISTA DE SÍMBOLOS}

$\Gamma_{\mathrm{t}} \quad$ Contorno com forças superficiais aplicadas

$\Gamma_{\mathrm{u}} \quad$ Contorno com deslocamentos prescritos

Distância percorrida em cada iteração

Fator de amortecimento

Limite móvel

$\sigma_{e}$

Tensão de Von Mises do elemento

$\sigma_{m}$

Tensão admissível de projeto

$\tau$

Vetor de tensões

$\tau$

Componente unitária do vetor de tensões

$\tau$

Tolerância

$\varepsilon$

Vetor de Deformações

$\varepsilon$

Componente unitária do vetor de deformações

$\kappa$

Módulo de compressibilidade

$\rho$

Densidade

$\lambda$

Multiplicador de Lagrange

v

Coeficiente de Poisson

$\Psi_{i}$

Rotação em torno do eixo $i$

$\varnothing$

Diâmetro

$\Omega$

Domínio

$\Omega_{\text {mat }}$

$\chi(\mathbf{x})$

Região do domínio onde existe material

$\eta$

Função de distribuição discreta

a

Pseudo-densidade do material

$a_{k}$

Espessura do elemento no nó $k$

$a(.,$.

Forma bi-linear da energia de deformação

B

Matriz das derivadas das funções de forma

C Matriz constitutiva

$\mathbf{C}_{\mathbf{3 d}} \quad$ Matriz constitutiva para o elemento sólido

C $_{\text {ept }} \quad$ Matriz constitutiva para o elemento de Estado Plano de Tensão

$\mathbf{C}_{\mathrm{fc}} \quad$ Matriz constitutiva para o elemento de fluido contido 


\begin{tabular}{|c|c|}
\hline $\mathbf{C}_{\text {sh }}$ & Matriz constitutiva para o elemento de casca \\
\hline $\mathbf{C}_{e}$ & Matriz constitutiva do elemento \\
\hline$D$ & Módulo de rigidez à flexão \\
\hline E & Módulo de Young \\
\hline $\mathbf{F}$ & Vetor de forças aplicadas \\
\hline f & Vetor de forças de campo \\
\hline$F()$. & Função objetivo \\
\hline g & Aceleração gravitacional \\
\hline$g(x)$ & Função de restrição de inegualdade \\
\hline G & Módulo de cisalhamento \\
\hline$h(x)$ & Função de restrição de igualdade \\
\hline $\mathbf{J}$ & Matriz Jacobiana \\
\hline$k$ & coeficiente dependente da razão de aspecto da chapa \\
\hline $\mathbf{k}_{\mathrm{e}}$ & Matriz de rigidez do elemento \\
\hline $\mathbf{K}$ & Matriz de rigidez \\
\hline $\mathbf{K}_{\mathbf{e}}$ & Matriz de rigidez do elemento em seu nível global \\
\hline$l$ & Forma linear da flexibilidade média \\
\hline$L$ & Lagrangeano \\
\hline$M_{i}$ & Momento em torno do eixo $i$ \\
\hline $\mathrm{N}$. & Função de forma \\
\hline$n_{e}$ & Número de elementos \\
\hline$n_{f}$ & Número de carregamentos \\
\hline$n_{g}$ & Número de restrições de inegualdade \\
\hline$n_{h}$ & Número de restrições de igualdade \\
\hline$n_{x}$ & Número de variáveis de projeto \\
\hline$p$ & Fator de penalização de pseudo-densidades intermediárias \\
\hline $\mathbf{P}$ & Peso \\
\hline$P$ & Pressão \\
\hline$P(x)$ & Função penalizadora \\
\hline$Q(x)$ & Função objetivo do problema penalizado (sem restrições) \\
\hline r & Ordenada do sistema de coordenadas naturais do elemento \\
\hline$R_{e j}$ & Distância entre os centróides dos elementos \\
\hline$R_{\text {filtro }}$ & Raio de atuação do filtro \\
\hline s & Abscissa do sistema de coordenadas naturais do elemento \\
\hline
\end{tabular}


Direção a ser seguida em cada iteração Espessura da chapa Vetor de forças superficiais

Deslocamento arbitrário no sentido do eixo $\mathrm{x}$ Vetor de deslocamentos nodais

Deslocamento do corpo em equilíbrio Deslocamento máximo da estrutura original Campo de deslocamentos admissíveis Deslocamento arbitrário no sentido do eixo z Peso da condição de carregamento $\mathrm{k}$.

Deslocamento arbitrário no sentido do eixo y Deslocamento virtual

Vetor diretor

Componente unitária do vetor diretor

Volume do elemento

Volume máximo

Variável de projeto

Posição

Norma Euclidiana

Índice de transposição de matriz ou vetor

Tende à 


\section{INTRODUÇÃO.}

Entende-se por estrutura com fluido contido (EFC), uma estrutura onde em seu interior haja um fluido, como por exemplo, água. Uma vez que tal fluido pode de alguma forma colaborar com a rigidez estrutural, torna-se conveniente o estudo em conjunto da estrutura com o fluido, principalmente quando o objetivo do estudo é uma otimização estrutural, já que este aumento de rigidez devido ao fluido pode possibilitar uma redução da estrutura em si.

Uma otimização estrutural nestes termos traz a desvantagem de limitar a utilização da estrutura quando o fluido esta ausente, porém, em alguns casos, a presença do fluido é obrigatória para operação, como por exemplo o estudo de caso apresentado nesta dissertação, onde se deseja otimizar uma antepara de blindagem em um compartimento que abriga um reator nucelar (Laboratório de Geração Núcleo-Elétrica - LabGeNE), e a presença de líquido em seu interior é obrigatória para operação, uma vez que o mesmo faz parte da blindagem radioativa (Figura 1.1).
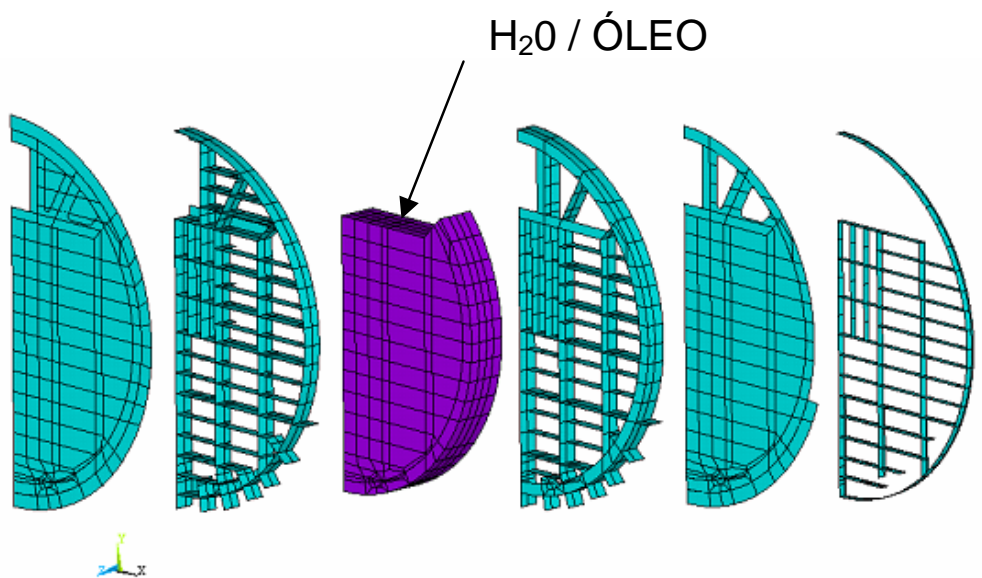

Figura 1.1 - Exemplo de estrutura com fluido contido, corte em seções.

Nesta dissertação, a modelagem desta estrutura é feita utilizando-se o Método dos Elementos Finitos (MEF), que tem como princípio a discretização de uma estrutura contínua. 
$\mathrm{Na}$ literatura encontram-se diversos artigos de simulação de interação fluidoestrutura utilizando-se o MEF, principalmente nas áreas de acústica (IZADPANAH et al., 1991), fluxo (RAMANSWAMY, 1989) e vibrações (AKL; RUZZEM; BAZ, 2002).

Izadpanah et al. (1991) apresentam uma análise acústica em automóvel sob fluxo de ar baseado na equação de Euler. Ramansway (1989) apresenta um estudo de fluxo laminar, onde são abordados exemplos de fluxo através de um alargamento de duto e fluxos causados por convecção e condução de calor, através da aproximação de Boussinesq. Akl; Ruzzem e Baz (2002) apresentam uma otimização paramétrica de um duto submerso, com reforços, excitado por um carregamento harmônico onde utiliza uma função multi-objetivo utilizando o critério de Pareto, que leva em conta à vibração do duto, peso dos reforços, propagação de som e custo.

Com relação à técnica de otimização paramétrica a literatura é ampla e diversos livros abordam a teoria de maneira clara e prática, apresentando abordagem teórica semelhante (HAFTKA; GÜRDAL, 1991; GILL; MURRAY; WRIGHT, 2003; PAPALAMBROS; WILDE, 2000).

No caso específico de otimização estrutural, Haftka e Gürdal (1991) apresentam em seu livro, além da teoria básica, exemplos específicos de otimização estrutural, como maximização da flexibilidade, das freqüências de ressonância, do desenho ótimo de material laminar composto, entre outros.

Como um ramo da otimização estrutural, surge em 1988 o Método de Otimização Topológica (MOT), proposto por Bendsøe e Kikuchi, oferecendo uma metodologia sistemática pra projetos otimizados de estruturas mecânicas, baseandose na distribuição de material. (BENDSøE; KIKUCHI, 1988; SUZUKI; KIKUCHI, 1991; ALLAIRE et al., 1997; BENDSØE; SIGMUND, 2003).

Como aplicações do MOT, podemos citar trabalhos de multi-flexibilidade, onde são considerados diversos casos de carregamento para a mesma estrutura e deseja-se maximizar a flexibilidade para um certo volume de material, (BENDS $\varnothing \mathrm{E}$; SIGMUND, 2003; LUO et al., 2005), carregamentos dependente da topologia como peso próprio (BENDS $\varnothing E ;$ SIGMUND, 2003; BRUYNEEL; DUYSINX, 2005) e carregamentos de pressão, onde a força transmitida à estrutura vai depender da forma da área de aplicação (HAMMER; OLHOLFF, 2000; FUCHS; SHEMESH, 2004) ou sujeitos a forças de campo mecânicas (LOPES, 2005), ou ainda um estudo mais geral sobre carregamentos dependentes de projeto, através de uma aplicação de 
carregamento térmico fictício simulando as forças dependentes de carregamento (CHEN; KIKUCHI, 2001).

Recentemente pode-se citar o desenvolvimento da OT em áreas como mecanismos flexíveis: Fredricson et al. (2003) nos mostra um estudo de juntas flexíveis em estruturas de vigas, Saxena (2005) nos mostra uma OT em micromecanismos com múltiplos materiais, e Silva; Fonseca e Kikuchi (1997) e Canfield e Frecker (2000) apresentam um artigo de OT em micromecanismos acionados por piezelétricos, ainda na área de piezelétricos, pode-se citar os trabalhos de Silva (KÖGL; SILVA, 2005; SILVA; NISHIWAKI, 2005).

\subsection{Objetivos e justificativa.}

Diante do atual cenário econômico, de alta competitividade e de informações globalizadas, o engenheiro necessita de metodologias que resultem em projetos cada vez mais eficientes. As técnicas de otimização estrutural possibilitam uma maior eficiência no projeto de estruturas quando comparadas com os projetos desenvolvidos utilizando-se apenas ferramentas de análises. Um grupo específico de estruturas são as estruturas com fluido contido, onde a presença do fluido colabora com a rigidez estrutural.

O objetivo desta dissertação é apresentar uma metodologia para otimização deste tipo de estrutura, utilizando o programa comercial ANSYS, com auxílio de rotinas existentes no próprio programa para realização de otimização paramétrica $(\mathrm{OP})$, bem como implementação de uma rotina adicional em linguagem "APDL" ("ANSYS Parametric Design Language") de uma otimização topológica (OT) para o caso de multicarregamento e presença de dois materiais, permitindo desta maneira, agregar a vantagem da análise de EF de um programa comercial, encontrado facilmente no mercado, com a versatilidade que uma programação própria pode oferecer. Tal metodologia é aplicada num estudo de caso real, de complexidade superior às apresentadas em problemas didáticos, de maneira a impor dificuldades inerentes a estes casos, como tempo de processamento, presença de diversas 
variáveis, necessidade de aproximações, busca de resultado viável do ponto de vista de Engenharia, entre outros e desta forma mostrar a validade da metodologia.

Uma vez que o LabGeNE (Figura 1.2) representa uma seção de casco de submarino, este trabalho tem também por objetivo exemplificar o emprego da otimização estrutural, em especial a OT no meio naval, e de estruturas de grande porte onde seu emprego adequado pode a vir gerar resultados satisfatórios em relação a peso de material, sem uma elevação obrigatória do custo de fabricação, principalmente no caso de submarinos e de estruturas pesadas onde haja restrições de espaço e peso significativas.

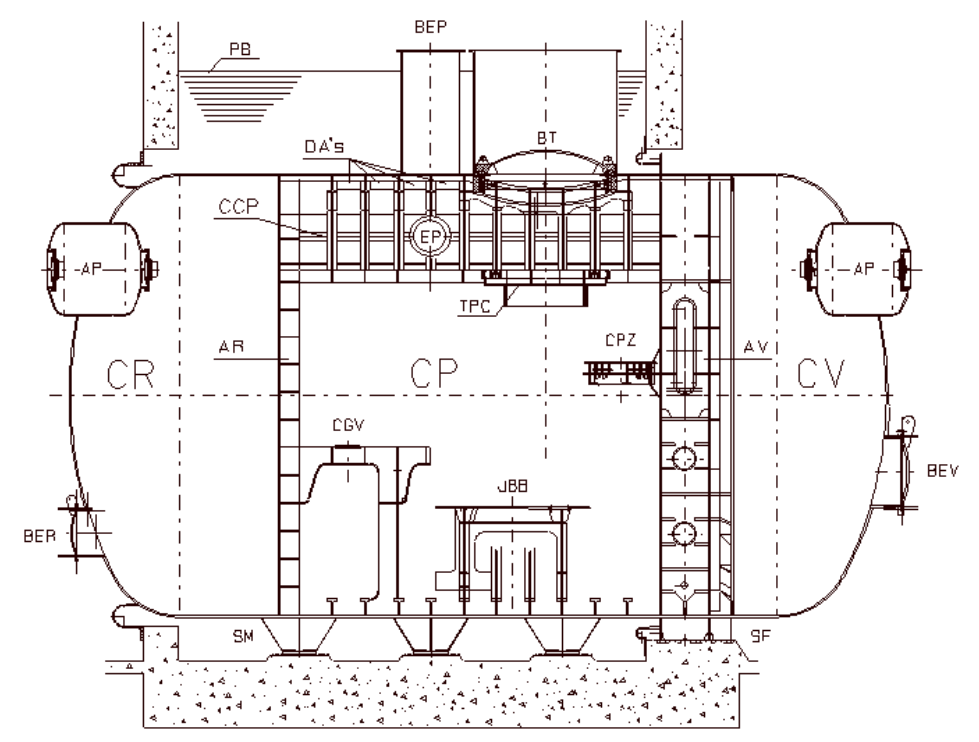

Figura 1.2 - Vista do LabGeNE. (CTMSP-2002) 


\section{MÉTODO DOS ELEMENTOS FINITOS (MEF).}

Atualmente, o Método de Elementos Finitos (MEF), é utilizado numa gama enorme de análises de Engenharia, que vão desde a análise estrutural, até distribuição de calor, fluxos magnéticos ou escoamento de fluidos.

Por se tratar de um método consagrado, existe uma vasta literatura em livros e artigos, entre os livros mais tradicionais, podem-se citar (BATHE, 1996) e (ZIENKIEWICZ, 1977) e outros que apresentam uma abordagem mais prática, onde os conceitos são apresentados de forma mais intuitiva como (COOK, 1994) e (SEGERLIND, 1984).

A escolha dos elementos utilizados nesta dissertação foi baseada no grau de hierarquia do modelo e em sua utilização. Modelos de menor hierarquia foram elaborados utilizando elemento de Estado Plano de tensão (EPT), devido sua baixa complexidade. Para análise de estruturas complexas tridimensionais e realização da otimização paramétrica foi combinado no modelo de EF elementos de fluido contido de oito nós e elementos de casca de quatro nós. No caso da OT, o fluido contido será modelado através de elemento sólido de oito nós, combinada com o mesmo elemento para modelagem do aço.

As características dos elementos utilizados neste trabalho, bem como do programa podem ser encontradas na documentação do programa (ANSYS, 2004).

A seguir são brevemente apresentados os fundamentos teóricos e as formulações dos elementos utilizados baseando-se principalmente nas referências (BATHE, 1996) e (ANSYS, 2004).

\subsection{Elementos de Estado Plano de tensão (EPT).}

Elementos de EPT são utilizados para uma aproximação bidimensional de estruturas planas finas, que possuam carregamento apenas no plano. Pode-se utilizar este elemento sempre que as dimensões do plano onde ocorre o 
carregamento sejam significamente maiores que a dimensão perpendicular ao plano. Neste caso, o elemento EPT apresenta bons resultados, além de ser de fácil modelagem, e de custo computacional bastante reduzido, uma vez que se trata de modelo bidimensional. Como principal desvantagem, pode ser usado apenas nos casos onde os esforços são aplicados no plano do elemento.

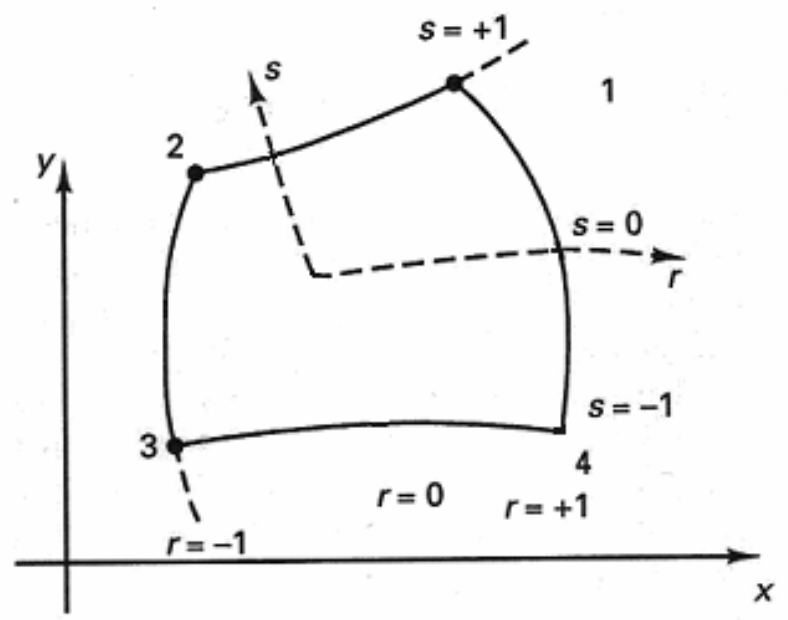

Figura 2.1 - Elemento isoparamétrico quadrilátero de quatro nós.

Seja o elemento de EPT mostrado na Figura 2.1, uma vez que a dimensão perpendicular ao plano xy é significamente menor que as demais, pode-se dizer que as tensões $\tau_{z z}, \tau_{z x}, \tau_{z y}$ são iguais a zero, onde os índices subscritos referem-se ao plano de aplicação das tensões, pode-se escrever os vetores de tensões $\tau$ e de deformações $\varepsilon$ como

$$
\begin{aligned}
\boldsymbol{\tau}^{T} & =\left[\begin{array}{lll}
\tau_{x x} & \tau_{y y} & \tau_{x y}
\end{array}\right], \mathrm{e} \\
\boldsymbol{\varepsilon}^{T} & =\left[\begin{array}{lll}
\varepsilon_{x x} & \varepsilon_{y y} & \varepsilon_{x y}
\end{array}\right] .
\end{aligned}
$$

A relação entre os dois vetores é escrita por

$$
\boldsymbol{\tau}=\mathbf{C}_{\mathrm{ept}} \boldsymbol{\varepsilon},
$$


onde $\mathbf{C}$ é a matriz constitutiva para material isotrópico do elemento EPT é

$$
\mathbf{C}_{\text {ept }}=\frac{E}{1-v^{2}}\left[\begin{array}{ccc}
1 & v & 0 \\
v & 1 & 0 \\
0 & 0 & \frac{1-v}{2}
\end{array}\right],
$$

onde $E$ é o módulo de Young, vé o coeficiente de Poisson.

Neste trabalho todos os elementos utilizados são isoparamétricos. Caracterizam-se como elemento isoparamétrico, elementos onde as suas coordenadas e seus deslocamentos são obtidos através das mesmas funções interpoladoras que são definidas no sistema de coordenadas naturais (BATHE, 1996). Sistema de coordenadas naturais é o sistema cartesiano de origem no centro do elemento de forma que a localização dos nós varie de -1 a 1 em cada eixo, (sistema rs da Figura 2.1).

Neste trabalho são utilizados elementos de quatro e oito nós, sendo a única diferença as funções de interpolação. Também conhecidas por equações de forma, que para elementos de quatro nós (Figura 2.1) são dadas por

$$
\begin{aligned}
& N_{1}=\frac{1}{4}(1+r)(1+s), N_{2}=\frac{1}{4}(1-r)(1+s), \\
& N_{3}=\frac{1}{4}(1-r)(1-s), N_{4}=\frac{1}{4}(1+r)(1-s),
\end{aligned}
$$

portanto, considerando que o elemento de EPT possui dois graus de liberdade em cada nó, que são translação em cada um dos eixos, pode se calcular o deslocamento de um ponto arbitrário do elemento em função das coordenadas nodais do elemento, através de

$$
u(r, s)=\sum_{i=1}^{4} N_{i} u_{i} ; \text { e } v(r, s)=\sum_{i=1}^{4} N_{i} v_{i}
$$


Da teoria do $M E F$, sabe-se que para obter as derivadas em relação às coordenadas cartesianas $(\mathrm{x}, \mathrm{y}, \mathrm{z})$, deve-se utilizar a transformada

$$
\left[\begin{array}{c}
\frac{\partial}{\partial x} \\
\frac{\partial}{\partial y}
\end{array}\right]=\mathbf{J}^{-1}\left[\begin{array}{c}
\frac{\partial}{\partial r} \\
\frac{\partial}{\partial s}
\end{array}\right],
$$

onde $\mathbf{J}$ é a matriz Jacobiana da função, ou seja,

$$
\mathbf{J}=\left[\begin{array}{ll}
\frac{\partial x}{\partial r} & \frac{\partial y}{\partial r} \\
\frac{\partial x}{\partial s} & \frac{\partial y}{\partial s}
\end{array}\right]
$$

Portanto a matriz B, que relaciona o deslocamento à deformação pode ser descrita por

$$
\mathbf{B}=\left[\begin{array}{ccccc}
\frac{\partial h_{1}}{\partial x} & 0 & \ldots . . & \frac{\partial h_{4}}{\partial x} & 0 \\
0 & \frac{\partial h_{1}}{\partial y} & \ldots . . & 0 & \frac{\partial h_{4}}{\partial y} \\
\frac{\partial h_{1}}{\partial y} & \frac{\partial h_{1}}{\partial x} & \cdots . . & \frac{\partial h_{4}}{\partial y} & \frac{\partial h_{4}}{\partial x}
\end{array}\right] .
$$

Obtidas a matriz constitutiva $\mathbf{C}_{\text {ept }}$, e de deslocamento-deformação $\mathbf{B}$, obtém-se a matriz $\mathbf{k}_{\mathbf{e}}$ de rigidez do elemento através de

$$
\mathbf{k}_{\mathbf{e}}=\int_{-1}^{1} \int_{-1}^{1} \mathbf{B}^{T} \mathbf{C}_{\text {ept }} \mathbf{B} \operatorname{det} \mathbf{J} d r d s .
$$

A obtenção dos deslocamentos nodais a partir da matriz de rigidez $\mathbf{k}_{\mathbf{e}}$ é apresentada na seção 2.4 . 


\subsection{Elemento de casca.}

Elementos de casca são utilizados para modelagem tridimensional de estruturas planas ou curvas, onde uma das dimensões é significamente menor que as outras duas (no caso deste trabalho, a dimensão perpendicular ao plano xy) e cujo carregamento é normal à superfície da placa ou casca, desta forma pode-se dizer que $\tau_{z z}$ é igual à zero. O elemento possui seis graus de liberdade em cada nó, translação e rotação em torno dos eixos cartesianos (x, y, z).

Outra consideração apresentada, é que os pontos de material unidos por uma reta perpendicular ao plano médio permanecerão unidos por uma reta (mesmo que não perpendicular ao plano médio) após a deformação (teoria de Reissner/Mindlin).

Diferente do caso do elemento de EPT, carregamentos perpendiculares ao plano do elemento podem ser impostos, sendo considerados tanto os esforços de membrana quanto os de flexão.
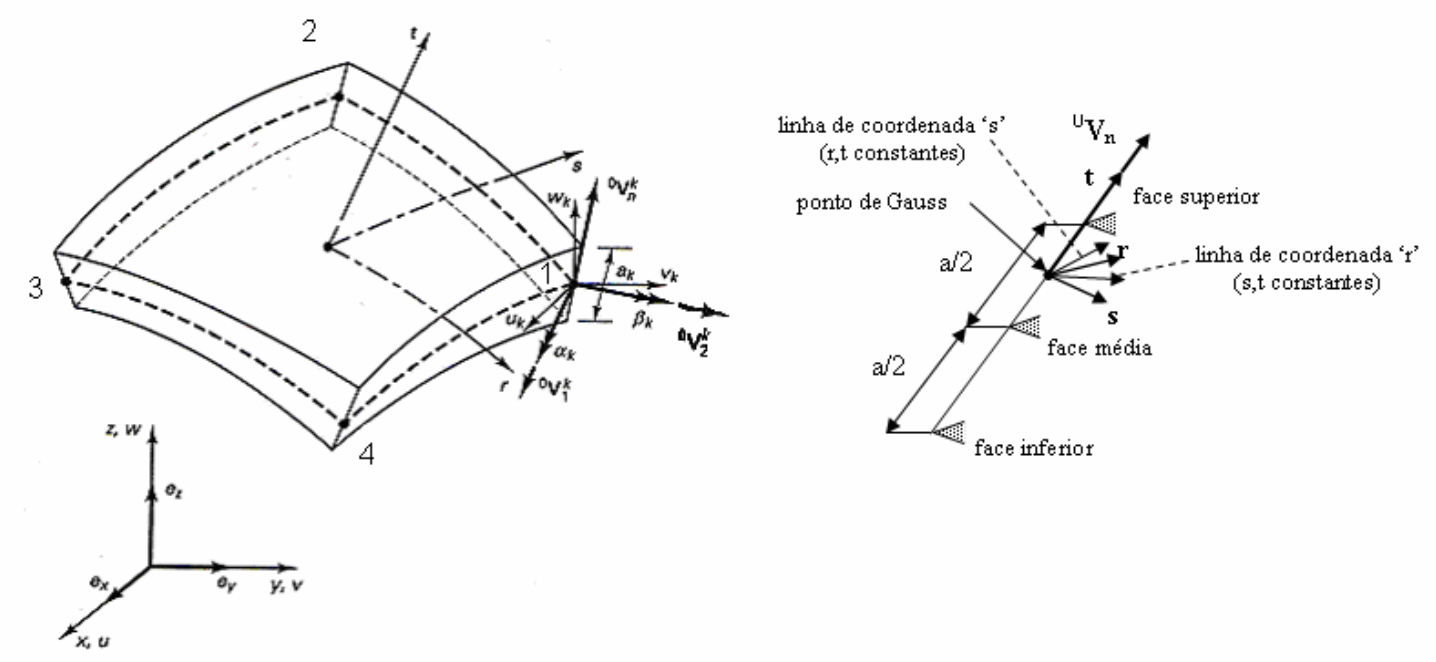

Figura 2.2- Elemento isoparamétrico de casca de quatro nós.

Por possuir menor número de nós que o elemento de sólido de mesma ordem, apresenta um custo computacional menor que o do elemento sólido, atingindo resultados melhores para casos onde a razão de aspecto das dimensões é condizente com a utilização do elemento. Como desvantagem, não é adequado para mostrar detalhes da estrutura que apresenta concentrações de tensão como quinas, soldas e outras. 
São apresentadas a seguir as formulações teóricas para elementos de casca de quatro nós (Figura 2.2).

Tratando-se de um elemento tridimensional, podem-se escrever os vetores de deformação $\varepsilon$ e de tensão $\tau$ por

$$
\varepsilon^{T}=\left[\begin{array}{llllll}
\varepsilon_{x x} & \varepsilon_{y y} & \varepsilon_{z z} & \varepsilon_{x y} & \varepsilon_{y z} & \varepsilon_{z x}
\end{array}\right] \text {, e } \tau^{T}=\left[\begin{array}{llllll}
\tau_{x x} & \tau_{y y} & \tau_{z z} & \tau_{x y} & \tau_{y z} & \tau_{z x}
\end{array}\right] .
$$

A relação entre os dois vetores é dada por

$$
\tau=\mathbf{C}_{\mathbf{s h}} \boldsymbol{\varepsilon}
$$

onde $\mathbf{C}_{\mathbf{s h}}$ é a matriz constitutiva para material isotrópico do elemento de casca, que da teoria do MEF, pode ser escrita por

$$
\mathbf{C}_{\mathbf{s h}}=\mathbf{Q}_{\mathbf{s h}}^{T}\left(\frac{E}{1-v^{2}}\left[\begin{array}{cccccc}
1 & v & 0 & 0 & 0 & 0 \\
& 1 & 0 & 0 & 0 & 0 \\
& 0 & 0 & 0 & 0 \\
& & & \frac{1-v}{2} & 0 & 0 \\
\text { Simétrica } & & k \frac{1-v}{2} & 0 \\
& & & & k \frac{1-v}{2}
\end{array}\right]\right) \mathbf{Q}_{\mathbf{s h}}
$$

onde $\mathbf{Q}_{\text {sh }}$ representa a matriz de transformação da lei de tensão deformação de coordenadas naturais para coordenadas globais e pode ser escrita por

$$
\mathbf{Q}_{\mathbf{s h}}=\left[\begin{array}{cccccc}
l_{1}^{2} & m_{1}^{2} & n_{1}^{2} & l_{1} m_{1} & m_{1} n_{1} & n_{1} l_{1} \\
l_{2}^{2} & m_{2}^{2} & n_{2}^{2} & l_{2} m_{2} & m_{2} n_{2} & n_{2} l_{2} \\
l_{3}^{2} & m_{3}^{2} & n_{3}^{2} & l_{3} m_{3} & m_{3} n_{3} & n_{3} l_{3} \\
2 l_{1} l_{2} & 2 m_{1} m_{2} & 2 n_{1} n_{2} & l_{1} m_{2}-l_{2} m_{1} & m_{1} n_{2}-m_{2} n_{1} & n_{1} l_{2}-n_{2} l_{1} \\
2 l_{2} l_{3} & 2 m_{2} m_{3} & 2 n_{2} n_{3} & l_{2} m_{3}-l_{3} m_{2} & m_{2} n_{3}-m_{3} n_{2} & n_{2} l_{3}-n_{3} l_{2} \\
2 l_{3} l_{1} & 2 m_{3} m_{1} & 2 n_{3} n_{1} & l_{1} m_{3}-l_{3} m_{1} & m_{1} n_{3}-m_{3} n_{1} & n_{1} l_{3}-n_{3} l_{1}
\end{array}\right],
$$


onde

$$
\begin{array}{lll}
l_{1}=\cos \left(e_{x}, e_{\bar{r}}\right), & m_{1}=\cos \left(e_{y}, e_{\bar{r}}\right), & n_{1}=\cos \left(e_{z}, e_{\bar{r}}\right), \\
l_{2}=\cos \left(e_{x}, e_{\bar{s}}\right), & m_{2}=\cos \left(e_{y}, e_{\bar{s}}\right), & n_{s}=\cos \left(e_{z}, e_{\bar{s}}\right), \\
l_{3}=\cos \left(e_{x}, e_{t}\right), & m_{3}=\cos \left(e_{y}, e_{t}\right), & n_{3}=\cos \left(e_{z}, e_{t}\right) .
\end{array}
$$

Considerando o elemento de quatro nós da Figura 2.2, suas coordenadas globais (x, y, z), e suas coordenadas naturais ( $r, s, t)$ e sendo os vetores $\mathbf{r}, \mathbf{s}$ e t tangentes às linhas de coordenadas $r, \mathrm{~s}$ e t, respectivamente, podem-se escrever as coordenadas cartesianas de qualquer ponto do elemento como

$$
\begin{aligned}
& { }^{e} x(r, s, t)=\sum_{k=1}^{4} N_{k}{ }^{e} x_{k}+\frac{t}{2} \sum_{k=1}^{4} a_{k} N_{k}{ }^{e} V_{n x}^{k}, \\
& e^{e} y(r, s, t)=\sum_{k=1}^{4} N_{k}{ }^{e} y_{k}+\frac{t}{2} \sum_{k=1}^{4} a_{k} N_{k}{ }^{e} V_{n y}^{k}, \\
& { }^{e} z(r, s, t)=\sum_{k=1}^{4} N_{k}{ }^{e} z_{k}+\frac{t}{2} \sum_{k=1}^{4} a_{k} N_{k}{ }^{e} V_{n z}^{k},
\end{aligned}
$$

onde ${ }^{e} X,{ }^{e} y,{ }^{e} Z$ são as coordenadas cartesianas do qualquer ponto do elemento; ${ }^{e} X_{k}$, ${ }^{e} y_{k},{ }^{e} Z_{k}$ são as coordenadas do nó $k$; $a_{k}$ é a espessura do elemento no nó $k ;{ }^{e} V_{n x}^{k},{ }^{e} V_{n y}^{k}$, ${ }^{e} V_{n z}^{k}$ são as componentes unitárias do vetor ${ }^{e} \mathbf{V}_{n}^{k}$ normal a superfície da casca no nó $k$, também chamado de vetor diretor do nó $k$; $N_{k}$ são obtidas das funções de forma, que para o elemento retangular da Figura 2.2 podem ser escritas por

$$
\begin{aligned}
& N_{1}=\frac{1}{4}(1+r)(1+s) ; N_{2}=\frac{1}{4}(1-r)(1+s), \\
& N_{3}=\frac{1}{4}(1-r)(1-s) ; N_{4}=\frac{1}{4}(1+r)(1+s) .
\end{aligned}
$$

O índice $e$ nas coordenadas e nos vetores diretores indica a configuração original e deformada do elemento (0 e 1 respectivamente), ou seja, 


$$
\mathbf{V}_{n}^{k}={ }^{1} \mathbf{V}_{n}^{k}-{ }^{0} \mathbf{V}_{n}^{k}
$$

desta forma, os deslocamentos $u, v$ e $w$ podem ser escritos por

$$
\begin{aligned}
& u(r, s, t)=\sum_{k=1}^{4} N_{k} u_{k}+\frac{t}{2} \sum_{k=1}^{4} a_{k} N_{k} V_{n x}^{k}, \\
& v(r, s, t)=\sum_{k=1}^{4} N_{k} v_{k}+\frac{t}{2} \sum_{k=1}^{4} a_{k} N_{k} V_{n y}^{k}, \\
& w(r, s, t)=\sum_{k=1}^{4} N_{k} w_{k}+\frac{t}{2} \sum_{k=1}^{4} a_{k} N_{k} V_{n z}^{k} .
\end{aligned}
$$

Os componentes de $\mathbf{V}_{n}^{k}$ podem ser expressos em termo da rotação do nó $k$, porém não é a única forma de proceder, Bathe (1996) mostra uma outra forma de se definir os vetores ${ }^{0} \mathbf{V}_{1}^{k}$ e ${ }^{0} \mathbf{V}_{2}^{k}$ ortogonais a ${ }^{0} \mathbf{V}_{n}^{k}$ :

$$
{ }^{0} \mathbf{V}_{1}^{k}=\frac{\mathbf{e}_{\mathbf{y}} \times{ }^{0} \mathbf{V}_{n}^{k}}{\left\|\mathbf{e}_{\mathbf{y}} \times{ }^{0} \mathbf{V}_{n}^{k}\right\|_{2}}, \mathrm{e}{ }^{0} \mathbf{V}_{2}^{k}={ }^{0} \mathbf{V}_{n}^{k} \times{ }^{0} \mathbf{V}_{1}^{K}
$$

onde $\mathbf{e}_{\mathbf{y}}$ é um vetor unitário na direção do eixo y.

Rotacionando ${ }^{0} \mathbf{V}_{n}^{k}$ de $\alpha_{k}$ e $\beta_{k}$ sobre os vetores ${ }^{0} \mathbf{V}^{k}{ }_{1}$ e ${ }^{0} \mathbf{V}_{2}^{k}$ respectivamente, sendo $\alpha_{k}$ e $\beta_{k}$ pequenos, pode-se escrever

$$
\mathbf{V}_{n}^{k}=-{ }^{0} \mathbf{V}_{2}^{k} \alpha_{k}+{ }^{0} \mathbf{V}_{1}^{k} \beta_{k}
$$

Substituindo a Eq. (2.21) nas Eqs. (2.17 a 2.19) obtém-se

$$
u(r, s, t)=\sum_{k=1}^{4} N_{k} u_{k}+\frac{t}{2} \sum_{k=1}^{4} a_{k} N_{k}\left(-{ }^{0} V_{2 x}^{k} \alpha_{k}+{ }^{0} V_{1 x}^{k} \beta_{k}\right)
$$




$$
\begin{aligned}
& v(r, s, t)=\sum_{k=1}^{4} N_{k} v_{k}+\frac{t}{2} \sum_{k=1}^{4} a_{k} N_{k}\left(-{ }^{0} V_{2 y}^{k} \alpha_{k}+{ }^{0} V_{1 y}^{k} \beta_{k}\right), \\
& w(r, s, t)=\sum_{k=1}^{4} N_{k} w_{k}+\frac{t}{2} \sum_{k=1}^{4} a_{k} N_{k}\left(-{ }^{0} V_{2 z}^{k} \alpha_{k}+{ }^{0} V_{1 z}^{k} \beta_{k}\right) .
\end{aligned}
$$

Derivando-se as Eq. (2.22 a 2.24) em função de $r, s$ e $t$, obtém-se a matriz deformação-deslocamento $\mathbf{B}$, que para o deslocamento $u$, pode ser escrita por

$$
\left[\begin{array}{c}
\frac{\partial u}{\partial r} \\
\frac{\partial u}{\partial s} \\
\frac{\partial u}{\partial t}
\end{array}\right]=\sum_{k-1}^{4}\left[\begin{array}{ccc}
\frac{\partial h_{k}}{\partial r} & \frac{\partial N_{k}}{\partial r} \operatorname{tg}_{1 x}^{k} & \frac{\partial N_{k}}{\partial r} \operatorname{tg}_{2 x}^{k} \\
\frac{\partial h_{k}}{\partial s} & \frac{\partial N_{k}}{\partial s} \operatorname{tg}_{1 x}^{k} & \frac{\partial N_{k}}{\partial s} \operatorname{tg}_{2 x}^{k} \\
0 & N_{k} g_{1 x}^{k} & N_{k} g_{2 x}^{k}
\end{array}\right]\left[\begin{array}{c}
u_{k} \\
\alpha_{k} \\
\beta_{k}
\end{array}\right]
$$

onde

$$
\mathbf{g}_{1}^{k}=-\frac{1}{2} a_{k}^{0} \mathbf{V}_{2}^{k} ; \text { e } \mathbf{g}_{2}^{k}=\frac{1}{2} a_{k}{ }^{0} \mathbf{V}_{1}^{k}
$$

Para obtenção dos deslocamentos $v$ e $w$, substitui-se na Eq. (2.26), a coordenada $x$ por $y$ e $z$ respectivamente.

Para o caso de casca, a transformada para se obter as derivadas em relação às coordenadas cartesianas $(x, y, z)$, fica

$$
\left[\begin{array}{c}
\frac{\partial}{\partial x} \\
\frac{\partial}{\partial y} \\
\frac{\partial}{\partial z}
\end{array}\right]=\mathbf{J}^{-1}\left[\begin{array}{c}
\frac{\partial}{\partial r} \\
\frac{\partial}{\partial s} \\
\frac{\partial}{\partial t}
\end{array}\right]
$$

onde J é a matriz Jacobiana da função, ou seja, 


$$
\mathbf{J}=\left[\begin{array}{lll}
\frac{\partial x}{\partial r} & \frac{\partial y}{\partial r} & \frac{\partial z}{\partial r} \\
\frac{\partial x}{\partial s} & \frac{\partial y}{\partial s} & \frac{\partial z}{\partial s} \\
\frac{\partial x}{\partial t} & \frac{\partial y}{\partial t} & \frac{\partial z}{\partial t}
\end{array}\right]
$$

Substituindo a Eq. (2.35) na Eq.(2.34) obtém-se

$$
\left[\begin{array}{c}
\frac{\partial u}{\partial x} \\
\frac{\partial u}{\partial y} \\
\frac{\partial u}{\partial z}
\end{array}\right]=\sum_{k-1}^{4}\left[\begin{array}{ccc}
\frac{\partial N_{k}}{\partial x} & g_{1 x}^{k} G_{x}^{k} & g_{2 x}^{k} G_{x}^{k} \\
\frac{\partial N_{k}}{\partial y} & g_{1 x}^{k} G_{y}^{k} & g_{2 x}^{k} G_{y}^{k} \\
\frac{\partial N_{k}}{\partial z} & g_{1 x}^{k} G_{z}^{k} & g_{2 x}^{k} G_{z}^{k}
\end{array}\right]\left[\begin{array}{c}
u_{k} \\
\alpha_{k} \\
\beta_{k}
\end{array}\right],
$$

onde

$$
\frac{\partial N_{k}}{\partial x} \mathbf{J}_{11}^{-1} \frac{\partial N_{k}}{\partial r}+\mathbf{J}_{12}^{-1} \frac{\partial N_{k}}{\partial s}, \text { e } \quad G_{x}^{k}=t\left(\mathbf{J}_{11}^{-1} \frac{\partial N_{k}}{\partial r}+\mathbf{J}_{12}^{-1} \frac{\partial N_{k}}{\partial s}\right)+\mathbf{J}_{13}^{-1} N_{k}
$$

As derivadas de $v$ e $w$ são obtidas de maneira análoga, e a partir destas derivadas, pode-se montar a matriz de deformação-deslocamento B.

Tendo a matriz $\mathbf{B}$ e a matriz $\mathbf{C}_{\mathbf{s h}}$, obtém-se a matriz $\mathbf{k}_{\mathbf{e}}$ rigidez do elemento por

$$
\mathbf{k}_{\mathbf{e}}=\int_{-1}^{1} \int_{-1}^{1} \int_{-\frac{a_{k}}{2}}^{\frac{a_{k}}{2}} \mathbf{B}^{T} \mathbf{C}_{\mathbf{s h}} \mathbf{B} \operatorname{det} \mathbf{J} d r d s d t
$$




\subsection{Elemento sólido tridimensional e elemento de fluido contido tridimensional.}

Elementos de sólidos tridimensionais são utilizados para modelagem de maior grau de hierarquia, podendo ser mostrado detalhes no modelo impossíveis de serem representados por outro tipo de elemento. Porém possui um custo computacional maior quando comparado a outros elementos, e para modelos de baixa hierarquia, geralmente tal custo não é compensado por uma maior precisão no resultado.

Em contrapartida, por ser um elemento de razão de aspecto tridimensional, apenas três graus de liberdade são necessários ao elemento (translação nos eixos cartesianos).

O elemento de fluido contido é uma modificação do elemento de sólido tridimensional, utilizado para representações de fluidos onde não haja fluxo. Ao invés de utilizar o módulo de Young, o elemento utiliza o coeficiente de elasticidade fluida, além de incorporar a viscosidade de fluido para confecção da matriz de amortecimento para os casos de análise dinâmica (ANSYS, 2004).

Este trabalho será restrito a análise estática, e no caso de OT, o elemento sólido será utilizado para modelagem do fluido contido ao invés do elemento de fluido contido.

A seguir será apresentada a base teórica para elemento sólido tridimensional de oito nós, quando necessário são apresentadas às diferenças entre o elemento sólido e o de fluido contido.

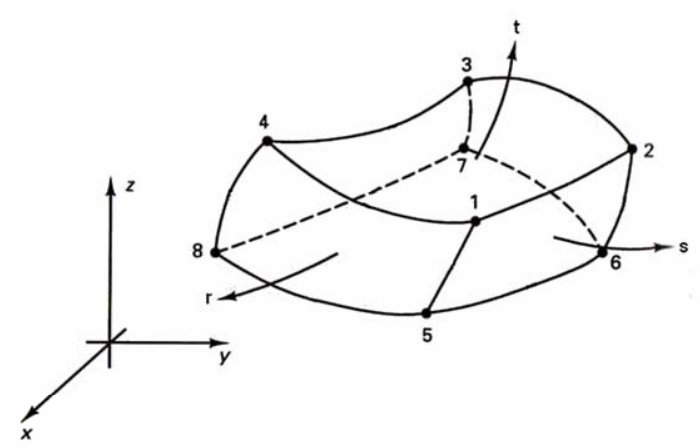

Figura 2.3 - Elemento isoparamétrico tridimensional de 8 nós. 
Tratando-se de um elemento tridimensional sólido, podem-se escrever os vetores de deformação $\varepsilon$ e de tensão $\tau$ por

$$
\boldsymbol{\varepsilon}^{T}=\left[\begin{array}{llllll}
\varepsilon_{x x} & \varepsilon_{y y} & \varepsilon_{z z} & \varepsilon_{x y} & \varepsilon_{y z} & \varepsilon_{z x}
\end{array}\right], \text { e } \boldsymbol{\tau}^{T}=\left[\begin{array}{llllll}
\tau_{x x} & \tau_{y y} & \tau_{z z} & \tau_{x y} & \tau_{y z} & \tau_{z x}
\end{array}\right]
$$

A relação entre os dois vetores é dada por

$$
\tau=\mathbf{C}_{3 \mathbf{D}} \boldsymbol{\varepsilon}
$$

onde $\mathbf{C}_{3 \mathrm{D}}$ é a matriz constitutiva do elemento tridimensional, que da teoria do MEF, pode ser escrita por

$$
\mathbf{C}_{3 \mathbf{D}}=\frac{E(1-v)}{(1+v)(1-2 v)}\left[\begin{array}{cccccc}
1 & \frac{v}{(1-v)} & \frac{v}{(1-v)} & 0 & 0 & 0 \\
1 & \frac{v}{(1-v)} & 0 & 0 & 0 \\
& 1 & 0 & 0 & 0 \\
\text { Simétrica } & \frac{(1-2 v)}{2(1-v)} & 0 & 0 \\
& & \frac{(1-2 v)}{2(1-v)} & 0 \\
& & \frac{(1-2 v)}{2(1-v)}
\end{array}\right] .(2.34)
$$

No caso do elemento de fluido contido, onde os vetores de deformação $\varepsilon$ e de tensão $\tau$ são dados por

$$
\begin{aligned}
\boldsymbol{\varepsilon}^{\mathbf{T}} & =\left[\begin{array}{lllllll}
\varepsilon_{\kappa} & \varepsilon_{x y} & \varepsilon_{y z} & \varepsilon_{x z} & \psi_{x} & \psi_{y} & \psi_{z}
\end{array}\right], \\
\boldsymbol{\tau}^{\mathbf{T}} & =\left[\begin{array}{lllllll}
P & \tau_{x y} & \tau_{y z} & \tau_{x z} & M_{x} & M_{y} & M_{z}
\end{array}\right],
\end{aligned}
$$

onde $\varepsilon_{\kappa}$ é a deformação de compressão $(\partial \mathrm{u} / \partial \mathrm{x}+\partial \mathrm{v} / \partial \mathrm{y}+\partial \mathrm{w} / \partial \mathrm{z}) ; \psi_{i}$ é a rotação em torno do eixo $i$; $P$ é a pressão; e $M_{i}$ é a componente paralela ao eixo $i$ do momento.

A matriz constitutiva do elemento será dada por 


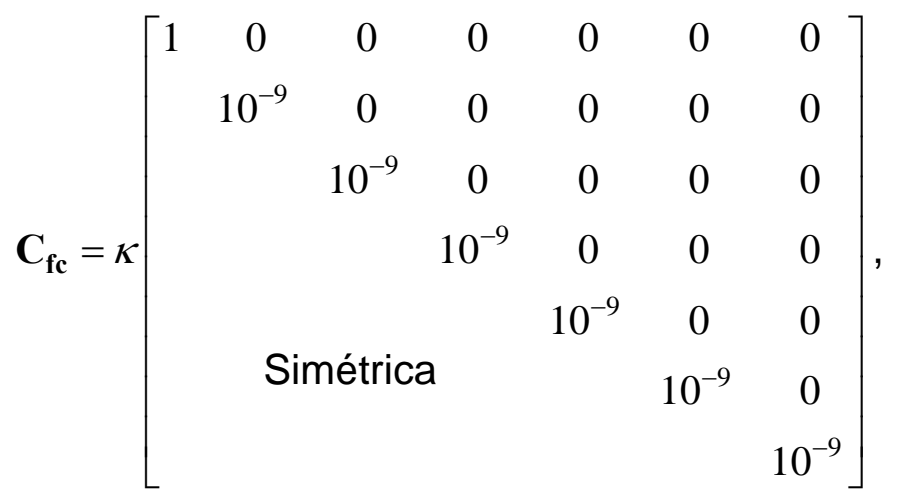

onde: $\kappa$ é o módulo de compressibilidade do material e os termos de cisalhamento e de rotação são valores significamente menores, cujo objetivo é impedir o movimento de corpo livre do elemento.

Sendo as equações de forma do elemento mostrado na Figura 2.3 dadas por

$$
\begin{array}{ll}
N_{1}=\frac{1}{4}(1+r)(1+s)(1+t), & N_{2}=\frac{1}{4}(1-r)(1+s)(1+t), \\
N_{3}=\frac{1}{4}(1-r)(1-s)(1+t), & N_{4}=\frac{1}{4}(1+r)(1-s)(1+t), \\
N_{5}=\frac{1}{4}(1+r)(1+s)(1-t), & N_{6}=\frac{1}{4}(1-r)(1+s)(1-t), \\
N_{7}=\frac{1}{4}(1-r)(1-s)(1-t), & N_{8}=\frac{1}{4}(1+r)(1-s)(1-t),
\end{array}
$$

pode-se calcular os deslocamentos de um ponto arbitrário do elemento isoparamétrico em função das coordenadas nodais do elemento, através de

$$
u(r, s, t)=\sum_{i=1}^{8} N_{i} u_{i}, \quad v(r, s, t)=\sum_{i=1}^{8} N_{i} v_{i}, \text { e } \quad w(r, s, t)=\sum_{i=1}^{8} N_{i} w_{i}
$$

Da teoria do MEF, sabe-se que para obter as derivadas em relação às coordenadas cartesiana $(x, y, z)$, deve-se utilizar a transformada 


$$
\left[\begin{array}{c}
\frac{\partial}{\partial x} \\
\frac{\partial}{\partial y} \\
\frac{\partial}{\partial z}
\end{array}\right]=\mathbf{J}^{-1}\left[\begin{array}{c}
\frac{\partial}{\partial r} \\
\frac{\partial}{\partial s} \\
\frac{\partial}{\partial t}
\end{array}\right],
$$

onde $\mathbf{J}$ é a matriz Jacobiana da função, ou seja,

$$
\mathbf{J}=\left[\begin{array}{lll}
\frac{\partial x}{\partial r} & \frac{\partial y}{\partial r} & \frac{\partial z}{\partial r} \\
\frac{\partial x}{\partial s} & \frac{\partial y}{\partial s} & \frac{\partial z}{\partial s} \\
\frac{\partial x}{\partial t} & \frac{\partial y}{\partial t} & \frac{\partial z}{\partial t}
\end{array}\right]
$$

portanto a matriz de deslocamento-deformações B, pode ser obtida por

$$
\mathbf{B}=\left[\begin{array}{ccccccc}
\frac{\partial N_{1}}{\partial x} & 0 & 0 & \ldots . . & \frac{\partial N_{8}}{\partial x} & 0 & 0 \\
0 & \frac{\partial N_{1}}{\partial y} & 0 & \ldots . . & 0 & \frac{\partial N_{8}}{\partial y} & 0 \\
0 & 0 & \frac{\partial N_{1}}{\partial z} & \ldots . . & 0 & 0 & \frac{\partial N_{8}}{\partial z} \\
\frac{\partial N_{1}}{\partial y} & \frac{\partial N_{1}}{\partial x} & 0 & \ldots . . & \frac{\partial N_{8}}{\partial y} & \frac{\partial N_{8}}{\partial x} & 0 \\
0 & \frac{\partial N_{1}}{\partial z} & \frac{\partial N_{1}}{\partial y} & \ldots . . & 0 & \frac{\partial N_{8}}{\partial z} & \frac{\partial N_{8}}{\partial y} \\
\frac{\partial N_{1}}{\partial z} & 0 & \frac{\partial N_{1}}{\partial x} & \ldots . . & \frac{\partial N_{8}}{\partial z} & 0 & \frac{\partial N_{8}}{\partial x}
\end{array}\right] .
$$

Obtidas a matriz constitutiva $\mathbf{C}_{\mathbf{3 d}}\left(\right.$ ou $\mathbf{C}_{\mathbf{f c}}$ ) e de deslocamento-deformação $\mathbf{B}$, obtém-se a matriz $\mathbf{k}_{\mathbf{e}}$ de rigidez do elemento através de

$$
\mathbf{k}_{\mathbf{e}}=\int_{-1}^{1} \int_{-1}^{1} \int_{-1}^{1} \mathbf{B}^{T} \mathbf{C}_{\mathbf{3 d}} \mathbf{B} \operatorname{det} \mathbf{J} d r d s d t
$$




\subsection{Deslocamentos nodais.}

Obtidas as matrizes de rigidez de todos os elementos que representam a estrutura, inclusive seu conteúdo fluido, estas são inseridas na matriz de rigidez global $\mathbf{K}$ de acordo com a matriz de conectividade, que associa um número a cada elemento, e o número de nós a que está ligado. De maneira geral pode-se escrever que

$$
\mathbf{K}=\sum_{e=1}^{n e}{ }^{\mathbf{n g}} \mathbf{K}_{\mathbf{e}}
$$

onde ${ }^{\mathbf{n g}} \mathbf{K}_{\mathrm{e}}$ é a matriz rigidez do elemento em seu nível global e $n_{e}$ é o número de elementos da malha de EF. A montagem detalhada da matriz $\mathbf{K}$ pode ser obtida em Zienkiewicz (1977).

Obtida a matriz $\mathbf{K}$, bem como, o vetor $\mathbf{f}$ das forças aplicadas aos nós, calculase o vetor de deslocamentos nodais u a partir da relação de equilíbrio

$$
\mathbf{K u}=\mathbf{f} .
$$




\section{OTIMIZAÇÃO}

\subsection{Introdução.}

O conceito de otimização é intrinsecamente ligado ao desejo humano de se superar, na busca diária do atleta em atingir um tempo menor na corrida, ao empresário em aumentar seus lucros. Porém, mesmo entre os engenheiros ainda existe uma confusão entre uma abordagem de análises e um processo de otimização.

Vanderplaats (1984) nos mostra que na abordagem de análise, se determina a resposta de um sistema específico, o que permite, através de uma variação aleatória de seus parâmetros, a comparação entre as diversas respostas. Diferentemente, a proposta da otimização, é a busca racional do melhor projeto para atender às necessidades impostas. Apesar da abordagem de análise fazer parte de um processo de otimização, para um grande número de parâmetros torna-se inviável apenas seu uso, sem a abordagem técnica de otimização.

Novaes (1978) cita que: "As técnicas usuais de otimização são baseadas em duas premissas implícitas de conseqüências importantes na aplicação prática. Em primeiro lugar admite-se que possa ser definida uma função objetivo, a qual exprime através de uma escala única, a medida de mérito do sistema analisado. A segunda premissa refere-se ao caráter determinístico da avaliação: admite-se que as relações entre a variável dependente e os parâmetros independentes ocorram deterministicamente. Em outras palavras, um determinado conjunto de valores das variáveis independentes deve produzir apenas um resultado na função objetivo."

Os primeiros trabalhos de otimização estrutural foram resolvidos por Maxell em 1872 e Michell em 1904 (MICHELL, 1904) que usando a teoria da elasticidade calculavam o campo de tensões mêcanicas de uma força aplicada num ponto de um domínio infinito sujeito a restrições em outros pontos e sugeriam uma estrutura de treliças, de maneira que cada elemento da treliça estivesse alinhado com a direção 
das tensões principais, de maneira que a estrutura ótima estaria apenas sujeira a tração ou compressão e não há momentos fletores.

Como exemplo do trabalho de Michell observa-se na Figura 3.1 (a) a estrutura proposta para uma viga fixa num ponto e sujeito a uma força concentrada em outro ponto, e em (b), uma viga bi-apoiada sujeita a uma força central. Em (c) e (d) observa-se as mesmas estruturas obtidas por OT. Até hoje os trabalhos de Michell são utilizados como parâmetros.

(a)

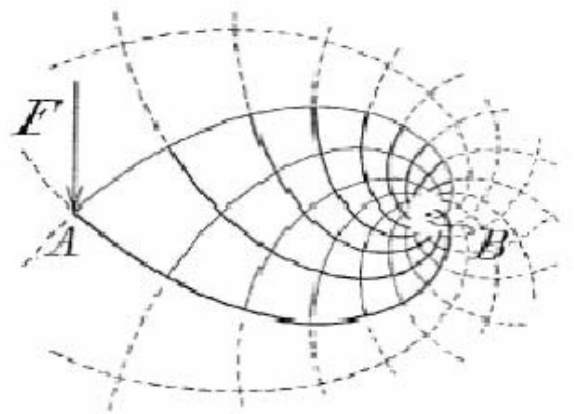

(c)

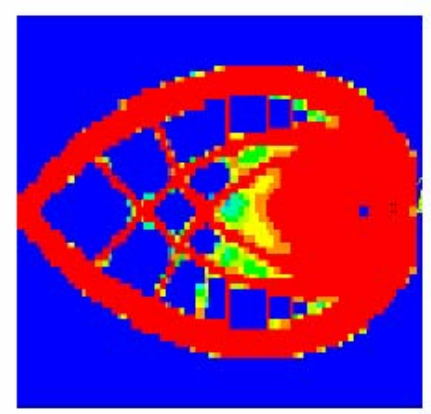

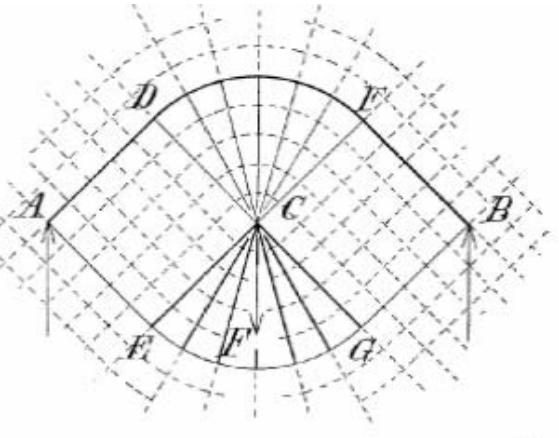

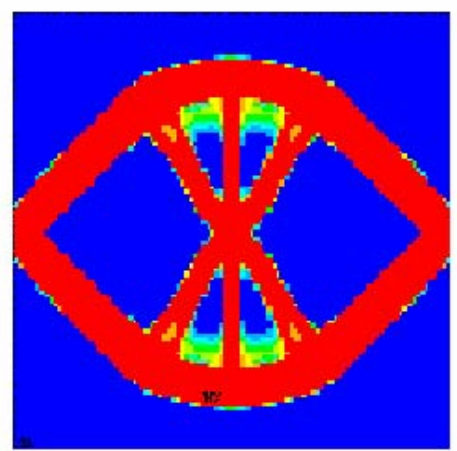

(b)

(d) OT.

Figura 3.1 - (a e b) Exemplo de estruturas de Michell (1904), (c e d) estruturas obtidas por

Somente com o surgimento do computador, e conseqüente viabilização do MEF é que problemas práticos de otimização estrutural paramétricas passaram a ser estudados. Assim, por exemplo, Gellatly e Gallagher (1966), apresentam um estudo de otimização paramétrica já utilizando o MEF, em conjunto com o conceito de "Fully Stressed Design (FSD)", ou seja, onde toda estrutura é sujeita a tensão máxima admissível, e algoritmo de otimização “Steepest Descent” (MOHR, 1994a).

Uma revisão mais detalhada sobre o tema, incluindo aspectos históricos pode ser obtida em Rozvany; Bendsøe e Kirsch (1995). 
Atualmente, as técnicas de otimização estrutural são vastamente encontradas na literatura, e apresentam basicamente três abordagens: otimização paramétrica, de forma e topológica.

Na otimização paramétrica, a estrutura de forma pré-definida é caracterizada por parâmetros, como exemplo, altura da alma $h$, espessura t e largura b do flange de uma viga em I mostrados na Figura 3.2. Através de um algoritmo de otimização são calculados valores ótimos para estes parâmetros.

$\mathrm{Na}$ otimização de forma, são parametrizadas curvas "splines" que constituem o contorno da estrutura. Desta forma calculando-se os valores ótimos dos parâmetros, altera-se a geometria do modelo.

Já na otimização topológica os parâmetros a serem otimizados não estão relacionados com a forma ou dimensão da estrutura, mas com a distribuição de material em um domínio inicial. Desta forma encontram-se a forma ótima da estrutura (dentro deste domínio) e furos em seu interior, de maneira a retirar a maior quantidade de material possível, extremizando-se uma função objetivo.
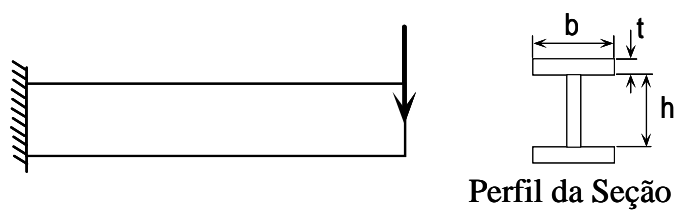

Otimização Paramétrica
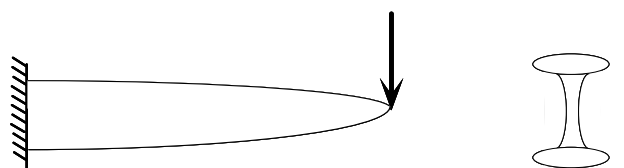

\section{Otimização de Forma}

Perfil da Seção
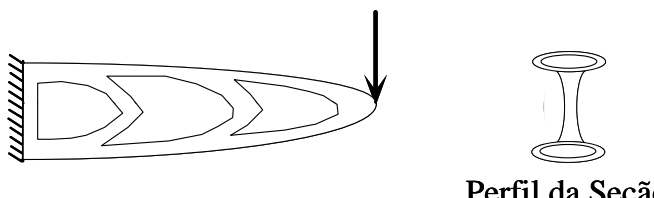

Otimização Topológica

Perfil da Seção

Figura 3.2 - Exemplo de abordagens de otimização estrutural.

Para uma mesma rigidez, a optimalidade do resultado melhora com a generalidade do método, ou seja, otimização topológica apresenta uma melhor optimalidade que a de forma que apresenta melhor optimalidade que a paramétrica.

Dependendo dos parâmetros escolhidos na otimização paramétrica, e na otimização de forma, podem ocorrer problemas na confecção da malha de 
elementos finitos em iterações mais avançadas, devido ao estreitamento de algumas regiões, causando a deformação da malha.

\subsection{Otimização Paramétrica.}

Um problema de otimização paramétrica é sempre escrito através de uma função objetivo $(F(x))$, em função de variáveis de projeto $\left(x_{i}\right)$ e limitado por restrições de igualdade $\left(h_{j}(x)\right)$, e de inegualdade $\left(g_{k}(x)\right)$ como pode ser observado na Eq. (3.1).

$$
\begin{aligned}
& \operatorname{Min} F(x) \\
& x_{i} \\
& \text { tal que: } \\
& h_{j}(x)=0 \\
& g_{k}(x) \leq \bar{g}_{k}, \\
& \underline{x}_{i} \leq x_{i} \leq \bar{x}_{i} \\
& i=1,2, \ldots, n_{x} \\
& j=1,2, \ldots, n_{h} \\
& k=1,2, \ldots, n_{g}
\end{aligned}
$$

onde $\underline{x}_{i}$ é o limite inferior do valor das variável $x_{i} ; \bar{x}_{i}$ é o limite superior da variável $x_{i}$; $\bar{g}_{k}$ é uma constante, que limita superiormente a restrição $g_{k} n_{x}$ é o número de variáveis do problema; $n_{h}$ é o número de restrições de igualdade; e $n_{g}$ é o número de restrições de inegualdade.

Para facilitar a implementação numérica, a restrição de igualdade pode ser transformada em duas restrições de inegualdade da seguinte maneira (Vanderplaats, 1984)

$$
\begin{aligned}
& h(x)=a \Rightarrow \\
& g_{1}(x) \leq a \\
& g_{2}(x) \geq a
\end{aligned}
$$


sendo a uma constante.

Desta maneira pode-se simplificar o problema proposto na Eq. (3.1) para

$$
\begin{aligned}
& \text { Min } F(x) \\
& x_{i} \\
& \text { tal que: } \\
& g_{k}(x) \leq \bar{g}_{k}, \\
& \underline{x}_{i} \leq x_{i} \leq \bar{x}_{i} \\
& i=1,2, \ldots, n_{x} \\
& k=1,2, \ldots, n_{g}
\end{aligned}
$$

onde as restrições de igualdade estão implícitas nas restrições de inegualdade.

Existem diversos algoritmos que resolvem este problema de diferentes formas, sua utilização vai depender da linearidade da função objetivo e das restrições, e até mesmo da existência ou não de restrições. Sundaram (1996), Haftka e Gürdal (1991) ou Borusse (1988) apresentam diversos desses algoritmos todos eles bem explorados na literatura.

Para problemas não-lineares, dois algoritmos largamente utilizados são os algoritmos de direção conjugada de Fletcher-Reeves e o algoritmo "Steepest Descent" (HAFTKA; GÜRDAL, 1991), ambos de primeira ordem, ou seja, que utilizam informações das derivadas da função objetivo para encontrar o ponto ótimo, e também são utilizados para problemas de otimização onde não há restrições, portanto para utilização destes algoritmos em problemas com restrição, é necessário incorporar as restrições na função objetivo.

Nesta dissertação é utilizado o módulo de otimização paramétrica de primeira ordem do programa ANSYS, que se baseia na incorporação das restrições na função objetivo através da penalização exterior para restrições de caixa das variáveis e penalização interior estendida para as demais restrições. A solução da função objetivo é obtida pelo método de direções conjugadas de Fletcher-Reeves, inicializado (ou reinicializado quando necessário) pelo método "Steepest Descent". Tais métodos são descritos a seguir. 


\subsubsection{Método de penalização da função objetivo.}

A literatura apresenta diversos métodos para incorporar as restrições na função objetivo, utilizando multiplicador de Lagrange, ou métodos de penalização exterior, interior, interior-estendido ou lagrangiano aumentado. Tais métodos se caracterizam pela incorporação de funções penalizadoras, alterando a função objetivo de maneira que próxima à restrição a função objetivo se aproxima da função restrição seguindo determinadas regras de acordo com o método utilizado.

A razão de se incorporar às restrições na função objetivo é permitir a utilização de um algoritmo para problemas sem restrições como o os algoritmos de direção conjugada de Fletcher-Reeves e o algoritmo "Steepest Descent", que são utilizados neste trabalho.

De maneira geral, pode-se escrever o problema da Eq. (3.2), utilizando-se funções penalizadoras da seguinte forma (ANSYS; 2004):

$$
\operatorname{Min} Q(x)=\frac{F}{F_{0}}+\sum_{i=1}^{n_{X}} P_{x}\left(x_{i}\right)+r \sum_{k=1}^{n_{g}} P_{g}\left(g_{k}\right)
$$

onde $Q(x)$ é a nova função objetivo do problema, normalizada e sem restrições; $F_{0}$ é o valor da função $F(x)$, calculado em $x_{0}$ inicial; $P_{x}\left(x_{i}\right)$ é a função penalizadora da restrição da variável $x_{i} ; P_{g}\left(g_{k}\right)$ é a função penalizadora da restrição $g_{k} ;$ e $r$ é um parâmetro de controle da restrição.

Como exemplo de funções penalizadoras, Haftka e Gürdal (1991) nos apresentam o método de penalização exterior, interior, interior estendido que se baseiam em aproximar externa ou internamente, conforme o caso, a função objetivo da restrição.

A chave para se atingir a minimização global da Eq. (3.3) é o ajuste do parâmetro $r$ a cada iteração, a fim de se aproximar gradativamente à restrição. 


\subsection{2 "Steepest Descent".}

Para resolução em cada iteração do problema obtido na Eq. (3.3), pode ser utilizado método "Steepest Descent". Sendo um dos métodos mais antigos, proposto em 1847, ainda é largamente utilizado sozinho ou em conjunto com o método de direções conjugadas de Fletcher-Reeves. O método pode ser encontrado nos trabalhos de Mohr, onde ele apresenta um estudo sobre otimização de uma estrutura de viga (MOHR; 1994a) e posteriormente expande o conceito para interação fluidoestrutura, de maneira a melhorar o escoamento (MOHR, 1994b) e em diversos outros.

Em casos de problemas mal-posto Nagy e Palmer (2003) mostram que o método "Steepest Descent" pode ser mais adequado do que o método de FletcherReeves, atingindo uma convergência mais rápida.

O objetivo do método é encontrar a direção s que proporciona a maior minimização da função objetivo a ser seguida, e caminhar a distância $\alpha$, parando no ponto de mínimo daquela direção, e assim sucessivamente até o ponto ótimo. Desta maneira, o problema de otimização é reduzido a um problema de otimização de variáveis s e $\alpha$ a cada iteração, conforme a Eq. (3.4).

$$
\begin{aligned}
& \text { Min } \nabla Q^{T} \mathbf{s}=\sum_{i=1}^{n_{X}} \frac{\partial Q}{\partial x_{i}} \mathbf{s}_{i}, \\
& \text { tal que } \mathbf{s}^{T} \mathbf{s}=1 .
\end{aligned}
$$

Desta forma, pode-se escrever o lagrangeano do problema por

$$
L(\mathbf{s}, \lambda)=\nabla Q^{T} \mathbf{s}+\lambda\left(\mathbf{s}^{T} \mathbf{s}-1\right)
$$

Impondo-se a condição de estacionaridade ao lagrangeano, obtem-se 


$$
\begin{aligned}
& \frac{\partial L}{\partial \mathbf{s}}=\nabla Q+2 \lambda \mathbf{s}=0 \Rightarrow \mathbf{s}=-\frac{\partial Q}{2 \lambda} \Rightarrow \mathbf{s}^{T} \mathbf{s}=1 \Rightarrow\|\nabla Q\|^{2}=4 \lambda^{2} \Rightarrow 2 \lambda=\|\nabla Q\| \Rightarrow \\
& \Rightarrow \mathbf{s}=-\frac{\nabla Q}{\|\nabla Q\|},
\end{aligned}
$$

onde || é a norma Euclidiana. Desta forma

$$
x_{j+1}=x_{j}+\alpha \mathbf{s}
$$

onde o índice subscrito em x, refere-se à iteração j.

Porém, dependendo do condicionamento da função objetivo o método pode apresentar uma convergência muito lenta, e às vezes, pode apresentar uma oscilação conhecida como fenômeno de "hemstitching", ou oscilação (Figura 3.3). A fim de se evitar esses problemas, pode ser utilizado o método das direções conjugadas de Fletcher-Reeves descrito a seguir.

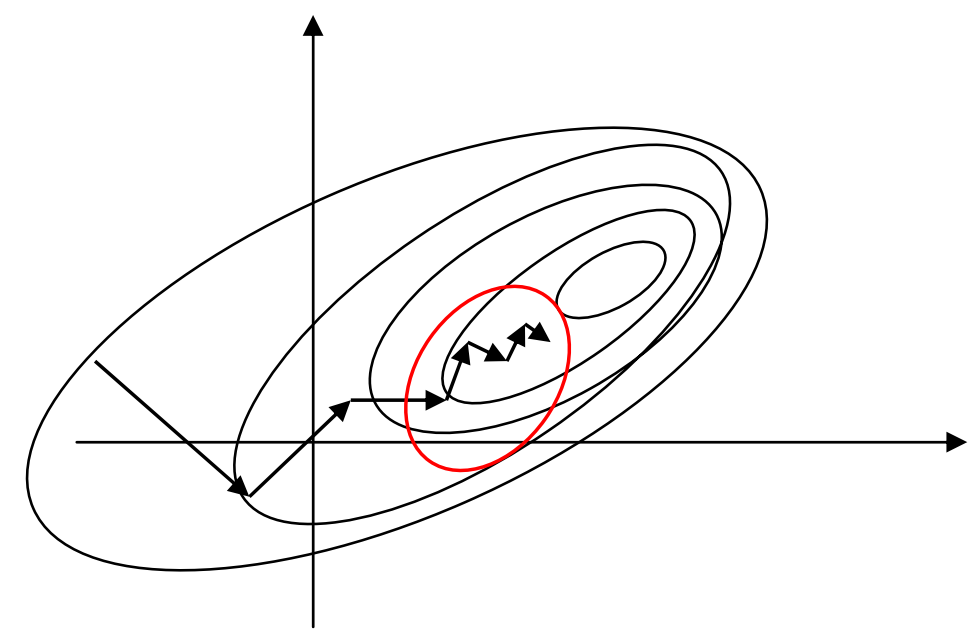

Figura 3.3- Exemplo de oscilação conhecida como fenômeno de "hemstitching" ou oscilação. 


\subsubsection{Direções conjugadas de Fletcher-Reeves.}

A fim de atingir uma convergência mais rapidamente, o método de direção conjugada se baseia em procurar uma nova direção que seja Q-conjugada com a direção obtida na iteração anterior, evitando dessa maneira a ocorrência do fenômeno de "hemstithing".

Após a primeira iteração pelo método "Steepest Descent", as novas direções da iteração $j, \mathbf{s}_{j}$ será dada por

$$
\mathbf{s}_{j}=-\nabla Q_{j}+\frac{\nabla Q_{j}^{T} \nabla Q_{j}}{\nabla Q_{j-1}^{T} \nabla Q_{j-1}}
$$

Calculando $\alpha$, de maneira que

$$
\frac{d Q\left(\alpha_{j+1}\right)}{d \alpha_{j+1}}=0 .
$$

Assim o ponto ótimo da iteração $j+1$, será dado pela Eq. (3.7), como no caso do método anterior.

Para funções quadráticas, prova-se que a convergência corresponde à direção obtida na iteração $n_{x}+1$, onde $n_{x}$ é o número de variáveis do problema, porém, para funções não quadráticas, a convergência raramente ocorre em mais de $n_{x}$ interações, portanto, após esse número, o algoritmo deve ser reiniciado. Um outro critério para reiniciar o método é baseado num teste de ângulo, onde é comparado o coseno do ângulo entre a direção de busca do método "Steepest Descent" e o gradiente negativo, com o coseno do ângulo entre a direção de busca do método de Fleetcher-Reeves (SHANNO, 1985). 


\subsection{Método de Otimização Topológica (MOT).}

O MOT apresenta como principal vantagem, não somente obter uma maior eficiência da função objetivo, quando comparado com os outros métodos de otimização, como auxiliar na busca de um melhor leiaute da estrutura que se deseja otimizar, não se prendendo necessariamente a um projeto inicial.

Proposto por Bendsøe e Kikuchi (1988), o MOT baseia-se na distribuição de material em uma região pré-definida do espaço, fornecendo para o engenheiro, o desenho ótimo preliminar da estrutura. Para isso, o método parametriza as propriedades dos materiais utilizando o conceito de microestrutura, e após uma análise estrutural, geralmente realizada através do MEF, é utilizado um algoritmo de otimização para distribuir o material de forma racional, alterando as propriedades do material em cada elemento de forma não alterar a malha inicial. Em seu trabalho, Bendsøe e Kikuchi (1988) apresentam a distribuição de dois materiais, numa malha de EF onde o primeiro material possui as propriedades da estrutura, e o segundo material é vazio.

Outro método que segue o conceito da otimização topológica, chamado de Otimização Estrutural Evolucionária (OEE), foi proposto por Xie e Steven (1997) e baseia-se na alteração da malha de EF através da subtração de elementos de baixa tensão mecânica. Posteriormente, foi apresentado um método onde existe adição de elementos em torno de áreas onde as tensões mecânicas são altas, chamado de Otimização Estrutural Evolucionária Reversa (QUERIN; STEVEN e XIE, 2000a) e a união dos dois métodos, onde é possível suprimir ou adicionar elementos, chamada de Otimização Estrutural Evolucionária Bidirecional. (QUERIN; STEVEN e XIE, 2000b)

Alguns exemplos de OEE podem ser encontrados em Albolbashari e Keshavarzmanesh (2006), que apresenta a obtenção da estrutura de Michell (MICHELL, 1904)(Figura 3.1), quando se aplica uma força no centro de uma viga biapoiada, e Steven; Querin e Xie (2000) mostra a OEE em estruturas discretas. 


\subsubsection{Introdução teórica.}

No MOT, é necessário conhecer apenas as forças aplicadas e as condições de contorno, não sendo necessário conhecer a geometria da estrutura, que será representada inicialmente pela região de um domínio, onde se podem determinar áreas onde é obrigatória a presença ou ausência de material, e áreas onde esta presença vai depender do resultado da otimização (Figura 3.4).

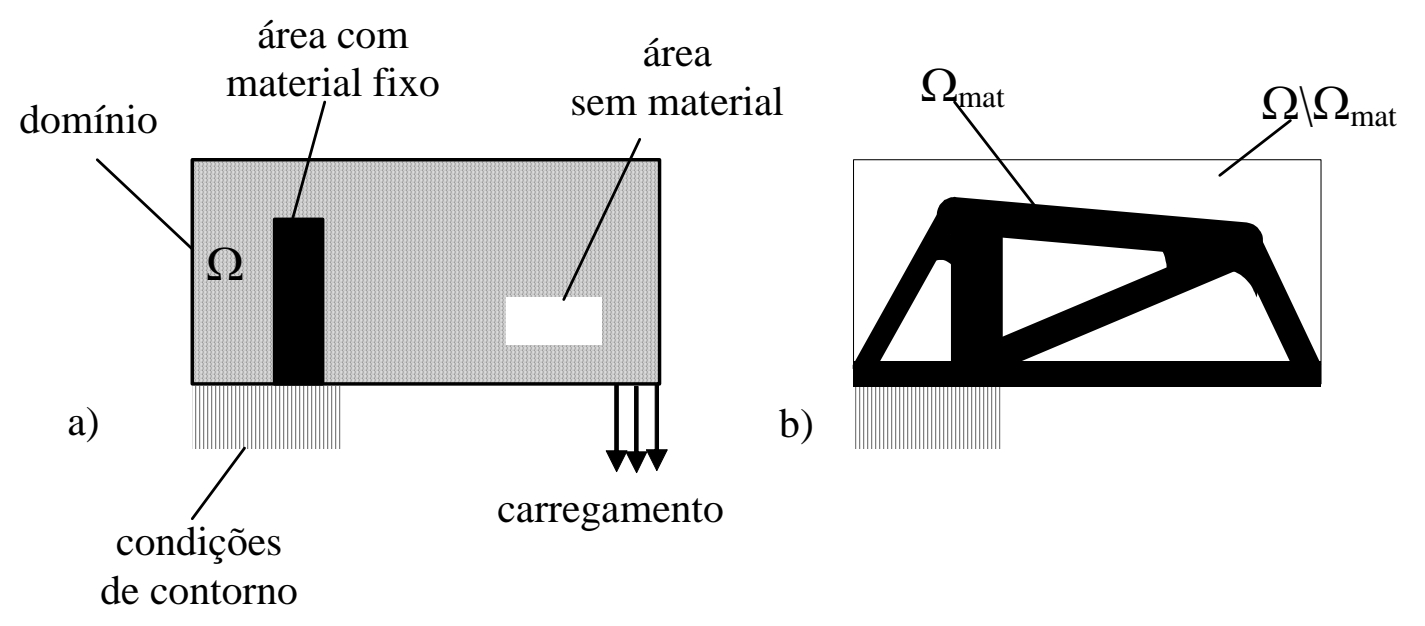

Figura 3.4 - Exemplo de um problema inicial e resultado da otimização topológica.

Uma grande vantagem desta abordagem, é que sendo o domínio fixo a cada iteração, a malha de EF permanece a mesma, mudando apenas a característica do material em cada elemento e, portanto, facilitando o processo de otimização, pois as derivadas de uma função contínua $q$ são obtidas através de

$$
\frac{\partial}{\partial A_{n}} \int_{\Omega} q d \Omega=\int_{\Omega} \frac{\partial q}{\partial A_{n}} d \Omega \text { dado que } \frac{\partial \Omega}{\partial A_{n}}=0 .
$$

Sua formulação tradicional, apresentada em Bendsøe e Kikuchi (1988), ou em Bendsøe e Sigmund (2003) utiliza como função objetivo a minimização da flexibilidade, e impõe uma restrição de volume. 


\subsubsection{Modelos de materiais}

Uma vez que a OT baseia-se na distribuição de material no domínio, as variáveis de projeto estão relacionadas com a presença ou não do material em cada elemento da malha de finitos. Sendo $\mathbf{C}_{\mathbf{0}}$ o tensor de propriedades de um material isotrópico, $\Omega_{\text {mat }}$ a região do domínio onde existe material (Figura 3.4), e $\mathbf{x}$ um ponto qualquer de $\Omega$ as propriedades do material otimizado $\mathbf{C}$ será dada por

$$
\mathbf{C}=\chi \mathbf{C}_{\mathbf{0}}, \quad \chi\left\{\begin{array}{ll}
1 & \text { se } \quad \mathbf{x} \in \Omega_{\text {mat }} \\
0 & \text { se } \mathbf{x} \in \Omega \backslash \Omega_{\text {mat }}
\end{array} .\right.
$$

A função $\chi$ é discreta, uma vez que possui apenas valores 0 ou 1 , e 0 problema de OT (seção 3.3.3) é mal-posto, ou seja, não apresenta solução uma vez que para diferentes discretizações de malha, o problema apresenta resultados diferentes.

Normalmente o aumento do número de buracos, sem a alteração do volume tende a diminuir a flexibilidade. A instabilidade numérica típica neste caso é que à medida que se aumenta a discretização de malha, se aumenta o número de buracos no modelo (ALLAIRE et al., 1997; SIGMUND; PETERSSON, 1998), fenômeno conhecido como dependência de malha (vide seção 3.3.6).

Desta maneira, para que o problema descrito na Eq. (3.11) apresente solução, é necessário a adoção de restrição do perímetro da função $\chi$ (HARBER; JOG; BENDSØE, 1996), ou através de relaxação matemática, que consiste no aumento do espaço de soluções admissíveis, através da utilização de modelos de materiais compostos. (KOHN; STRANG, 1986a, 1986b, 1986c).

Existem dois modelos de materiais muito difundidos para relaxação do problema, que permitem que a função $\chi$ assuma valores intermediários entre 0 e 1 . Um deles, conhecido como método de homogeneização, baseia-se na mistura homogênea de dois materiais na microestrutura, com o material resultante sendo interpretado como contínuo. 
Tais microestruturas podem assumir a forma de um material sólido com um buraco no meio. (célula 1, Figura 3.5), ou uma forma laminar, onde alternam-se lâminas de material e vazio (célula 2, Figura 3.5)( FUJII; CHEN; KIKUCHI., 2001 apud LIMA, 2002).

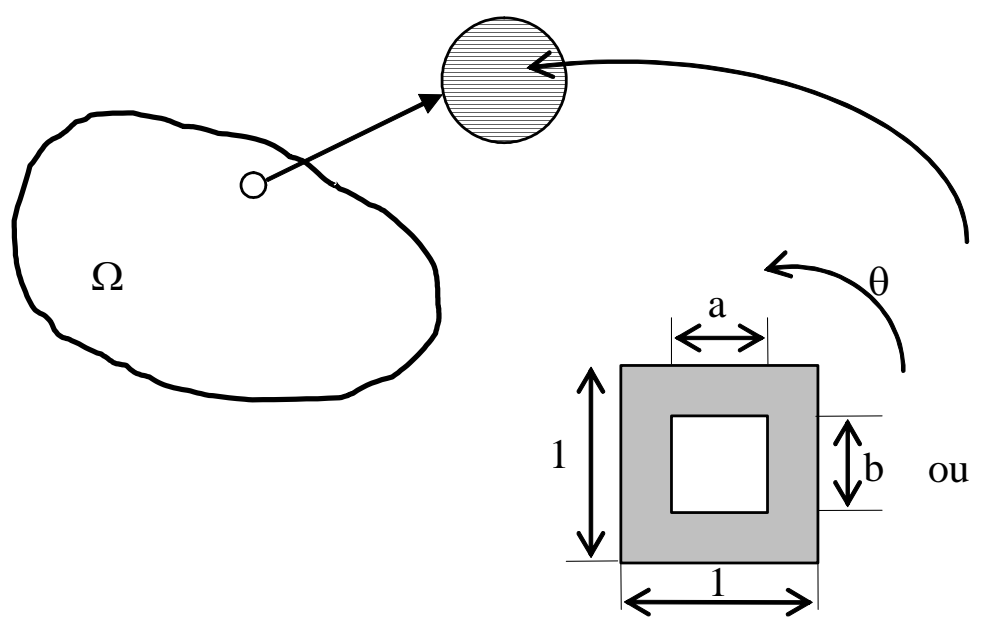

Célula 1

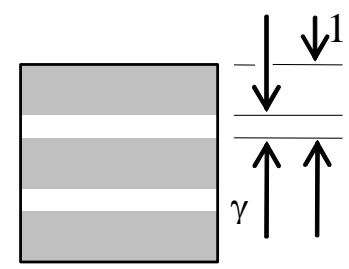

Célula 2

Figura 3.5 - Microestruturas utilizadas no método da homogeneização.

As propriedades do material composto e, portanto, as variáveis do problema de OT, são definidos pelos parâmetros geométricos da microestrutura utilizada para caracterizar o material. No caso de microestruturas como a célula 1 , são as dimensões $a$ e $b$ do buraco em seu interior e de seu ângulo de rotação $\theta$, e de microestruturas como a célula 2 será o espaço $\gamma$ entre elas, ou seja, quando $a=b=1$ na célula 1 , ou $\gamma=0$ na célula 2, o material é sólido, e quando $a=b=0$, ou $\gamma=1$, 0 material é vazio.

Esse modelo de material é bastante robusto, porém além de ser de difícil implementação, a utilização de várias variáveis de projeto apresenta um custo computacional desvantajoso para o uso no MOT.

Uma descrição detalhada do MOT utilizando o método da homogeneização, bem como, análise das condições de contorno, caso de múltiplo carregamento e restrição de domínio, além de um exemplo reproduzindo a treliça de Michell (Figura 3.1) é fornecida no trabalho de Suzuki e Kikuchi (1991) utilizando a célula tipo 1 (Figura 3.5).

A segunda forma de relaxação, que será a utilizada neste trabalho, é o modelo de material baseado no método das pseudo-densidades, cuja 
implementação mais utilizada na literatura é conhecida como material sólido isotrópico com penalização, ou em inglês, "Solid Isotropic Material with Penalization (SIMP)".

De implementação computacional mais simples, no "SIMP" a variável de projeto é a pseudo-densidade do material $(\eta)$, que variando entre 0 e 1 , multiplica o tensor $\mathbf{C}_{\mathbf{0}}$ de propriedades do material, determinando a propriedade do material do modelo em cada ponto do domínio entre 0 e $\mathbf{C}_{0}$ a cada iteração, (BENDS $\varnothing E$; SIGMUND, 2003). Assim, o tensor $\mathbf{C}(\mathbf{x})$ do material é dado por

$$
\begin{aligned}
& \mathbf{C}(\mathbf{x})=\eta(\mathbf{x})^{p} \mathbf{C}_{\mathbf{0}} . \\
& 0 \leq \eta(\mathbf{x}) \leq 1
\end{aligned}
$$

$\mathrm{Na}$ Eq. (3.12), a potência $p$ exerce a função de penalização das pseudodensidades intermediárias, com o objetivo de retornar ao problema discreto, uma vez que seu custo em volume, torna-se elevado, evitando desta maneira o aparecimento de áreas de pseudo-densidades intermediárias, conhecidas como escalas de cinzas (vide seção: 3.3.5), que são indesejáveis pois não podem ser fabricadas.

Hashin-Shtrikman (1963) demonstrou que os limites móveis inferiores e superiores dos coeficientes de compressibilidade e de cisalhamento de um material composto que seja quase-homogêneo e quase-isotrópico podem ser definidos independentemente da configuração geométrica de sua microestrutura. Neste exemplo, um dos materiais é "vazio" $(\mathbf{C}=0)$. A partir dos módulos de compressibilidade e de cisalhamento, pode se determinar os limites para módulo de Young (HASHIN; SHTRIKMAN, 2003), e do coeficiente de Poisson, conseqüentemente, pode-se determinar os limites de Hashin-Shtrikman para a rigidez (BENDSØE; SIGMUND, 2003).

Portanto, para obtenção de um resultado de pseudo-densidades tipo 0 ou 1 , de maneira a possibilitar que a rigidez fique dentro dos limites de Hashin-Sthtrikman (Figura 3.6), é necessário que (BENDSøE; SIGMUND, 1999) 


$$
\begin{aligned}
& p \geq \max \left\{\frac{2}{1-v}, \frac{4}{1+v}\right\} \\
& p \geq \max \left\{15 \frac{1-v}{7-5 v}, \frac{3(1-v)}{2(1-2 v)}\right\}
\end{aligned}
$$

para $v=0,3 ; p \geq 3$

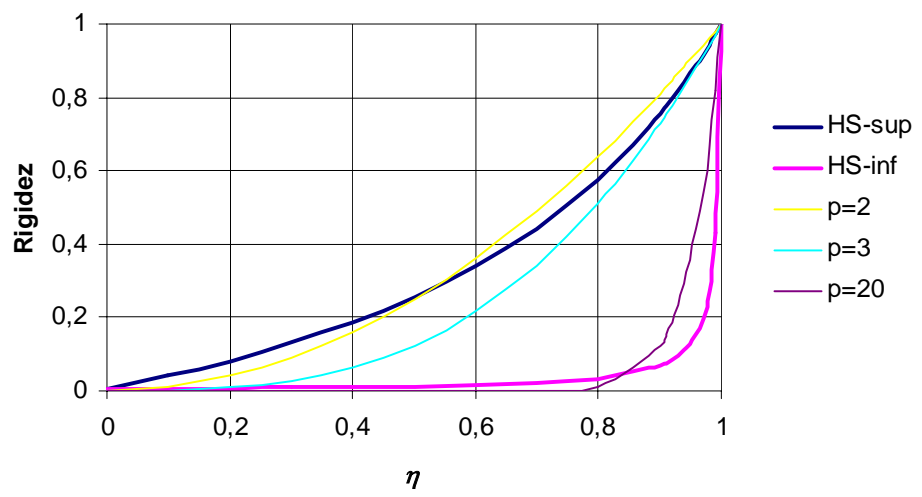

Figura 3.6 - Comparação entre o "SIMP" e os limites de Hashin-Shtrikman.

No caso de dois materiais, como aço e fluido contido, sem "vazio", altera-se a Eq. (3.12), de maneira a incluir uma interpolação entre os tensores das propriedades de cada um dos materiais $\left(\mathbf{C}_{\mathbf{0}}\right.$ e $\left.\mathbf{C}_{\mathbf{1}}\right)$

$$
\mathbf{C}(\mathbf{x})=\eta(x)^{p} \mathbf{C}_{\mathbf{0}}+(1-\eta(x))^{p} \mathbf{C}_{\mathbf{1}} .
$$

\subsubsection{Formulação do problema de otimização topológica}

Seja o domínio generalizado da Figura 3.7,composto por um material elástico linear, onde $\Gamma_{\mathrm{u}}$ é a região onde estão fixadas as condições de contorno, $\Gamma_{\mathrm{t}}$ é a região onde está aplicado o carregamento t, e $\Omega$ é o domínio e f representa as forças de campo aplicadas ao corpo. 


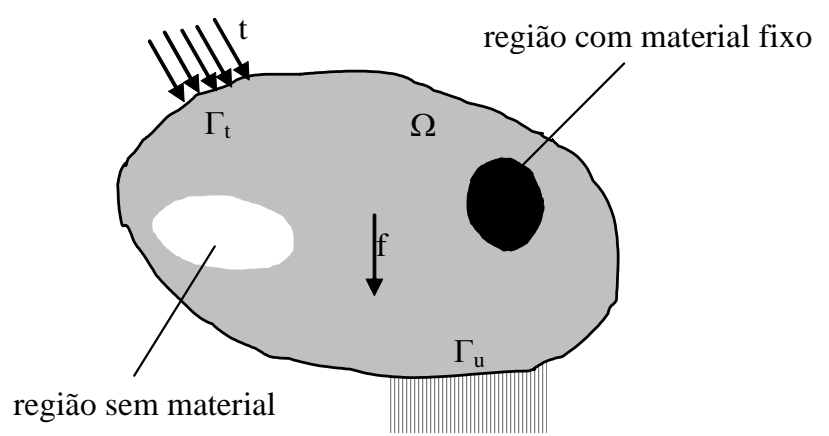

Figura 3.7- Modelo generalizado de domínio para OT.

A forma linear $l$ da flexibilidade média do corpo é definida pelo trabalho realizado pelas forças externas, que pode ser escrita por

$$
l(\mathbf{u})=\int_{\Omega} \mathbf{f u} d \Omega+\int_{\Gamma_{t}} \mathbf{t u} d \Gamma_{t}, \quad \text { para } \mathbf{u} \in \mathbf{W},
$$

onde u é o deslocamento do corpo em equilíbrio; e W é o campo de deslocamentos admissíveis.

Sendo $\mathbf{v}$ um deslocamento virtual, $\varepsilon_{\mathbf{u}}$ e $\varepsilon_{\mathbf{v}}$ as deformações referentes aos deslocamentos $\mathbf{u}$ e $\mathbf{v}$, respectivamente, a energia de deformação na sua forma bilinear $a(\mathbf{u}, \mathbf{v})$ pode ser escrita por

$$
a(\mathbf{u}, \mathbf{v})=\int_{\Omega} \boldsymbol{\varepsilon}_{\mathbf{u}}(\mathbf{u}) \mathbf{C}(\mathbf{x}) \boldsymbol{\varepsilon}_{\mathbf{v}}(\mathbf{v}) d \Omega
$$

de maneira que o problema de OT, de mínima flexibilidade com restrição de volume $\left(V_{\max }\right)$ pode ser escrito por

$$
\begin{aligned}
& \underset{\eta}{\operatorname{Min} l(\mathbf{u}),} \\
& \text { tal que: } \\
& a(\mathbf{u}, \mathbf{v})=l(\mathbf{v}) ; \quad \mathbf{v} \in \mathrm{W} \\
& \int_{\Omega} \eta(x) d \Omega \leq V_{\max }, \\
& 0 \leq \eta \leq 1 .
\end{aligned}
$$


Considerando-se o caso de múltiplos carregamentos, o problema (3.17) é facilmente generalizado, pela soma da minimização de cada caso de carregamento, sendo $n_{f} 0$ número de carregamentos independentes à que o corpo é sujeito, e $W_{k} 0$ peso dado ao carregamento ${ }_{k}$, o problema fica:

$$
\begin{aligned}
& \underset{\eta}{\operatorname{Min}} \sum_{k=1}^{n_{f}} W_{k} l_{k}\left(\mathbf{u}_{k}\right), \\
& \text { tal que: } \\
& a\left(\mathbf{u}_{k}, \mathbf{v}\right)=l_{k}(\mathbf{v}) ; \quad \mathbf{v} \in \mathrm{W}, \text { para } k=1, \ldots, n_{f}, \\
& \int_{\Omega} \eta(x) d \Omega \leq V_{\max }, \\
& 0 \leq \eta \leq 1 .
\end{aligned}
$$

Para solução numérica do problema descrito em (3.18), pode-se discretizar seu domínio em EF de maneira que o problema passa a ser dado por

$$
\begin{aligned}
& \underset{\eta_{e}}{\operatorname{Min}} \sum_{k=1}^{n_{f}} W_{k} \mathbf{f}_{k}^{T} \mathbf{U}_{k}, \\
& \text { tal que: } \\
& \mathbf{K U}_{k}=\mathbf{f}_{k}, \\
& \text { para } k=1, \ldots, n_{f} ; e=1, \ldots, n_{e}, \\
& \sum_{e=1}^{n_{e}} \eta_{e} V_{e} \leq V_{\max }, \\
& 0<\eta_{\min } \leq \eta \leq 1,
\end{aligned}
$$

onde $n_{\mathrm{e}}$ é o número de EF da malha discretizada, $V_{e}$ o volume de cada elemento, $\eta_{e}$ a pseudo-densidade definida para cada elemento e $\mathbf{U}$ o vetor de deslocamentos nodais.

Sendo $\mathbf{K}_{e}$ a matriz global de rigidez do elemento, e considerando o caso com dois materiais, sem "vazio", de acordo com a Eq. (3.14)

$$
\mathbf{K}=\sum_{e=1}^{n_{e}} \mathbf{K}_{e}\left(\mathbf{C}_{e}\right), \mathbf{C}_{e}(\mathbf{x})=\eta_{e}{ }^{p} \mathbf{C}_{\mathbf{0}}+\left(1-\eta_{e}\right)^{p} \mathbf{C}_{\mathbf{1}}, \text { e } \rho(\mathbf{x})=\eta_{e}{ }^{p} \rho_{0}+\left(1-\eta_{e}\right)^{p} \rho_{1},
$$


onde $\rho_{0}$ e $\rho_{1}$ são as densidades dos materiais.

A fim de se evitar alguma singularidade na equação de equilíbrio $(\mathbf{K U}=\mathbf{f})$, quando $\mathbf{C}_{1}=0$, e a pseudo-densidade do elemento $\eta_{e}=0$, (e conseqüentemente sua matriz de rigidez também será igual à zero), definiu-se na Eq. (3.19) um valor de $\eta_{\min }$. Em Bendsøe e Sigmund (2003) encontra-se um valor de $\eta_{\min }=10^{-3}$, que combinados com a rigidez do aço, que é da ordem de $10^{9}$, resulta numa rigidez mínima da ordem de $10^{6}$, considerada ainda muito alta, pois é semelhante a rigidez da água, portando optou-se neste trabalho por um valor de $\eta_{\min }=10^{-6}$.

\subsubsection{Método de solução - Critério de Optimalidade.}

O critério de optimalidade consiste num método semi-empírico para solução do problema definido na Eq. (3.19) baseado na atualização de variáveis (BENDS $\varnothing \mathrm{E}$; SIGMUND, 2003), e apesar de ser menos geral pois necessita de formulação específica para cada problema, trata-se de um método extremamente eficiente do ponto de vista computacional (ROZVANY; BENDSøE; KIRSCH, 1995).

Baseado nas condições de optimalidade de "Karush-Kuhn-Tucker" (KKT), que propõe condições matemáticas para verificar se um determinado ponto do espaço é ótimo, o método busca valores de variáveis que conduzam a derivada do Lagrangeano da função à zero.

Como desvantagem, trata-se de um método não-genérico, e por se basear no Lagrangeano do problema, o método deve ser reformulado para cada tipo de problema específico.

A seguir será apresentada a formulação matemática para o método de optimalidade utilizando o modelo de material "SIMP", (BENDS $\varnothing E ;$ SIGMUND, 2003)

Definindo o Lagrangeano no problema da Eq. (3.18) obtém-se 


$$
\begin{aligned}
& L=\sum_{k=1}^{n_{f}} W_{k} \mathbf{f}_{k}^{T} \mathbf{U}_{k}-\sum_{k=1}^{n_{f}} \lambda_{e q}^{k}\left(\mathbf{K} \mathbf{U}_{k}-\mathbf{f}_{k}\right)+\lambda_{v}\left(\sum_{e=1}^{n_{e}} \eta_{e} V_{e}-V_{\max }\right)+ \\
& \sum_{e=1}^{n_{e}} \lambda_{s}^{e}\left(\eta_{e}-1\right)+\sum_{e=1}^{n_{e}} \lambda_{i}^{e}\left(\eta_{\min }-\eta_{e}\right),
\end{aligned}
$$

onde $\lambda_{e q}{ }^{k}$ é o multiplicador de Lagrange associado às equações de equilíbrio de cada carregamento; $\lambda_{v}$ é o multiplicador de Lagrange associado à restrição de volume; $\lambda_{s}{ }^{e}$ é o multiplicador de Lagrange associado ao limite superior da variável $\eta_{e}$; e $\lambda_{i}^{e}$ é o multiplicador de Lagrange associado ao limite inferior da variável $\eta_{e}$.

Uma vez que as restrições de equilíbrio de cada carregamento $\left(\mathbf{K U}_{\mathrm{k}}=\mathbf{f}_{\mathrm{k}}\right)$ são satisfeitas no processo de solução das equações de equilíbrio pelo MEF, portanto $\lambda_{e q}{ }^{k}=0$, e como o algoritmo implementado não permite que $\eta_{e}$ viole as restrições, portanto $\lambda_{i}^{e}=\lambda_{s}{ }^{e}=0$, e derivando o Lagrangeano em função das variáveis

$$
\frac{\partial L}{\partial \eta_{e}}=\sum_{k=1}^{n_{f}} W_{k} \frac{\partial\left(\mathbf{f}_{k}^{T} \mathbf{U}_{k}\right)}{\partial \eta_{e}}+\lambda_{v} \frac{\sum_{e=1}^{n_{e}} \partial\left(\eta_{e} V_{e}-V_{\max }\right)}{\partial \eta_{e}}
$$

Expandindo a Eq. (3.21)

$$
\frac{\partial L}{\partial \eta_{e}}=\sum_{k=1}^{n_{f}} W_{k}\left(\frac{\partial \mathbf{U}_{k}^{T}}{\partial \eta_{e}} \mathbf{K U}_{k}^{T}+\mathbf{U}_{k}^{T} \frac{\partial \mathbf{K}}{\partial \eta_{e}} \mathbf{U}_{k}+\mathbf{U}_{k}^{T} \mathbf{K} \frac{\partial \mathbf{U}_{k}}{\partial \eta_{e}}\right)+\lambda_{v} V_{e}
$$

Reagrupando os termos da Eq. (3.22)

$$
\frac{\partial L}{\partial \eta_{e}}=\sum_{k=1}^{n_{f}} W_{k}\left(\mathbf{U}_{k}^{T} \frac{\partial \mathbf{K}}{\partial \eta_{e}} \mathbf{U}_{k}+2 \mathbf{U}_{k}^{T} \mathbf{K} \frac{\partial \mathbf{U}_{k}}{\partial \eta_{e}}\right)+\lambda_{v} V_{e}
$$

Derivando a equação de equilíbrio genérica $\left(\mathbf{K U}_{\mathrm{k}}=\mathbf{f}_{\mathrm{k}}\right)$ em relação às variáveis de projeto $\eta_{e}$, obtém-se 


$$
\frac{\partial\left(\mathbf{K} \mathbf{U}_{k}\right)}{\partial \eta_{e}}=\frac{\partial \mathbf{f}_{k}}{\partial \eta_{e}}
$$

Desenvolvendo a Eq. (3.24) pela regra da cadeia e isolando o termo de $\frac{\partial \mathbf{U}_{k}}{\partial \eta_{e}}$ obtém-se

$$
\frac{\partial \mathbf{U}_{k}}{\partial \eta_{e}}=\mathbf{K}^{-1}\left(\frac{\partial \mathbf{f}_{k}}{\partial \eta_{e}}-\frac{\partial \mathbf{K}}{\partial \eta_{e}} \mathbf{U}_{k}\right)
$$

Substituindo a Eq. (3.25) na Eq. (3.23) obtém-se

$$
\frac{\partial L}{\partial \eta_{e}}=\sum_{k=1}^{n_{f}} W_{k}\left(\mathbf{U}_{k}^{T} \frac{\partial \mathbf{K}}{\partial \eta_{e}} \mathbf{U}_{k}+2 \mathbf{U}_{k}^{T} \mathbf{K} \mathbf{K}^{-1}\left(\frac{\partial \mathbf{f}_{k}}{\partial \eta_{e}}-\frac{\partial \mathbf{K}}{\partial \eta_{e}} \mathbf{U}_{k}\right)\right)+\lambda_{v} V_{e}
$$

que simplificado, resulta na equação

$$
\frac{\partial L}{\partial \eta_{e}}=\sum_{k=1}^{n_{f}} W_{k}\left(2 \mathbf{U}_{k}^{T} \frac{\partial \mathbf{f}_{k}}{\partial \eta_{e}}-\mathbf{U}_{k}^{T} \frac{\partial \mathbf{K}}{\partial \eta_{e}} \mathbf{U}_{k}\right)+\lambda_{v} V_{e}
$$

$\mathrm{Na}$ Eq. (3.27), o primeiro termo dentro do somatório representa as parcelas relativas às forças de campo do carregamento $k$, enquanto que o segundo termo representa a parcela da derivada referente à flexibilidade da estrutura para o mesmo carregamento.

Considerando o peso próprio como única força de campo aplicada no corpo, pode se escrever que

$$
\frac{\partial \mathbf{f}_{k}}{\partial \eta_{e}}=\frac{\sum_{e=1}^{n_{e}} \partial\left(\eta_{e}^{p} \rho_{0}+\left(1-\eta_{e}\right)^{p} \rho_{1}\right) V_{e} \mathbf{g}}{\partial \eta_{e}}=p \eta_{e}^{p-1}\left(\rho_{0}-\rho_{1}\right) V_{e} \mathbf{g}
$$


onde $\mathbf{g}$ é a aceleração gravitacional.

Uma vez que a matriz de rigidez global $\mathbf{K}$ é definida pela somatória das matrizes de rigidez do elemento em seu nível global $\mathbf{K}_{\mathrm{e}}$ (Eq. 2.43) e que estas dependem apenas das pseudo-densidades $\eta_{e}$ do próprio elemento pode-se dizer que

$$
\frac{\partial \mathbf{K}_{e}}{\partial \eta_{i}}=\left\{\begin{array}{cc}
\frac{\partial \mathbf{K}_{e}}{\partial \eta_{e}}, & \text { quando } e=i, \\
0, & \text { quando } e \neq i,
\end{array}\right.
$$

portanto

$$
\frac{\partial \mathbf{K}}{\partial \eta_{e}}=\frac{\partial \mathbf{K}_{e}}{\partial \eta_{e}}
$$

Sendo $\mathbf{K}_{e}$ para um elemento geral é dada por

$$
\mathbf{K}_{e}=\int_{\Omega_{e}} \mathbf{B}^{T} \mathbf{C}_{e} \mathbf{B} d \Omega_{e} .
$$

Substituindo a Eq. (3.31) na Eq. (3.30) obtém-se

$$
\frac{\partial \mathbf{K}}{\partial \eta_{e}}=\frac{\partial \int_{\Omega_{e}} \mathbf{B}^{T} \mathbf{C}_{e} \mathbf{B} d \Omega_{e}}{\partial \eta_{e}}=\int_{\Omega_{e}} \mathbf{B}^{T} \frac{\partial \mathbf{C}_{e}}{\partial \eta_{e}} \mathbf{B} d \Omega_{e}
$$

Sendo o tensor de propriedades do material $\mathbf{C}_{e}$ dado pela Eq. (3.14), sua derivada em função de $\eta_{e}$ é dada por 


$$
\frac{\partial \mathbf{C}_{e}}{\partial \eta_{e}}=p \eta_{e}^{p-1} \mathbf{C}_{\mathbf{0}}-p\left(1-\eta_{e}\right)^{p-1} \mathbf{C}_{\mathbf{1}}
$$

Considerando-se as Eqs. (3.27), (3.28), (3.32) e (3.33) e igualando a derivada do Lagrangeano à zero (condição de estacionaridade), obtém-se

$$
\begin{aligned}
& \frac{\partial L}{\partial \eta_{e}}=\sum_{k=1}^{n_{f}} W_{k}\left(2 p \eta_{e}^{p-1}\left(\rho_{0}-\rho_{1}\right) V_{e} \mathbf{U}_{k}^{T} \mathbf{g}-\mathbf{U}_{k}^{T} \int_{\Omega_{e}} \mathbf{B}^{T}\left(p \eta_{e}^{p-1} \mathbf{C}_{\mathbf{0}}-p\left(1-\eta_{e}\right)^{p-1} \mathbf{C}_{\mathbf{1}}\right) \mathbf{B} d \Omega_{e} \mathbf{U}_{k}\right)+ \\
& \lambda_{v} V_{e}=0 .
\end{aligned}
$$

Rearranjando os termos da Eq. (3.34) obtém-se

$$
\frac{\sum_{k=1}^{n_{f}} W_{k}\left(2 p \eta_{e}^{p-1}\left(\rho_{0}-\rho_{1}\right) V_{e} \mathbf{U}_{k}^{T} \mathbf{g}-\mathbf{U}_{k}^{T} \int_{\Omega_{e}} \mathbf{B}^{T}\left(p \eta_{e}^{p-1} \mathbf{C}_{\mathbf{0}}-p\left(1-\eta_{e}\right)^{p-1} \mathbf{C}_{\mathbf{1}}\right) \mathbf{B} d \Omega_{e} \mathbf{U}_{k}\right)}{\lambda_{v} V_{e}}=1
$$

Indicando que a densidade de energia potencial deve permanecer constante em todo domínio do problema. Um método heurístico para determinação da variável de densidade do material na iteração (i+1) pode ser definido como (BENDS $\varnothing \mathrm{E}$; SIGMUND, 1999)

$$
{ }_{i+1} \eta_{e}=\left\{\begin{array}{l}
\max \left\{(1-\varsigma)_{i} \eta_{e}, \eta_{\min }\right\}, \text { se }{ }_{i} \eta_{e} B_{e}^{\xi} \leq \max \left\{(1-\varsigma){ }_{i} \eta_{e}, \eta_{\min }\right\} \\
{ }_{i} \eta_{e} B_{e}^{\xi}, \text { se } \max \left\{(1-\varsigma)_{i} \eta_{e}, \eta_{\min }\right\}<{ }_{i} \eta_{e} B_{e}^{\xi}<\max \left\{(1+\varsigma)_{i} \eta_{e}, \eta_{\min }\right\} \\
\min \left\{(1+\varsigma)_{i} \eta_{e}, 1\right\}, s e{ }_{i} \eta_{e} B_{e}^{\xi} \geq \max \left\{(1+\varsigma)_{i} \eta_{e}, \eta_{\min }\right\}
\end{array}\right.
$$

onde $\zeta$ é o limite móvel e $\xi$ um fator de amortecimento do algoritmo de otimização, ambos os valores interferem na eficiência do método iterativo. Valores típicos para estas variáveis são 0,2 e 0,5, respectivamente; o índice $i$ faz referência ao número da iteração, e $B_{e}$ pode ser escrito por 


$$
B_{e}=-\frac{\sum_{k=1}^{n_{f}} W_{k}\left(2 p \eta_{e}^{p-1}\left(\rho_{0}-\rho_{1}\right) V_{e} \mathbf{U}_{k}^{T} \mathbf{g}-\mathbf{U}_{k}^{T} \int_{\Omega_{e}} \mathbf{B}^{T}\left(p \eta_{e}^{p-1} \mathbf{C}_{\mathbf{0}}-p\left(1-\eta_{e}\right)^{p-1} \mathbf{C}_{\mathbf{1}}\right) \mathbf{B} d \Omega_{e} \mathbf{U}_{k}\right)}{\lambda_{v} V_{e}}
$$

Desta maneira o algoritmo iterativo de $\eta_{e}$ descrito na Eq. (3.36) aumenta a densidade em áreas onde a energia de deformação é maior que $\lambda_{v}$, e diminui onde a energia de deformação é menor que $\lambda_{v}$.

Observando a Eq. (3.37), percebe-se que se a derivada da função objetivo Eq. (3.34) for positiva, $B_{e}$ será negativo o que implicaria em raiz quadrada de número negativo, quando considerado um valor de $\xi=0,5$. A fim de se evitar tal problema, Bendsøe e Sigmund (2003) propõem uma alteração da Eq. (3.37) para:

$$
B_{e}=\max \left\{0,-\frac{\sum_{k=1}^{n_{f}} W_{k}\left(2 p \eta_{e}^{p-1}\left(\rho_{0}-\rho_{1}\right) V_{e} \mathbf{U}_{k}^{T} \mathbf{g}-\mathbf{U}_{k}^{T} \int_{\Omega_{e}} \mathbf{B}^{T}\left(p \eta_{e}^{p-1} \mathbf{C}_{\mathbf{0}}-p\left(1-\eta_{e}\right)^{p-1} \mathbf{C}_{\mathbf{1}}\right) \mathbf{B} d \Omega_{e} \mathbf{U}_{k}\right)}{\lambda_{v} V_{e}}\right\}
$$

\subsubsection{Pseudo-densidades intermediárias}

Pseudo-densidades intermediárias, também conhecida por escalas de cinza, ocorrem em problemas com variáveis contínuas, onde algumas regiões do domínio podem apresentar pseudo-densidades de valores intermediários entre 0 e 1.

Tal problema está intimamente ligado com o modelo do material utilizado, para o caso do "SIMP", o controle de escalas de cinza é feito através do índice $p$, conforme apresentado anteriormente.

Através da Eq. (3.13) obtém-se o valor mínimo de $p$ para garantir um resultado de pseudo-densidades tipo 0 ou 1. Um dos inconvenientes desta solução é 
que um índice de $p$ superior a 1 tende a retornar para o problema discreto (BENDSØE; SIGMUND, 2003).

A fim de possibilitar o uso de um índice maior de $p$ (para diminuir a escala de cinza), e ao mesmo tempo chegar o mais próximo da solução global do problema, é utilizado o método da continuação em diversos trabalhos (ROZVANI; BENDS $\varnothing E$;; KIRSCH, 1995; SIGMUND; PETERSSON, 1998).

O método da continuação consiste em iniciar o problema com o índice $p$ igual a 1, de forma que a solução caminhe em direção a um mínimo global, e à medida que a solução tende a convergir, aumenta-se gradativamente seu valor a fim de se eliminar as pseudo-densidades intermediárias e aproximar a solução de um mínimo local mais próximo do mínimo global (Figura 3.8).

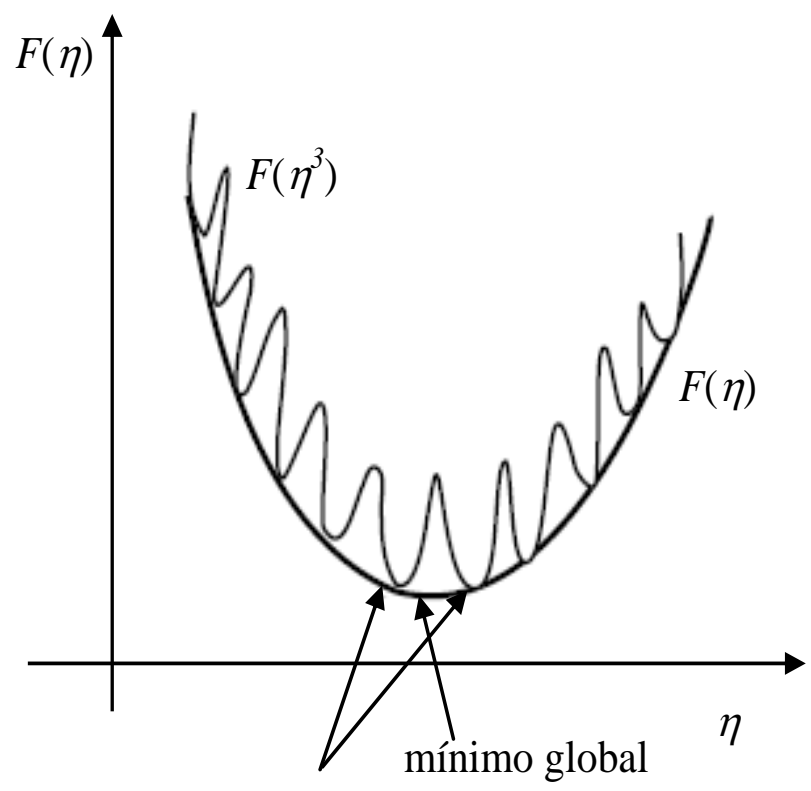

mínimos locais

Figura 3.8 - Representação esquemática da influencia da penalização $p$ na solução do problema de OT.

No entanto, em alguns casos outra interpretação pode ser dada para pseudodensidades intermediárias. Assim, por exemplo, em OT de cascas ou placas, o modelo de material não é penalizado $(p=1)$, a fim de se incentivar pseudodensidades intermediárias, que são interpretadas como a espessura variável da casca (BENDSØE; SIGMUND, 1999; RIETZ; PETERSSON, 2001). 


\subsubsection{Dependência de malha}

A dependência de malha é caracterizada pela obtenção de soluções ótimas diferentes para cada discretização da malha de EF. Quanto mais discretizada a malha, maior a quantidade de buracos introduzidos se aproximando cada vez mais da forma de microestruturas.

A dependência de malha pode ser dividida em três categorias (SIGMUND; PETERSSON, 1998):

- Problemas onde não existem soluções únicas, (como tração uniaxial de barra), que pode ser resolvido utilizando-se restrições de manufatura.

- Problemas onde não existem soluções. Causados pelo retorno à função discreta (devido à implementação do modelo do material), causada, como visto anteriormente, pelo fato de normalmente a flexibilidade da estrutura diminuir quando se aumenta o número de buracos, sem alterar o volume.

- Problemas não-convexos.

a)

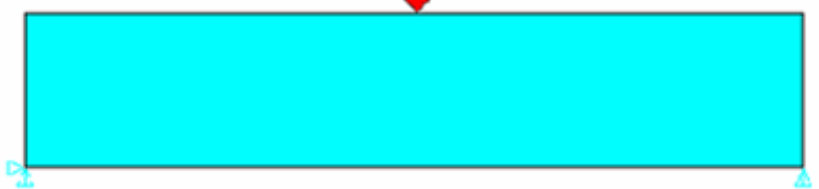

b)

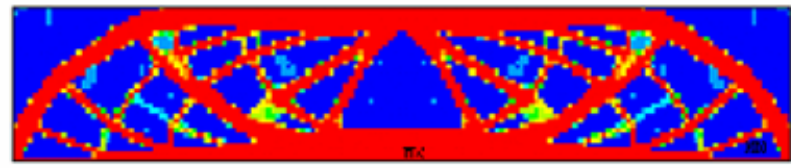

c)

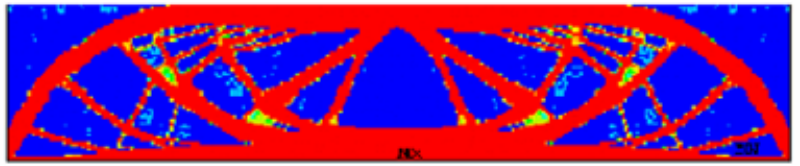

d)
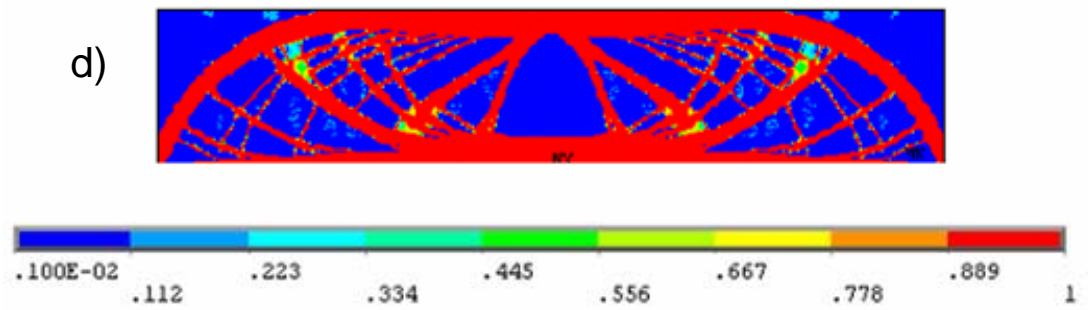

Figura 3.9 - Exemplo de dependência de malha, (a) viga bi-apoiada com uma carga no centro, solução com: 5.120 EF em (b); 22.378 EF em (c); e 65.780 EF em (d). 
Na Figura 3.9 observa-se um exemplo clássico de dependência de malha (BENDSØE; SIGMUND, 2003; SIGMUND; PETERSSON, 1998; entre outros), sendo uma viga bi-apoiada sujeita a uma força aplicada no centro da viga (a), e otimizada topologicamente para 5.120 EF em (b), 22.378 EF em (c) e 65.780 EF em (d), percebe-se que a medida que se discretiza a malha, aumenta o número de buracos, e os membros da estrutura vão se tornando mais finos, e em maior quantidade.

Esse problema pode ser resolvido através da imposição de uma restrição de perímetro, ou através da implementação de filtro de controle de gradiente de material, que será apresentada na seção 3.3.8.

\subsubsection{Instabilidade de xadrez}

Trata-se de um erro numérico causado pela aproximação pobre do problema contínuo pelo MEF, que resulta numa distribuição de material que lembra um tabuleiro de xadrez, onde elementos com densidade 1 se misturam a elementos de densidade 0 de maneira alternada (Figura 3.11). Tal anomalia independe do modelo de material, sendo encontrado em modelos de material laminares, de células quadradas com buracos retangulares (células 2 e 1, na Figura 3.5, respectivamente) e modelos baseados no "SIMP" (JOG; HARBER, 1996) e ocorre especialmente quando utilizados elementos de baixa ordem (ZHOU; SHYY; THOMAS, 2001).

Os elementos de baixa ordem possuem uma função de interpolação pobre do campo de deslocamentos, e consequentemente, do campo de deformações quando comparado aos elementos de ordens superiores. Desta maneira, o erro nas deformações de cisalhamento do elemento é maior, aparentando uma maior rigidez para uma distribuição em xadrez do material (Figura 3.10 - a), do que uma distribuição uniforme (Figura 3.10 - b). 


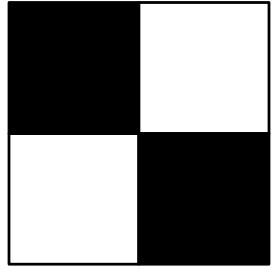

(a)

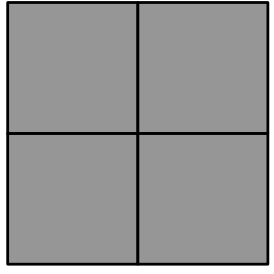

(b)

Figura 3.10 - (a) Distribuição do material em xadrez. (b) Distribuição do material uniforme.

O exemplo mostrado na Figura 3.11 refere-se ao mesmo exemplo apresentado na Figura 3.9, ou seja, viga bi-apoiada sujeita a um carregamento central, porém aqui, foi utilizado elemento de 4 nós.

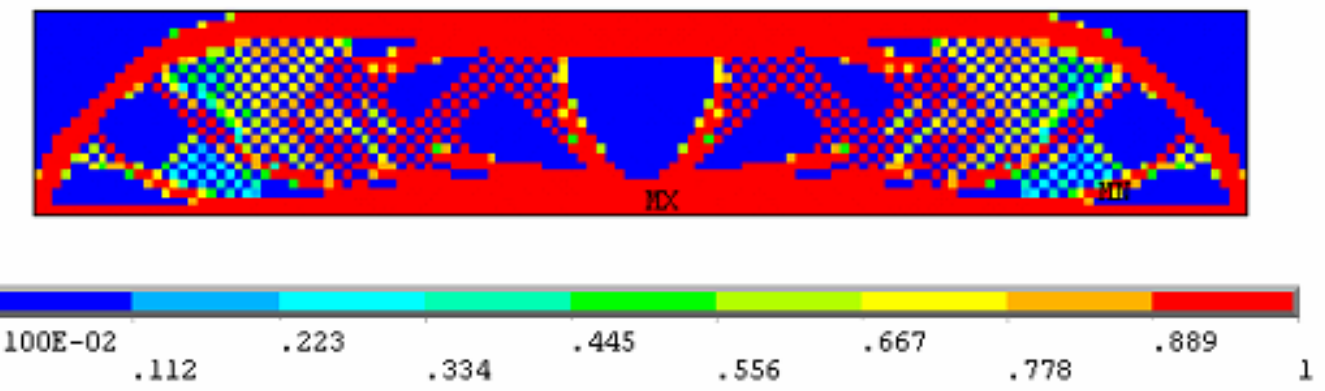

Figura 3.11 - Exemplo de estrutura apresentando padrão de instabilidade de xadrez

Uma das maneiras apresentadas para se evitar a instabilidade de xadrez é a utilização de elementos quadriláteros de oito ou nove nós (BENDS $\varnothing \mathrm{E}$; SIGMUND, 2003), já que os mesmos possuem uma função de interpolação mais refinada para representar o campo de deslocamentos do elemento, no entanto, isso resulta num substancial incremento no tempo de processamento, que pode ser muito significativo para o caso de modelos tridimensionais complexos. Além disso, Diaz e Sigmund (1995) mostram que elementos de alta ordem evitam o aparecimento da instabilidade de xadrez, quando utilizado o "SIMP", apenas se $p$ for suficientemente pequeno.

Outra solução é a implementação de filtro de controle de gradiente de material, que além de corrigir a dependência de malha também evita a instabilidade de xadrez. 


\subsubsection{Método de filtragem.}

O método de filtragem que se utiliza nesta dissertação, baseia-se numa alteração da sensibilidade do elemento, transformando a função sensibilidade, numa média ponderada entre a sensibilidade do próprio elemento, e a sensibilidade dos elementos vizinhos. A razão para ponderação da média é a distância entre os centróides dos elementos, de maneira que quanto mais perto os elementos, estiverem do elemento considerado, maior o peso de sua sensibilidade impedindo desta maneira, variações bruscas na distribuição das pseudo-densidades.

Sigmund (1994) (apud ZHOU; SHYY; THOMAS., 2001); propõe a utilização de um filtro que atua diretamente na função objetivo $\left(\mathbf{f}^{T} \mathbf{u}\right)$, de maneira que seu novo gradiente possa ser escrito por

$$
\frac{\partial \overline{\mathbf{f}^{T} \mathbf{U}}}{\partial \eta_{e}}=\frac{1}{\eta_{e} \sum_{j=1}^{n_{e}} \hat{H}_{j}} \sum_{j=1}^{n_{e}} \eta_{j} \hat{H}_{j} \frac{\partial \mathbf{f}^{T} \mathbf{U}}{\partial \eta_{e}}
$$

onde

$\hat{H}_{j}=R_{\text {filtro }}-R_{e j} \quad\left\{f \in n_{e}\right.$, tal que $\left.R_{e j} \leq R_{\text {filtro }}\right\} \quad j-1, \ldots, n_{e}$,

sendo $\mathrm{R}_{e j}$ a distância entre os centróides dos elementos "e" e "j", e $R_{\text {filtro }}$ o raio de atuação do filtro. O mesmo filtro é apresentado novamente em Sigmund e Petersson (1998).

$\mathrm{Na}$ Figura 3.12 onde foi realizada OT utilizando-se filtro no mesmo exemplo apresentado na Figura 3.9 percebe-se uma grande diminuição do número de buracos e de elementos finos quando comparada com o item d daquela figura. 


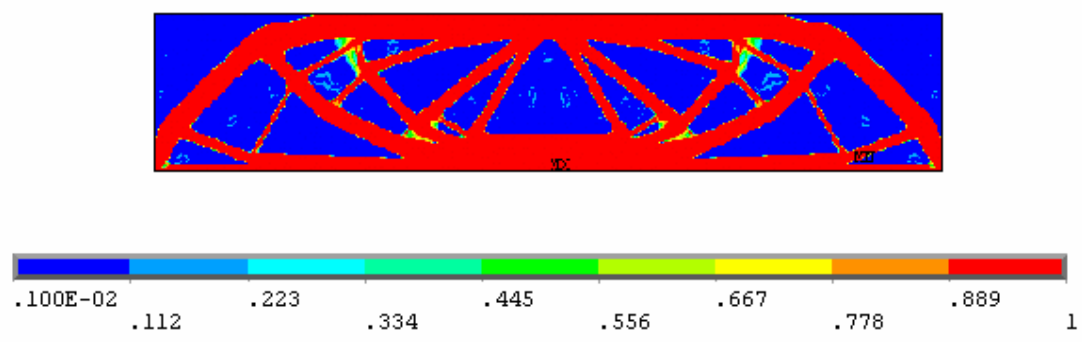
$\mathrm{EF})$

Figura 3.12- Exemplo de utilização de filtro para correção de dependência de malha (65.780

A Figura 3.13 reproduz o exemplo apresentado na Figura 3.11 porém, utilizando o filtro, percebe-se a ausência do padrão instabilidade de xadrez, que naquela figura torna impossível a interpretação do modelo.

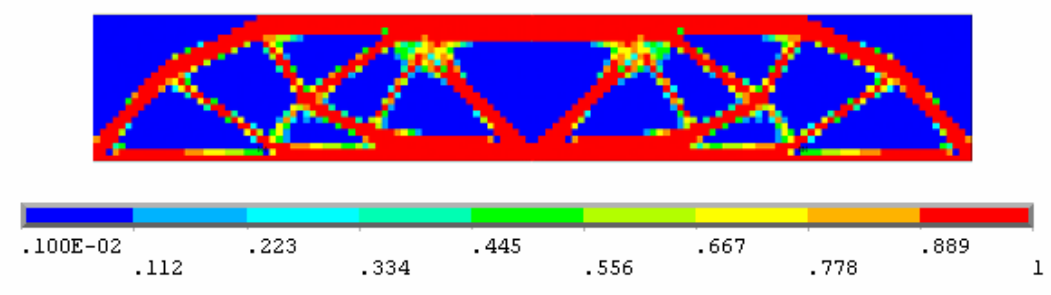
nós).

Figura 3.13 - Exemplo de utilização do filtro para correção da instabilidade de xadrez (EF de 4

Uma vez que os filtros atuam diretamente na sensibilidade, não permitindo alterações bruscas das variáveis de projeto, os mesmos devem ser desligados nas últimas iterações permitindo assim um resultado final tipo 0 ou 1.

Apesar das técnicas de filtragem serem baseadas em métodos heurísticos, são amplamente utilizadas devido sua eficiência e ao baixo custo computacional (SIGMUND; PETERSSON, 1998).

\subsubsection{Múltiplo carregamento, peso próprio e utilização de dois materiais.}

Como pode ser observado na Figura 3.14, se as condições de carregamento em uma viga bi-apoiada (a), forem aplicadas simultaneamente ou considerando-se 0 caso de múltiplo carregamento, ou seja, a aplicação alternada das condições de 
carregamento obtém-se diferentes soluções (b e c) respectivamente), (BENDS $\varnothing \mathrm{E}$; SIGMUND, 2003).

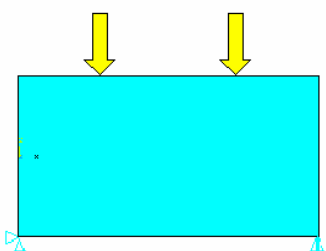

(a)

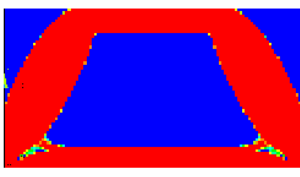

(b)

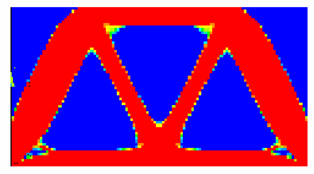

(c)

Figura 3.14 - Exemplo do efeito do múltiplo carregamento em uma viga biapoiada (a), onde as forças são aplicadas simultaneamente (b), e de maneira alternada (c).

Deve-se considerar também, que muitas vezes múltiplas condições de carregamento, quando somadas podem se anular total ou parcialmente, resultado numa estrutura sub-dimensionada (Figura 3.15 - b), ou podem se superpor, causando uma estrutura super-dimensionada (Figura 3.15 - a).

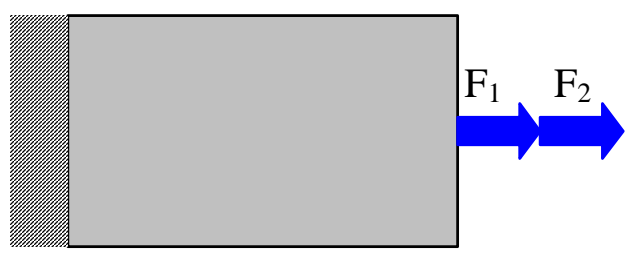

(a)

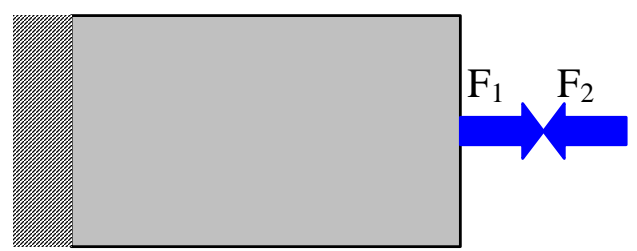

(b)

Figura 3.15 - Exemplo de carregamentos alternados que geram estruturas superdimensionadas (a), ou sub-dimensionadas (b), quando considerados simultaneamente.

Quando considerado o peso próprio, percebe-se através da Figura 3.16 que à medida que a razão entre o peso próprio $\mathbf{P}$ e o carregamento concentrado $\mathbf{F}$ aumenta, o material tende a se concentrar junto ao engaste, de maneira a diminuir o momento causado pelo peso. Trabalhos como Bendsøe e Sigmund (2003), ou Bruyneel e Duysinx (2005) apresentam a influência do peso próprio na topologia do modelo de maneira mais detalhada. 


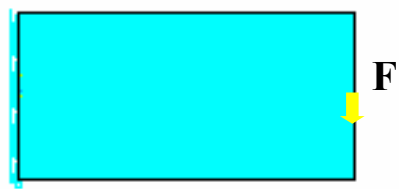

$\mathbf{P} / \mathbf{F}=0$
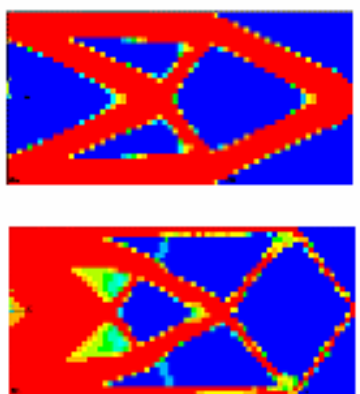

$\mathbf{P} / \mathbf{F}=5$
$\mathbf{P} / \mathbf{F}=1$
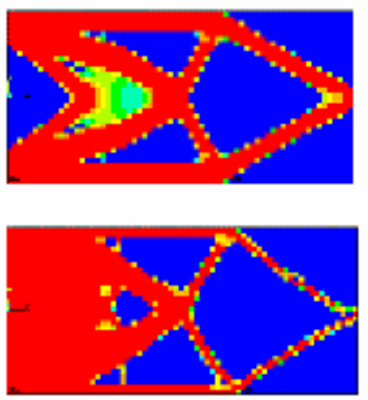

$\mathbf{P} / \mathbf{F}=10$
$\mathbf{P} / \mathbf{F}=2$
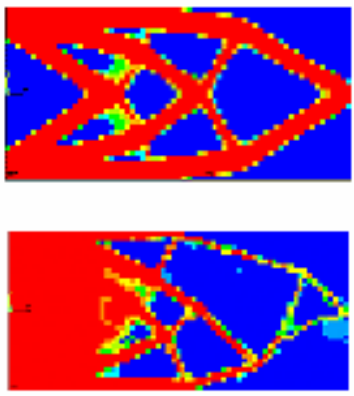

$\mathbf{P} / \mathbf{F}=20$

Figura 3.16 - Exemplo de influência do peso próprio (P).

Com relação à utilização de dois matériais (sem "vazio"),a maneira com que razão entre o Módulo de Young de dois materiais altera a topologia final do modelo pode ser vista em Rodrigues; Soto e Taylor (1999), onde os autores apresentam uma formulação baseada em iniciar o processo com os dois materiais distribuídos pela estrutura (somando-se os tensores das propriedades dos materiais no domínio inteiro), e que inclui uma restrição que impede que os materiais ocupem o mesmo lugar no domínio. Apesar da formulação ser diferente da utilizada nesta dissertação, seus resultados podem ser comparados aos apresentados na Figura 3.17 (mesmas condições de contorno e carregamento concentrado da viga da Figura 3.16).

Na Figura 3.17 observam-se os resultados de OT de uma viga engastada, entre dois materiais isotrópicos de mesmo coeficiente de Poisson $(v=0,2)$, e razões entre os módulos de Young entre o material mais rígido ( 0 , em vermelho) e o material menos rígido (1, em azul) como apresentado na figura para cada resultado. 


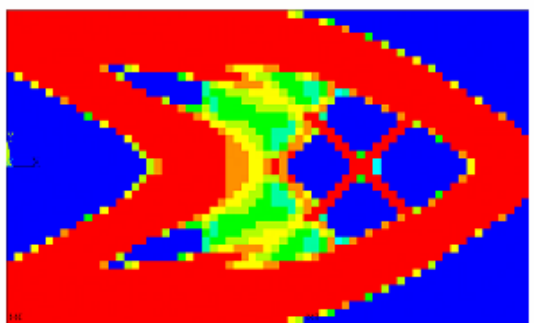

$$
\frac{E_{0}}{E_{1}}=10^{7}
$$

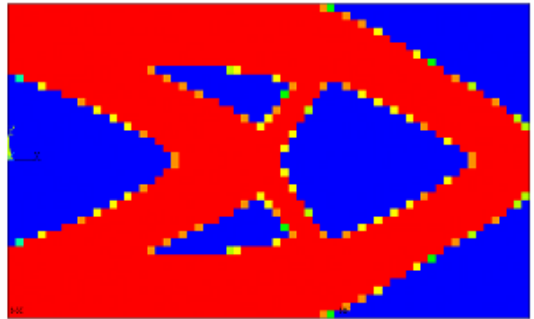

$$
\frac{E_{0}}{E_{1}}=10
$$

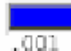

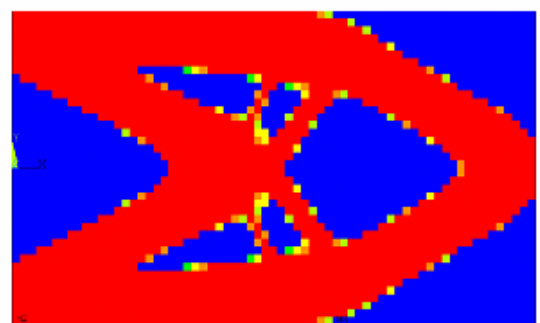

$$
\frac{E_{0}}{E_{1}}=50
$$

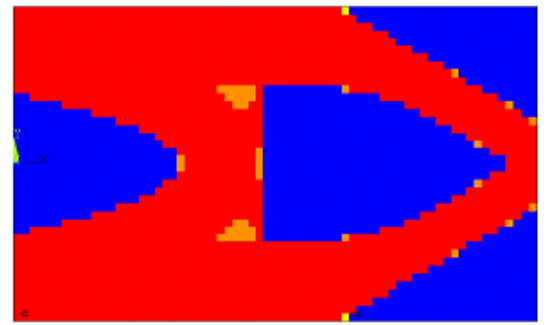

$$
\frac{E_{0}}{E_{1}}=3
$$

112 .334

.445

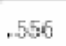

(n)

Figura 3.17 - Resultados de OT utilizando dois materiais. (material "0" em vermelho, material "1" em azul). 


\section{FORMULAÇÃO DO PROBLEMA E IMPLEMENTAÇÃO NUMÉRICA.}

Para implementação numérica, utiliza-se o programa de EF comercial ANSYS devido à grande variedade de elementos implementados, à complexidade de elaborar um modelo tridimensional complexo e a dificuldade de implementar um algoritmo de análise eficiente de EF em um programa como o MATLAB, ou outro qualquer.

Trata-se de um programa amplamente utilizado no meio industrial, que permite elaboração de modelos grandes e complexos. Além disso, o programa associa algoritmos de otimização à análise de EF, e permite que novos algoritmos sejam implementados através de linguagem própria do programa ("ANSYS Parametric Design Language - APDL"), aumentando desta maneira sua capacidade.

\subsection{Formulação do problema e implementação numérica da otimização paramétrica.}

A primeira interpretação que se dá ao conceito de otimizar uma estrutura é reduzir ao máximo seu peso, de maneira que a mesma ainda suporte as solicitações de carga. Assim a maioria dos problemas de otimização estrutural consiste num problema de minimização do peso, onde a função objetivo é dada por

Minimizar massa $=\rho V$

onde $\rho$ é a densidade do material; e $V$ é o volume da estrutura.

Considerando uma estrutura homogênea, e portanto $\rho=$ cte, pode-se escrever

Minimizar $V$ 
Porém, toda estrutura deve atender aos requisitos de projeto, normalmente impostos em termos de tensões máximas admissíveis, até porque, trata-se de uma limitação do material, e portanto um problema de otimização estrutural deve possuir a seguinte restrição

$$
\max \left(\sigma_{e}\right)_{i} \leq \sigma_{m}
$$

onde $\sigma_{e}$ é a tensão de Von Mises do elemento $e$, o índice $i$ refere-se à condição de carregamento de projeto e $\sigma_{m}$ é a tensão admissível de projeto.

Porém, nem sempre a restrição de tensão máxima é o suficiente para definir o problema, pois pode acontecer uma grande minimização do volume da estrutura às custas de um enorme deslocamento, portanto pode se complementar a restrição de tensão máxima com uma restrição de flexibilidade ou rigidez, ou, de uma maneira mais intuitiva, pode-se impor também uma restrição de deslocamento

$$
\max \left(u_{e}\right)_{i} \leq U_{\max }
$$

onde $U_{\max }$ é o deslocamento máximo da estrutura original, e $\max \left(u_{e}\right)_{i}$ é o deslocamento máximo da estrutura para o caso de carregamento $i$, ou seja, para estrutura otimizada não será permitido deslocamento maior que para estrutura original.

Portanto, o problema de otimização pode ser escrito por

Minimizar $V$,

Sujeito a:

$$
\begin{aligned}
& \max \left(\sigma_{e}\right)_{i} \leq \sigma_{m}, e \\
& \max \left(u_{e}\right)_{i} \leq U_{\max }
\end{aligned}
$$

onde as variáveis de projeto são as dimensões geométricas do modelo, como espessura de chapas, larguras, etc.

A formulação apresentada na Eq. (4.1), apresenta um problema conhecido como MinMax, que é exemplificado a seguir. 
Considere a barra engastada da Figura 4.1, onde se tem o problema formulado como na Eq. (4.1), onde as variáveis de projeto é a área da seção transversal do trecho inferior da barra $\left(A_{1}\right)$. $A_{2}$ é a área da seção transversal do trecho superior da barra, $L_{1}$ e $L_{2}$ são os comprimentos de cada trecho da barra.

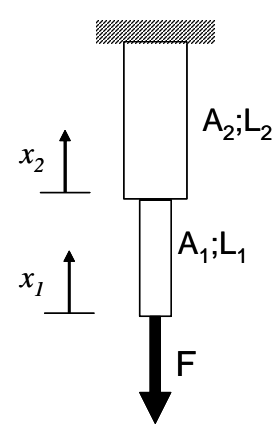

Figura 4.1 - Exemplo de OP onde se verifica a formulação MinMax.

As tensões nos respectivos trechos da barra são dadas por

$$
\sigma_{1}=\frac{F}{A_{1}}+x_{1} \rho ; \quad \sigma_{2}=\frac{F+A_{1} L_{1} \rho}{A_{2}}+x_{2} \rho
$$

e são máximas quando $x_{1}=L_{1}$ ou quando $x_{2}=L_{2}$.

As variáveis $\sigma_{1}$ e $\sigma_{2}$ em função de $A_{1}$ são mostradas na Figura 4.2, e pode-se observar que a tensão máxima alterna entre $\sigma_{1}$ e $\sigma_{2}$, ou seja, o local de aplicação de $\sigma_{\max }$ muda de acordo com $A_{1}$, causando uma descontinuidade na derivada da função $\max \left(\sigma_{\mathrm{e}}\right)$.

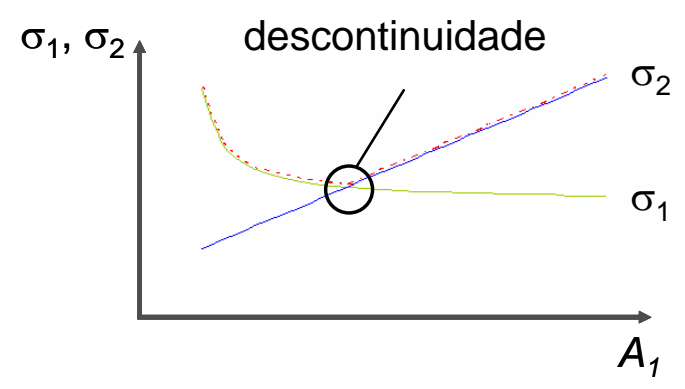

Figura 4.2- Tensões máximas em função da área da seção transversal $\left(\left(\sigma_{1}, \sigma_{2}\right) \times A_{1}\right)$ 
Visto que o ANSYS não possui uma ferramenta para contornar este problema, observa-se seu efeito nas descontinuidades causadas no gráfico de iteração $x$ volume do problema (Erro! Fonte de referência não encontrada.).

Para implementação numérica do problema da Eq. (4.1), podem-se utilizar algoritmos de otimização de primeira ou segunda ordem (HAFTKA; GÜRDAL, 1991). Para isto, é necessária a implementação do modelo de forma interativa, ou utilizando uma rotina em linguagem "APDL", de maneira a permitir a análise de EF no ANSYS, e uma segunda rotina a fim de implementar a otimização.

A rotina de otimização escolhida foi a rotina de primeira ordem do programa ANSYS, que por basear seu algoritmo não somente no valor da função objetivo, mas também nas derivadas da função em relação aos parâmetros, atinge o resultado ótimo num menor número de iterações.

Esta rotina se baseia na inclusão das restrições na função objetivo através da penalização exterior para restrições de caixa dos parâmetros, e penalização interior estendida para as demais restrições. A função objetivo é então resolvida através do método de direções conjugadas, inicializado (ou reinicializado quando necessário) pelo método "Steepest Descent".

A otimização é interrompida quando satisfazer as condições de convergência, ou seja

$$
\left|Q_{j}-Q_{j-1}\right| \leq \tau, \mathrm{e} \quad\left|Q_{j}-Q_{b}\right| \leq \tau
$$

onde $Q$ é a função objetivo sem restrições, o índice $j$ refere-se ao número da iteração, e o índice $b$ refere-se ao melhor resultado obtido e $\tau$ é a tolerância permitida (no caso 1\%).

\subsubsection{Verificação de estabilidade.}

No problema especifico em estudo, uma vez concluída a OP, torna-se necessária à verificação da estabilidade das chapas ou painéis componentes do 
modelo sujeitos à compressão, flexão ou cisalhamento, uma vez que existe a possibilidade dos mesmos flambarem devido à alteração da espessura. Por não se tratar do tema deste trabalho, apresenta-se diretamente a formulação relativa à tensão critica de flambagem $\left(\sigma_{c r}\right)$ na Eq. (4.3), e sua formulação detalhada pode ser obtida nas referências utilizadas (TIMOSHENKO; GERE, 1961; FREITAS, 1980).

$$
\sigma_{c r}=k \frac{\pi^{2} D}{b^{2} t}
$$

onde $k$ é um coeficiente dependente da razão de aspecto $a / b$ entre os lados da chapa, de acordo com a Figura 4.3, $t$ é a espessura da chapa, e $D$ é o módulo de rigidez à flexão, definido por

$$
D=\frac{E t^{3}}{12\left(1-v^{2}\right)} .
$$

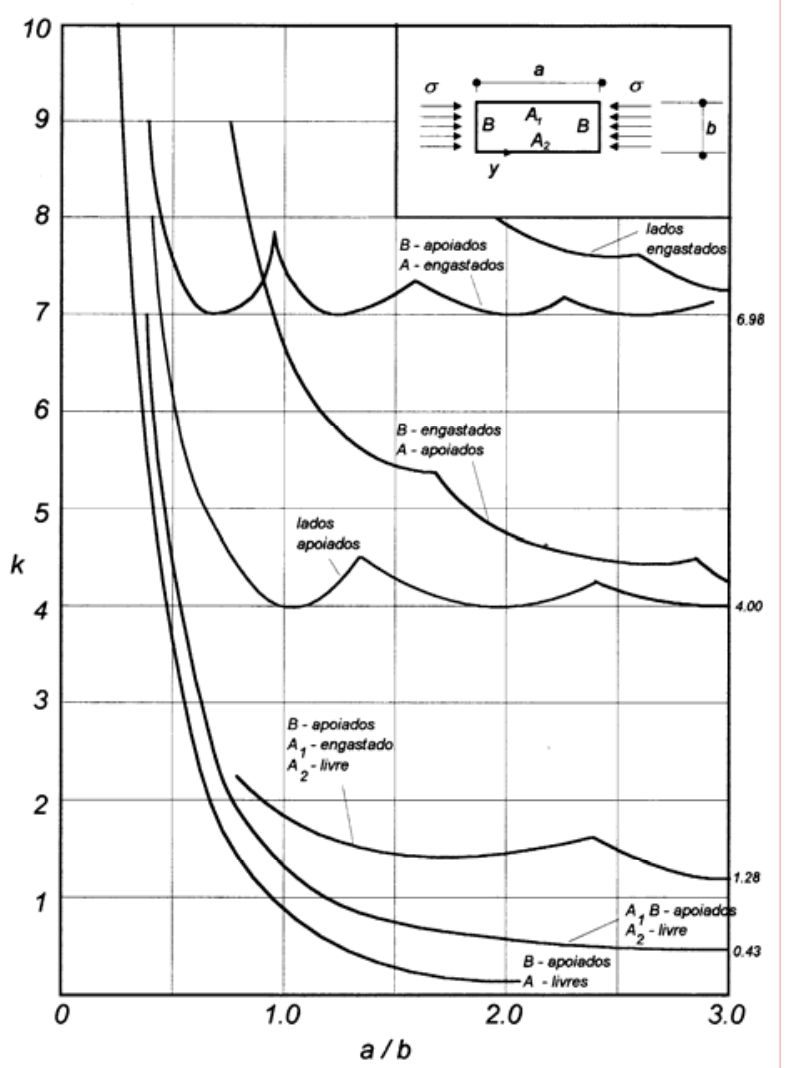

Figura 4.3 - Tensão crítica de flambagem de chapas. 


\subsection{Formulação do problema e implementação numérica da otimização topológica.}

Uma vez que o ANSYS não possui rotina de OT que leve em conta a otimização entre dois materiais, para otimização topológica utilizando elementos sólidos, implementou-se uma rotina própria de OT, que considera presença de dois materiais, múltiplo carregamento, bem como permite selecionar partes do modelo a serem otimizadas ou não.

Para implementação da OT no ANSYS foi necessária a alteração do problema apresentado na Eqs. (3.36) e (3.38), uma vez que o programa não permite que se acessem os dados referentes à matriz de rigidez do problema.

Da teoria do MEF, sabe-se que

$$
\mathbf{K}_{e}=\int_{\Omega_{e}} \mathbf{B}^{T} \mathbf{C}_{e} \mathbf{B} d \Omega_{e}
$$

Substituindo a Eq. (3.14) na Eq. (4.5) obtém-se

$$
\mathbf{K}_{e}=\eta_{e}^{p} \int_{\Omega_{e}} \mathbf{B}^{T} \mathbf{C}_{0} \mathbf{B} d \Omega_{e}+(1-\eta)^{p} \int_{\Omega_{e}} \mathbf{B}^{T} \mathbf{C}_{1} \mathbf{B} d \Omega_{e}
$$

que pode ser escrito como

$$
\mathbf{K}_{e}=\eta_{e}^{p} \mathbf{K}_{\mathbf{0} e}+\left(1-\eta_{e}\right)^{p} \mathbf{K}_{\mathbf{1}_{e}},
$$

onde

$$
\mathbf{K}_{0 e}=\int_{\Omega_{e}} \mathbf{B}^{T} \mathbf{C}_{0 e} \mathbf{B} d \Omega_{e}, \mathrm{e} \quad \mathbf{K}_{1 e}=\int_{\Omega_{e}} \mathbf{B}^{T} \mathbf{C}_{1 e} \mathbf{B} d \Omega_{e},
$$

porém:

$$
\mathbf{K}_{1 e} \cong \mathbf{K}_{\mathbf{0} e} \frac{E_{1}}{E_{0}}
$$

onde $E_{0}$ e $E_{1}$ são os módulos de Young dos respectivos materiais. 
A Eq.(4.8) torna-se exata se os materiais forem isotrópicos e possuírem os mesmos coeficientes de Poisson, neste caso, a matriz constitutiva é proporcional ao coeficiente de elasticidade. No entanto, o fluido contido não é um material isotrópico.

Substituindo a Eq. (4.8) na Eq. (4.7) obtém-se

$$
\mathbf{K}_{e} \cong \eta_{e}^{p} \mathbf{K}_{\mathbf{0} e}+\left(1-\eta_{e}\right)^{p} \mathbf{K}_{\mathbf{0} e} \frac{E_{1}}{E_{0}} \cong\left(\eta_{e}^{p}+\left(1-\eta_{e}\right)^{p} \frac{E_{1}}{E_{0}}\right) \mathbf{K}_{\mathbf{0} e}
$$

Derivando $\mathbf{K}_{e}$ em função de $\eta_{e}$ obtém-se

$$
\frac{\partial \mathbf{K}_{e}}{\partial \eta_{e}} \cong p\left(\eta_{e}^{p-1}-\left(1-\eta_{e}\right)^{p-1} \frac{E_{1}}{E_{0}}\right) \mathbf{K}_{\mathbf{0} e} .
$$

Isolando $\mathbf{K}_{\mathbf{0} e}$ na Eq. (4.9) e substituindo na Eq. (4.10) obtém-se

$$
\frac{\partial \mathbf{K}_{e}}{\partial \eta_{e}} \cong \frac{p\left(\eta_{e}^{p-1}-\left(1-\eta_{e}\right)^{p-1} \frac{E_{1}}{E_{0}}\right)}{\left(\eta_{e}^{p}+\left(1-\eta_{e}\right)^{p} \frac{E_{1}}{E_{0}}\right)} \mathbf{K}_{e}
$$

Considerando-se as Eq. (3.27), (3.28) e (4.11) e igualando a derivada do Lagrangeano à zero (condição de estacionaridade)

$$
\frac{\partial L}{\partial \eta_{e}} \cong \sum_{k=1}^{n_{f}} W_{k}\left(2 p \eta_{e}^{p-1}\left(\rho_{0}-\rho_{1}\right) V_{e} \mathbf{U}_{k}^{T} \mathbf{g}-\frac{p\left(\eta_{e}^{p-1}-\left(1-\eta_{e}\right)^{p-1} \frac{E_{1}}{E_{0}}\right)}{\left(\eta_{e}^{p}+\left(1-\eta_{e}\right)^{p} \frac{E_{1}}{E_{0}}\right)} \mathbf{U}_{k}^{T} \mathbf{K}_{e} \mathbf{U}_{k}\right)+\lambda_{v} V_{e}=0 .
$$

Rearranjando os termos da Eq. (4.12) 


$$
\frac{\sum_{k=1}^{n_{f}} W_{k}\left(2 p \eta_{e}^{p-1}\left(\rho_{0}-\rho_{1}\right) V_{e} \mathbf{U}_{k}^{T} \mathbf{g}-\sum_{e=1}^{n_{e}} \frac{p\left(\eta_{e}^{p-1}-\left(1-\eta_{e}\right)^{p-1} \frac{E_{1}}{E_{0}}\right)}{\left(\eta_{e}^{p}+\left(1-\eta_{e}\right)^{p} \frac{E_{1}}{E_{0}}\right)} \mathbf{U}_{k}^{T} \mathbf{K}_{e} \mathbf{U}_{k}\right)}{\lambda_{v} V_{e}} \cong 1 .
$$

Desta forma, o problema apresentado na Eq.(3.36) e (3.38) passa a ser escrito por

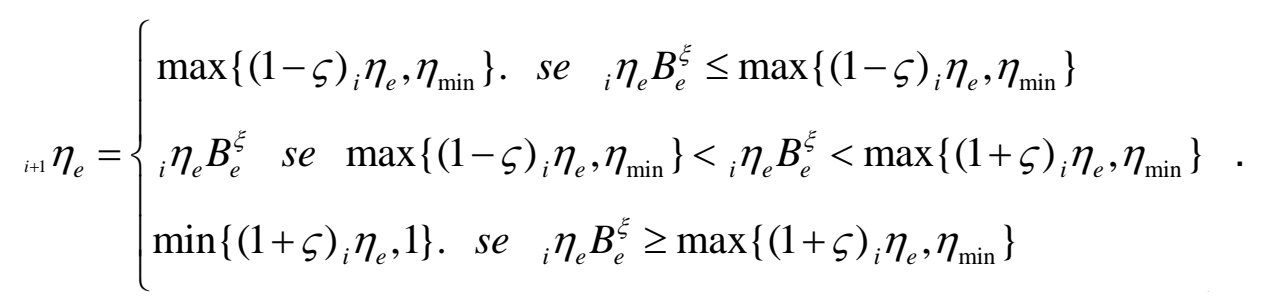

Com $\zeta$ e $\xi$ iguais a 0,2 e 0,5 respectivamente e $B_{e}$ escrito por

$$
B_{e}=\max \left\{0, \frac{\sum_{k=1}^{n_{f}} W_{k}\left(2 p \eta_{e}^{p-1}\left(\rho_{0}-\rho_{1}\right) V_{e} \mathbf{U}_{k}^{T} \mathbf{g}-\frac{p\left(\eta_{e}^{p-1}-\left(1-\eta_{e}\right)^{p-1} \frac{E_{1}}{E_{0}}\right)}{\left(\eta_{e}^{p}+\left(1-\eta_{e}\right)^{p} \frac{E_{1}}{E_{0}}\right)} \mathbf{U}_{k}^{T} \mathbf{K}_{e} \mathbf{U}_{k}\right)}{\lambda_{v} V_{e}}\right\}
$$

Para resolução do problema de OT determinado pelas Eq. (4.14 e 4.15), é necessária a representação do domínio e conseqüentemente do fluido contido através de elementos sólidos ("Solid64").

O elemento "Solid64" é um elemento sólido com as mesmas características do elemento "Solid45", porém, além de permitir a utilização de materiais isotrópicos e ortotrópicos, permite a introdução separadamente dos componentes de sua matriz constitutiva (materiais anisotrópicos). 
Para determinação das componentes da matriz constitutiva da água foi elaborado o estudo apresentado a seguir.

Dado a viga engastada bidimensional $(1 \times 0,5 \mathrm{~m})$ da Figura 4.4, preenchida de água

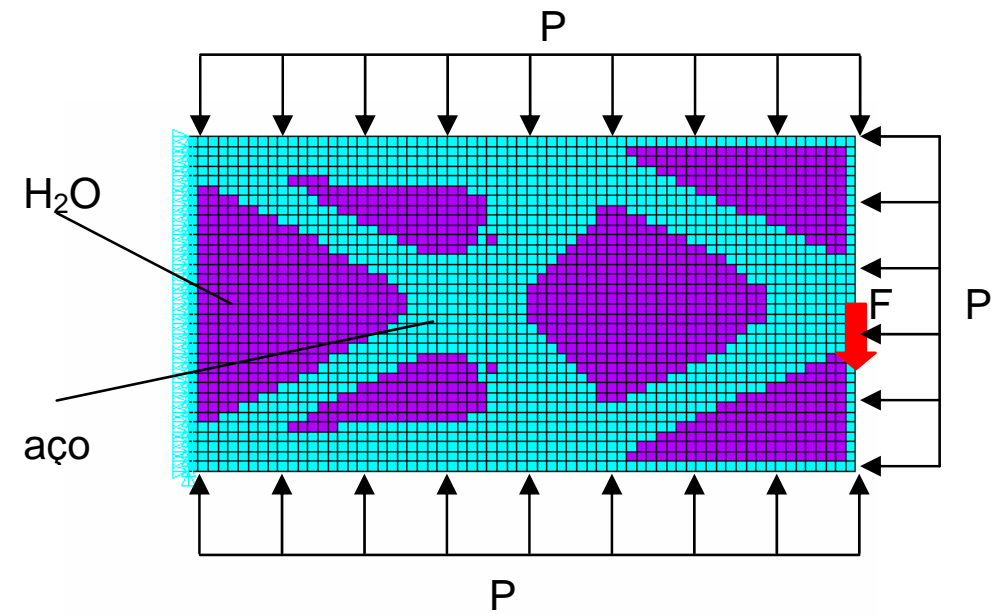

Figura 4.4- Viga bidimensional com fluído contido.

Sendo que a primeira condição de carregamento é a força $F=20.000 \mathrm{~N}$ aplicada na extremidade da viga e a segunda condição de carregamento é a pressão $\mathrm{P}=$ de $20.000 \mathrm{~N} / \mathrm{m}^{2}$ aplicada em todos os lados do modelo.

São elaborados cinco modelos, onde o aço foi representado por um elemento de estado plano de tensão (plane42), $(E=193,2 \mathrm{GPa}, v=0,33)$. A água é representada no modelo 1 , por um elemento de fluido contido ("Fluid79"), ( $E=$ 2.068.5MPa), nos demais modelos (2, 3, 4, e 5), por um elemento de estado plano de tensão (plane42), sendo que nos modelos 2 e 3 é utilizado um modelo de material isotrópico com $E=2.068,5 \mathrm{MPa}$, e $v=0$ e $v=0,499$, respectivamente. Nos modelos 4 e 5, é utilizado um modelo de material ortotrópico, onde $E_{x}=E_{y}=E_{z}=$ 2.068,5MPa, os módulos de cisalhamento $G_{x y}=G_{y z}=G_{x z}=2,0685 \mathrm{~Pa}\left(E^{*} 10^{-9}\right.$, vide Eq. (2.36)), e $v_{x}=v_{y}=v_{z}=0$ ou $v_{x}=v_{y}=v_{z}=0,499$, respectivamente.

A Tabela 4.1 mostra a flexibilidade (dos elementos referentes ao aço), o deslocamento máximo e a tensão máxima de Von Mises para cada caso de carregamento e para cada modelo. Os índices 1 e 2 referem-se à primeira e segunda condição de carregamento. 
Tabela 4.1 - Flexibilidade do aço para cada modelo de viga. (FC - fluido contido)

\begin{tabular}{lccccc}
\hline & $\begin{array}{c}1 \\
\end{array}$ & 2 (iso) & 3 (iso) & 4 (orto) & 5 (orto) \\
& 0,137 & 0,131 & 0,133 & 0,137 & 0,137 \\
\hline Flexibilidade 1 & 6,585 & 6,848 & 5,772 & 8,324 & 6,256 \\
Flexibilidade 2 $\left(\times 10^{3}\right)$ & 0,687 & 0,670 & 0,674 & 0,685 & 0,685 \\
Desloc. Máx. 1 $\left(\times 10^{-2} \mathrm{~mm}\right)$ & 0,156 & 0,0895 & 0,0762 & 0,109 & 0,0830 \\
Desloc. Máx. 2 $\left(\times 10^{-2} \mathrm{~mm}\right)$ & 0,127 & 0,120 & 0,122 & 0,126 & 0,126 \\
Tensão VM 1 $\left(* 10^{7} \mathrm{~Pa}\right)$ & 376.842 & 382.232 & 325.317 & 612.692 & 404.073 \\
Tensão VM 2 (Pa) & & & & & $v=0,499$ \\
\hline
\end{tabular}

Comparando se os resultados apresentados na Tabela 4.1, percebe-se que considerando modelo de material isotrópico, com $v=0$, obtém-se uma boa aproximação do elemento de fluido contido quando considerado o caso de carregamento hidrostático (segundo caso), porém, quando $v=0,499$, obtêm-se melhor aproximação quando a tensão de cisalhamento prevalece. Verifica-se também, que a melhor aproximação acontece quando utilizado o elemento ortotrópico, quando se obtém as melhores aproximações para os dois casos de carregamento, principalmente quando considerado $v=0,499$. Na Figura 4.5 pode se observar os deslocamentos para o primeiro caso de carregamento dos modelos $1 \mathrm{e}$ 5.

modelo1

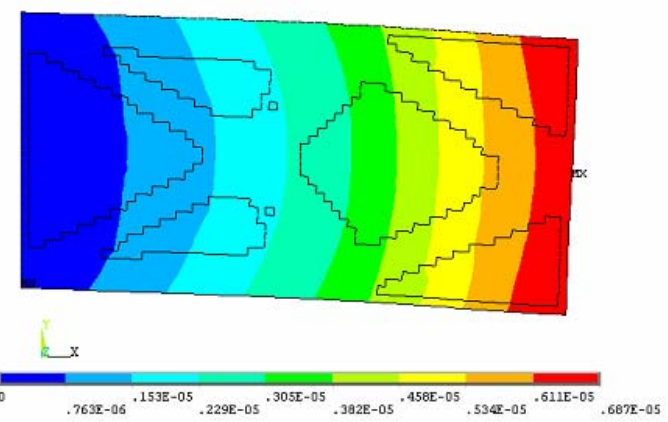

modelo 5

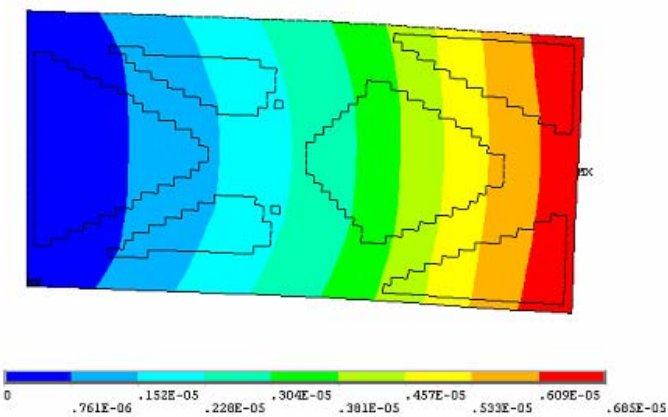

Figura 4.5 - Comparação entre deslocamentos entre modelo 1 e 5.

Quando ocorrer movimento de fluido devido às condições de carregamento, o modelo de material ortotrópico também será a melhor representação do elemento de 
fluido contido, porém, o erro será maior, uma vez que o elemento de estado plano de tensão (ou elemento sólido no caso tridimensional), não considera este efeito.

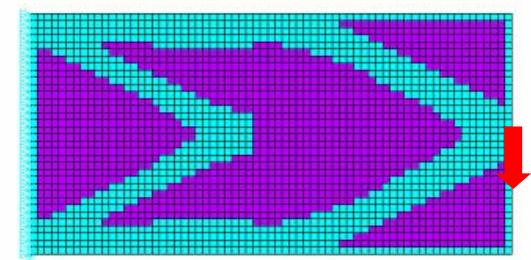

bx
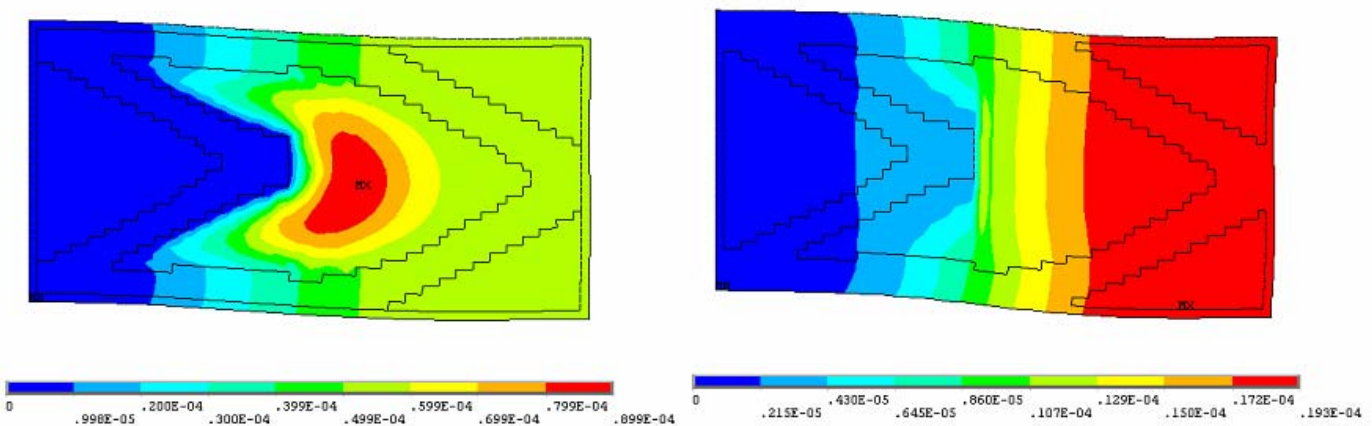

Figura 4.6- Comparação entre deslocamentos quando ocorrem fluxos (modelos 1 e 5)

A Figura 4.6 apresenta os deslocamentos de uma viga de mesma dimensão externa que a viga apresentada na Figura 4.4, porém com uma pequena alteração da geometria interna, e sujeita à primeira condição de carregamento (força concentrada $\mathrm{F}$ ), onde se pode verificar o movimento do fluido devido ao carregamento.

Assim, na OT aplicada ao estudo de caso apresentado neste trabalho, a água será modelada como elemento ortotrópico com $v=0,499$. 
5 ESTUDO DE CASO.

\section{CÓPIA CEGA}

Pg. 81 até pg 97 
6 RESULTADOS.

\section{CÓPIA CEGA}

Pg. 98 até pg 111 
A fim de se apresentar em um exemplo mais simples a influência da malha heterogênea na solução de OT, como observado na Figura 6.12 e na Figura 6.16, a Figura 6.1 mostra a solução de OT para uma viga engastada sujeita a uma força concentrada na extremidade, e as respectivas malhas do domínio da OT. Em ambos os casos, a solução foi obtida pelo método da continuação, com as mesmas condições de iteração ( $p=1$, filtro desligado, 10 iterações, $p=2$, filtro ligado, 15 iterações, $p=3$, filtro ligado, 55 iterações, e $p=3$, filtro desligado, 20 iterações,)
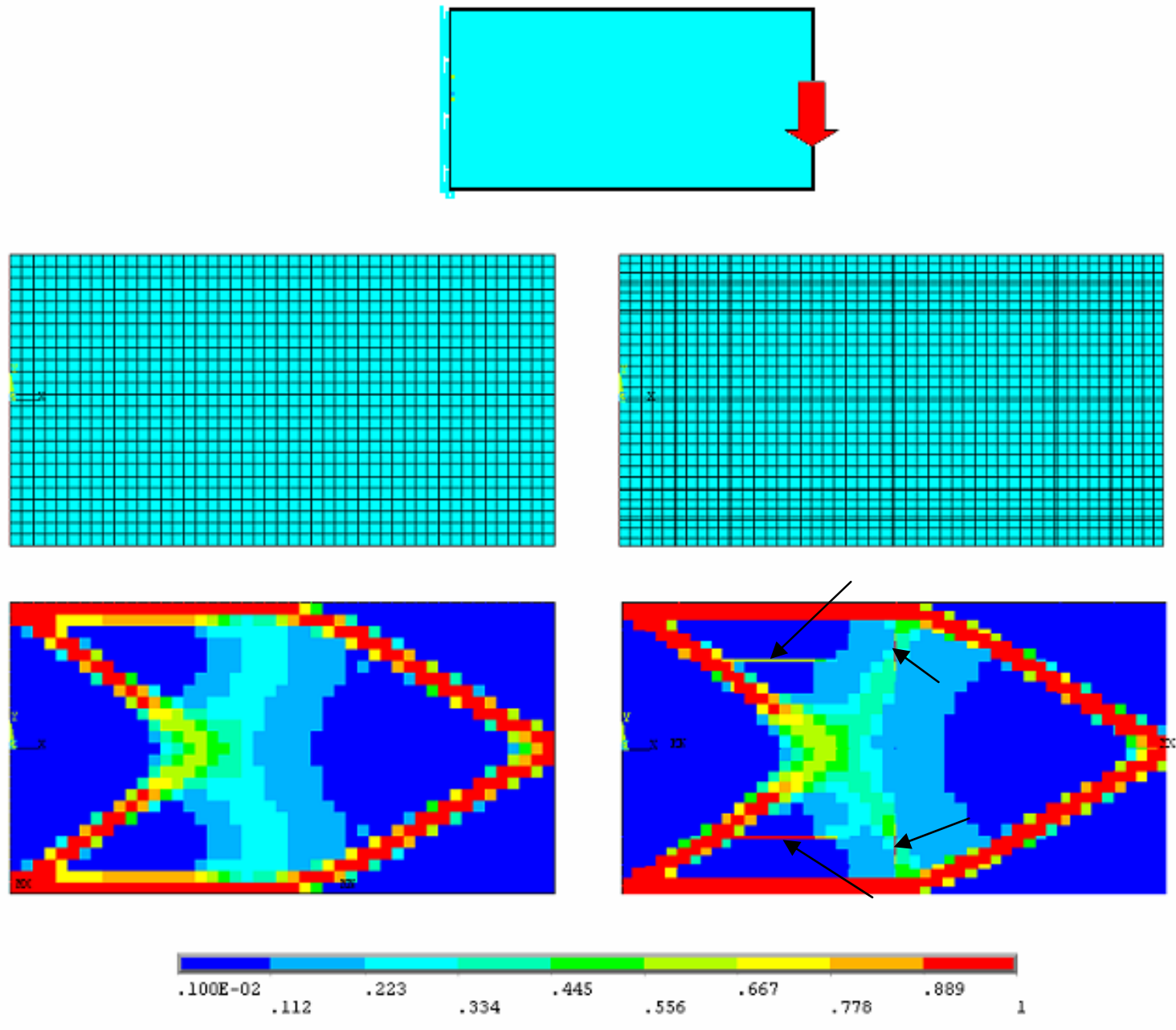

Figura 6.1 - Exemplo da influência da malha no resultado da OT.

Pode se observar que para um mesmo numero de iterações, as soluções foram diferentes para diferentes malhas, e na Figura 6.19 (b), percebe-se a formação de estruturas finas na região onde a malha é afinada, que não existiam na solução de malha homogênea Figura 6.19 (a). 


\section{CONCLUSÕES.}

Neste trabalho foi desenvolvido uma metodologia para otimização de estruturas com fluido contido. A importância de se considerar o fluido como parte integrante da estrutura pode ser verificada no estudo de caso apresentado, pois mostra-se em análise do modelo não-otimizado, a influência da água na rigidez estrutural para o caso de pressão bilateral, passando a tensão máxima de Von Mises de $52,7 \mathrm{MPa}$ para $98,7 \mathrm{MPa}$ e o deslocamento máximo de $0,56 \mathrm{~mm}$ para $0,99 \mathrm{~mm}$ quando não considerada a água no interior da estrutura.

Deve-se ressaltar novamente que tal consideração limita a operação da estrutura quando da não presença da água, uma vez que a mesma colabora com a rigidez.

Foi realizada uma otimização paramétrica, cuja função objetivo é a minimização do volume em aço da estrutura, através das espessuras de suas chapas, que se mostrou bastante eficiente, chegando a um resultado ótimo de $41,1 \%$ mais leve em relação ao modelo original, com apenas quatro espessuras diferentes de chapa. Nota-se também que a única restrição ativa é a tensão máxima para o caso de pressão pelo lado do CP. Um estudo inicial simplificado da estabilidade da estrutura mostra-se satisfatório. Salienta-se que esta otimização não alterou o método de fabricação da estrutura, portanto não alterando significativamente seus custos.

Para realizar a otimização topológica, foi implementada uma rotina em "APDL" cujo objetivo é a minimização da flexibilidade impondo-se restrição de volume que permite otimização de modelos bi e tri-dimensionais. A rotina foi validada através de exemplos clássicos da literatura.

Para o estudo de caso considerado, a OT se mostra inferior à OP, pois com uma redução de volume semelhante à da OP, as tensões máximas são superiores às tensões admissíveis.

Uma vez que as tensões mecânicas máximas observadas nos modelos resultantes da OT são localizadas, é possível que uma interpretação do resultado onde sejam eliminadas as irregularidades resultantes da malha de finitos, melhore 
significativamente este resultado, porém, a elaboração de uma ferramenta que permita esta interpretação se faz necessária.

Observa-se também, que a diversidade de tamanho dos EF na malha pode influenciar na topologia final (Figura 6.12, Figura 6.16 e Figura 6.19), e que através de pesos para cada condição de carregamento, é possível privilegiar na OT a rigidez para uma condição de carregamento mais rigorosa, em detrimento da rigidez para uma condição de carregamento mais leve. Outra desvantagem observada na OT é uma topologia final de fabricação mais complexa.

Através da Figura 6.14 e da Figura 6.18 percebe-se que para condição de carregamento bi-lateral, as tensões máximas são localizadas, apesar da estrutura como um todo estar pouco carregada, evidenciando desta maneira uma desvantagem na abordagem de máxima rigidez, quando comparada com a abordagem de tensão máxima admissível. Entretanto, a formulação de OT para tensão mecânica ainda esta em desenvolvimento na literatura, sendo de razoável complexidade (BENDSØE; SIGMUND, 2003).

\subsection{Trabalhos futuros.}

Devido ao grande número de entradas na rotina de OT elaborada, (modelo 3D/2D, restrição de volume, casos de carregamento a serem considerados, tamanho da malha, entre outras), a elaboração de uma interface gráfica, mais amigável é uma continuação importante deste trabalho.

Destaca-se também a importância da elaboração de uma ferramenta que possibilite a interpretação do resultado de finitos de maneira a eliminar as irregularidades que surgem na OT, principalmente em se tratando de modelos complexos, onde a elaboração de um novo modelo após a OT pode ser trabalhosa.

Em relação ao LabGeNE, mantendo-se a topologia original, com as espessuras já otimizadas, torna-se necessário nesta fase de projeto a determinação das aberturas na chapa a fim de possibilitar fluxo de pessoal para inspeção interna, e do líquido armazenado no interior da Antepara de Vante. Nesta fase, a OT pode 
ser utilizada para determinar a melhor geometria das aberturas, utilizando-se de uma OT para elementos de cascas.

Uma busca por outros pontos de mínimos nas otimizações efetuadas também é importante, a fim de se aproximar ao máximo do mínimo global. 


\section{REFERÊNCIAS}

AKL, W.; RUZZEM, M.; BAZ, A.; Optimal design of underwater stiffened shells. Structural and Multidisciplinary Optimization. v. 23. p. 297-310. 2002.

ALLAIRE, G.; BONNETIER, E.; FRANCFORT, G.; JOUVE, F. Shape Optimization by the Homogenization Method. Numerische Mathematic. v. 76. p. 2768. 1997.

ALBOLBASHARI, M.H.; KESHAVARZMANESH, S. On various aspects of application of the evolutionary structural optimization method for 2D and 3D continuum structures. Finite Elements in Analises and Design. v. 42. p. 478-491. 2006.

ANSYS, version 9.0.ANSYS, Inc.

ANSYS, Release 9.0 Documentation. ANSYS, Inc.2004.

BATHE, K. J. Finite Element Procedures, New Jersey. Prentice Hall. 1996.

BENDSØE, M. P.; KIKUCHI, N. Generating optimal topologies in structural design using a homogenization method. Computer Methods in Applied Mechanics and Engineering. v. 71. p. 197-224. 1988.

BENDSØE, M.P.; SIGMUND, O. Material interpolation schemes in topology optimization. Archives of Applied Mechanics. v. 69 p. 635-654. 1999.

BENDS $\varnothing E$, M.P.; SIGMUND, O. Topology Optimization-Theory, Methods and Applications, Berlin. Springer-Verlag. 2003.

BORUSSE, P. Optimization in mechanics: problems and methods. Amsterdam. Elsevier Science. 1988.

BRUYNEEL, M.; DUYSINX, P. Note on Topology Optimization of Continuum Structures Including Self-Weight. Structural and Multidisciplinary Optimization. v. 29. p. 245-256. 2005.

CANFIELD, S.; FRECKER, M. Topology optimization of compliant mechanical amplifiers for piezoelectric actuators. Structural and Multidisciplinary Optimization. v. 20. p. 269-279. 2000.

CENTRO TÉCNOLOGICO DA MARINHA EM SÃO PAULO. São Paulo. Apresenta submarinos nucleares em atividade no mundo. Disponível em: http://www.ctmsp.mar.mil.br Acesso em 20 de jan de 2006.

CENTRO TÉCNOLOGICO DA MARINHA EM SÃO PAULO. Especificação Técnica do Vaso e Estruturas Internas da Contenção da INAP, São Paulo. CTMSP, 2002. 
CHEN, B. C.; KIKUCHI, N. Topology optimization with design-dependent loads. Finite Elements in Analysis and Design. v. 37. p. 57-70. 2001.

COOK, R. D. Finite Element Modeling for Stress Analysis, New York. John Wiley \& Sons. 1994.

DIAZ, A. R.; SIGMUND, O. Checkboard pattern in layout optimization. Structural Multidisciplinaty Optimization. v. 10. p. 40-45. 1995.

FEDRICSON, H.; JOHANSEN, T.; KLARBRING, A.; PETERSSON, J. Topology optimization of frame structures with flexible joints. Structural Multidisciplinaty Optimization. v. 25. p. 199-214. 2003.

FREITAS, E. S. Curvas, Tabelas e Notas para projetos, Área de Estruturas Navais. São Paulo. DEN-EPUSP.1980.

FUCHS, M. B.; SHEMESH, N. N. Y.; Density-based topological design of structures subjected to water pressure using a parametric load surface. Structural Multidisciplinaty Optimization. v. 28. p. 11-19. 2004.

FUJII, D.; CHEN, B. C.; KIKUCHI, N. Composite material design of twodimensional structures using homogenization design methods. International Jornal for Numerical Methods in Engineering. v. 50. p. 2031-2051. 2001.

GELLATLY, R. A.; GALLAGHER, R. H.; A procedure for automated minimum weight structures design , II: Application. Aero. Quart. v. 17. p. 216-224.1966.

GILL, P. E.; MURRAY, W.; WRIGHT, M. H. Pratical Optimization. London. Elsevier Science. 2000.

HAFTKA, R. T.; GÜRDAL, Z. Elements of Structural Optmizatiom, 3ed. The Netherlands. Dortrecht, Kluwer Academic Publishers. 1991.

HAMMER, V. B.; OLHOLFF, N. Topology optimization of continuum structures subject to pressure loading. Structural Multidisciplinaty Optimization. v. 19. p. 8592. 2000.

HARBER, R. B.; JOG, C. S.; BENDS $\varnothing E$, M.P. A new approach to variabletopology shape design using a constraint on perimeter. Structural and Multidisciplinary Optimization. v. 11. p. 1-12. 1996.

HASHIN, Z.; SHTRIKMAN, S.; A variational approach to the theory of the elastic behaviour of multiphase materials. Journal of Mechanics and Physics of Solids. v. 11. p. 127-140. 1963.

IZADPANAH, K. HARDER, R. L.; KANSAKAR, R.; REYMOND, M. Coupled fluid-structure interaction analysis. Finite Element in Analysis and Design. v. 7. p. 331-342. 1991. 
JOG, C. S.; HARBER, R. B. Stability of finite element models for distributedparameter optimization and topology design. Computer Methods in Applied Mechanics and Engineering. v. 130, p. 203-226. 1996.

KÖGL, M.; SILVA, E. C. N. Topology optimization of smart structures: design of piezoeleletric plate and shell actuators. Smart Material Structures. v. 14. p. 387399. 2005.

KOHN, R. V. STRANG, G. Optima-design and relaxation of variationalproblemas.1. Communication on Pure and Applied Mathematics. v. 39. p. 113137. 1986a.

KOHN, R. V. STRANG, G. Optima-design and relaxation of variationalproblemas.2. Communication on Pure and Applied Mathematics. v.39. p. 139182. $1986 \mathrm{~b}$.

KOHN, R. V. STRANG, G. Optima-design and relaxation of variationalproblemas.3. Communication on Pure and Applied Mathematics. v. 39. p. 353377. 1986c.

LIMA, C. R. Projeto de mecanismo flexível usando o método de otimização topológica. 2002. 167f. Dissertação (mestrado em engenharia)-Escola Politécnica, Universidade de São Paulo.

LOPES, A. L. Otimização topológica aplicada ao projeto de estruturas submetidas a forças de campo mecânicas. 2005. 104f Dissertação (mestrado em engenharia)-Escola Politécnica, Universidade de São Paulo.

LUO, Z.; CHEN, L. P.; YANG, J.; ZHANG, Y. P. Multiple stiffness topology optimizations of continuum structures. International Journal Advance Manufacturing Technology. 2005.

MICHELL, A. G. M. The limit of economy of material in elastic structures of minimum weight. Philosophical Magazine. v. 8. p. 589-597. 1904.

MOHR; G. A. Finite Element Optimization of Structures-I. Computers \& Structures. v. 53. p. 1217-1220. 1994a.

MOHR; G. A. Finite Element Optimization of Structures-II. Computers \& Structures. v. 53. p. 1221-1224. 1994b.

MOURA, L. A. A.; VEIGA, J. P. C.; FREITAS, E. S. F. Arquitetura Naval de Submarinos. São Paulo. ETCN. 1981

NAGY, J.G.; PALMER, K.M. Steepest Descent, CG, and iterative regularization of ill-posed problems. BIT Numerical Mathemathics. v. 43. p. 10031017. 2003. 1978.

NOVAES, A. G. N. Métodos de Otimização, São Paulo: Edgar Blüncher, 
PAPALAMBROS, P. Y.; WILDE, D. J. Principles of Optimal Design. 2ed. Cambridge. Syndicate of the University of Cambridge. 2000.

QI, H.; KIKUCHI, N.; MAZUMDER, J. Interface study and bondary smoothing on designed composite material microstructures for manufacturing purposes. Structural and Multidisciplinary Optimization. v. 26. p. 326-332. 2004.

QUERIN, O. M.; STEVEN, G. P.; XIE, Y. M. Evolucionary structural optimization using an additive algorithm. Finite Elements in Analises and Design. v. 34. p. 291-308. 2000a.

QUERIN, O. M.; YOUNG, V. STEVEN, G.P.; XIE, Y. M. Computacional efficiency and validation of bi-directional evolucionary structural optimization. Computer Methods in Applied Mechanics and Engineering. v. 189, p. 559-573. 2000b.

RAMASWAMY; B. Solution of Boussinesq Equations by Finite Element Method. Finite Elements in Analysis and Design. v. 6. p. 319-335. 1989.

RIETZ, A. PETERSSON, J. Simultaneous shape and thickness optimization. Structural and Multidisciplinary Optimization. v. 23. p14-23. 2001.

RODRIGUES, H.; SOTO, C. A.; TAYLOR, J. E. A design model to predict optimal two-material composite structures. Structural Multidisciplinaty Optimization. v. 17. p. 186-198. 1999.

ROZVANY, G. I. N.; BENDS $\varnothing E$, M.P.; KIRSCH, U. Layout Optimization of Structures. Applied Mechanical Review. v. 48. p. 41-119. 1995.

SAUNDERS, S. (editor) Jane's Fighting Ships. 170 ed. United Kington. Jane's Information Group. 2004-2005.

SAXENA, A. Topology design of large displacement compliant mechanisms with multiple materials and multiple output ports. Structural Multidisciplinaty Optimization. v. 30. p. 477-490. 2005.

SEGERLIND, L. J. Applied Finite Element Analysis. 2ed. New York. John Wiley \& Sons. 1984.

SHANNO, D. F. Globally convergent conjugate gradient algorithms. Mathematical Programming. v. 33. p. 61-67. 1985.

SIGMUND, O.; Design of material structures using topology optimization. 1994. Ph. D. Thesis. Department of Solid Mechanics, Technical University of Denmark.

SIGMUND, O. On the Design of Compliant Mechanisms using Topology Optimization. Mechanics of Structures and Machines. v. 25. p. 495-526. 1997. 
SIGMUND, O. A 99 line optimization code written in Matlab. Structural Multidisciplinaty Optimization. v. 21. p. 120-127. 2001.

SIGMUND, O.; PETERSSON, J. Numerical instabilities in topology optimization. A survey on procedures dealing with checkerboards, mesh dependencies and local minima. Structural Optimization. v. 16. p. 68-75. 1998.

SILVA, E. C. N.; FONSECA, J. S. O.; KIKUCHI, N. Optimal design of piezoeletric microstructures. Computational Mechanics. v. 19. p. 397-409. 1997.

SILVA, E. C. N.; NISHIWAKI, S. Design of piezoeletric multi-actuated microtools using topology optimization. Smart Material Structures. v. 14. p. 14311447. 2005.

STEVEN, G.; QUERIN, O.; XIE, M. Evolutionary structural optimization (ESO) for combined topology and size optimization of discrete structures. Computer Methods in Applied Mechanics and Engineering. v. 188. p. 743-754. 2000.

SUNDARAM, R. K. A First Course in Optimization Theory. Cambridge. Syndicate of the University of Cambridge. 1996.

SUZUKI, K. KIKUCHI, N. A homogenization method for shape and topology optimization. Computer Methods in Applied Mechanics and Engineering. v. 93. p. 291-318. 1991.

THE AMERICAN SOCIETY OF MECHANICAL ENGINEERS, Rules for Construction of Power Boilers. New York. 2004.

TIMOSHENKO, S. P.; GERE, S.; Theory of Elastic Stability. New York. McGraw-Hill.1961.

VANDERPLAATS, G. V. Numerical Optimization Techniques for Engineering Design: With Application. New York. McGraw-Hill.1984.

XIE, Y. M.; STEVEN, G. P. Evolucionary Structural Optimization. London. Springer. 1997.

ZHOU, H.; SHYY, Y. K.; THOMAS, H. L. Checkerboard and minimum member size control in topology optimization. Structural Multidisciplinaty Optimization v. 21. p. 152-158. 2001. Hill.1977.

ZIENKIEWICZ, O. C. The Finite Element Method. 3ed. Maidehead. McGraw- 
APÊNDICE A.

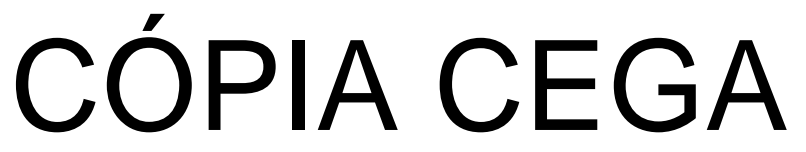

Pg. 121 até pg 122 
APÊNDICE B.

CÓPIA CEGA

Pg. 123 